\title{
BIOELECTROCHEMICAL METAL RECOVERY WITH MICROBIAL FUEL CELLS
}


Thesis committee

Promotor

Prof. Dr C.J.N. Buisman

Professor of Biological Recovery and Re-use Technology

Wageningen University \& Research

Co-promotors

Dr A. ter Heijne

Assistant professor, Sub-department of Environmental Technology

Wageningen University \& Research

Dr T.H.J.A. Sleutels

Researcher,

WETSUS (European centre of excellence for sustainable water technology), Leeuwarden

Other members

Prof. Dr J.H. Bitter, Wageningen University \& Research

Prof. Dr F. Fabregat-Santiago, Universitat Jaume I, Castelló de la Plana, Spain

Prof. Dr E. Volcke, Ghent University, Belgium

Dr A Deeke, Waterschap De Dommel, Boxtel

This research was conducted under the auspices of the Wageningen Institute for Environment and Climate. Research

This research was conducted under the auspices of the Graduate School for SocioEconomic and Natural Sciences of the Environment (SENSE) 


\section{BIOELECTROCHEMICAL METAL RECOVERY WITH MICROBIAL FUEL CELLS}

Thesis

submitted in fulfilment of the requirements for the degree of doctor at Wageningen University

by the authority of the Rector Magnificus,

Prof. Dr A.P.J. Mol, in the presence of the

Thesis Committee appointed by the Academic Board to be defended in public on Friday 21 April 2017 at 1:30 p.m. in Leeuwarden. 
Pau Rodenas Motos

Bioelectrochemical Metal Recovery with Microbial Fuel Cells, 115 pages.

$\mathrm{PhD}$ thesis, Wageningen University, Wageningen, the Netherlands (2017) With references, with summary in English

ISBN: 978-94-6343-096-8

DOI: http://dx.doi.org/10.18174/405862 


\section{Contents}

Chapter 1: Introduction..................................................................................................9

1.1 State-of-the-art technologies for metal recovery................................................................................... 11

Chemical precipitation ...............................................................................................................................11

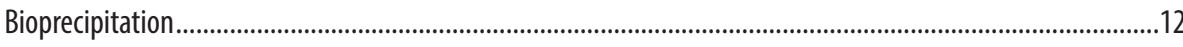

lon-exchange and adsorption.............................................................................................................12

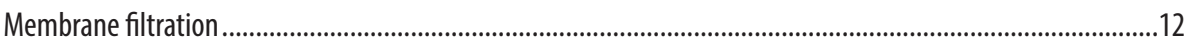

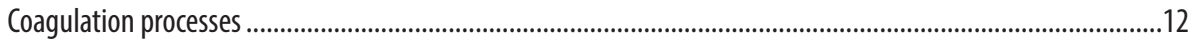

Electrochemical treatment ...................................................................................................................13

Cementation................................................................................................................................13

1.2 Bioelectrochemical Systems; state-of-the-art............................................................................................ 13

Thermodynamics of BESs........................................................................................................................... 15

Electron acceptors (Cathode) .................................................................................................................... 20

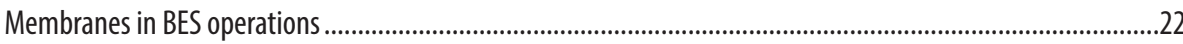

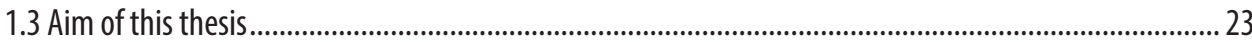

Chapter 2. High Rate Copper and energy recovery in Microbial Fuel Cells .............................27

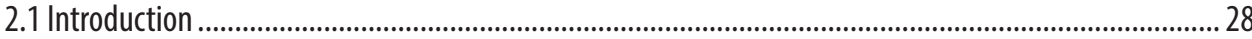

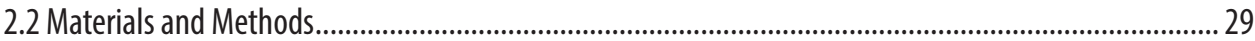

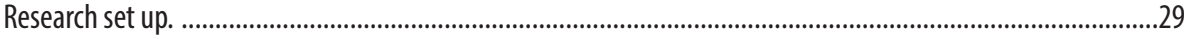

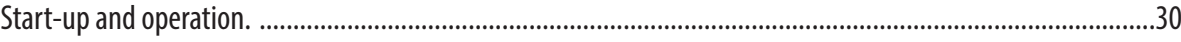

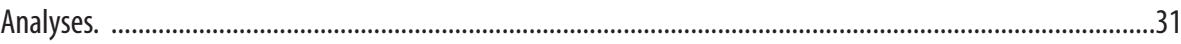

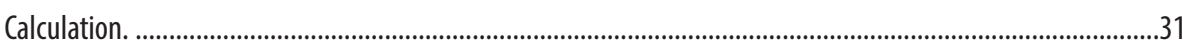

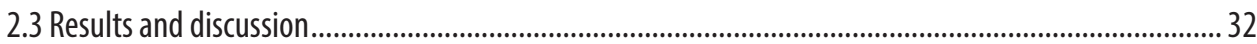

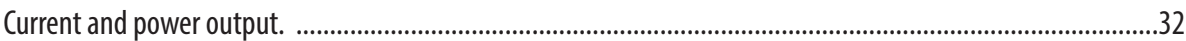

Analysis of the performance.

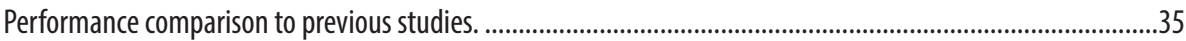

Copper removal and analysis of the deposited copper. ......................................................................................36

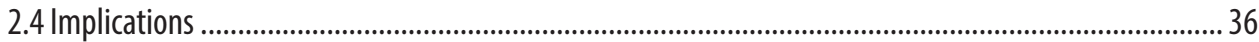


Chapter 3. Hydrogen as electron donor for copper removal in bioelectrochemical systems 41

3.1 Introduction ................................................................................................................................ 42

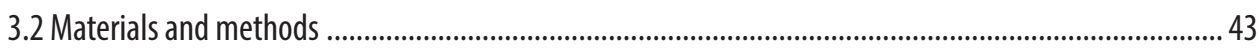

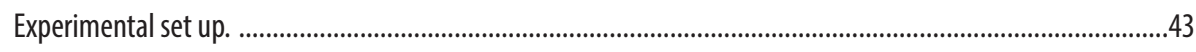

Electron donor and electrolyte composition ..................................................................................................4

Experimental strategy ..............................................................................................................................4

Electrochemical control ........................................................................................................................4

Electrochemical control. .........................................................................................................................4

Analytical procedures and calculations:................................................................................................4

3.3 Results and discussion ............................................................................................................. 48

Hydrogen as electron donor for an electroactive biofilm. .............................................................................48

Abiotic control experiments. ...................................................................................................................49

Cathodic copper reduction coupled with anodic hydrogen oxidation..............................................................49

Perspectives and long term performance. ................................................................................................51

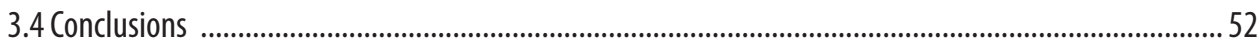

Chapter 4. Gas Diffusion Electrodes improve hydrogen gas mass transfer for a hydrogen oxidizing bioanode coupled to copper recovery ..................................................................54

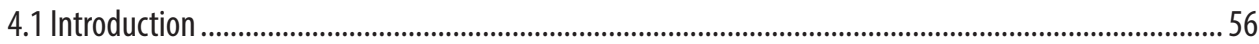

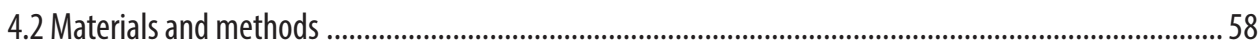

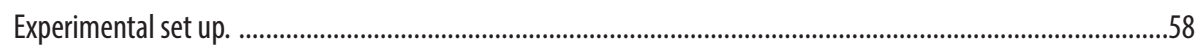

Electron donor and electrolyte composition. .................................................................................................58

Experimental strategy. ………………………...............................................................................................58

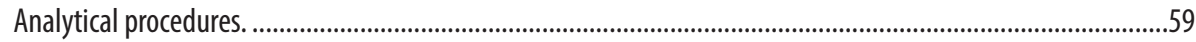

4.3 Results and discussion .................................................................................................................

Improved hydrogen mass transfer led to an increase in current production......................................................59

Effect of bicarbonate addition on bioanode performance. ……………..........................................................61

Improved mass transfer in anolyte led to higher current density. ................................................................62

Mechanisms for current production from hydrogen and bicarbonate. ...........................................................63

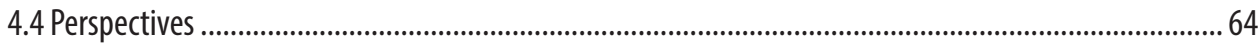

Chapter 5. Prototype of a scaled-up Bioelectrochemical System for copper recovery .............67

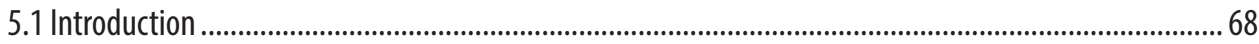

5.2 Materials and experimental procedure.................................................................................................. 69 
Design of the prototype BES ................................................................................................................69

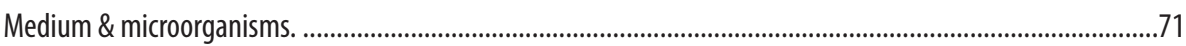

Experimental procedure ......................................................................................................................

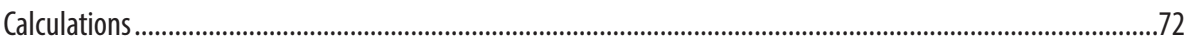

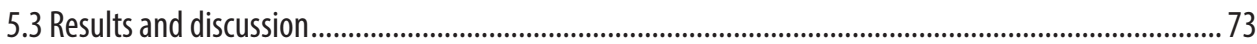

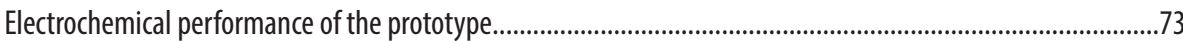

Performance indicators of the prototype ……………………………...........................................................

Internal resistance distribution of the prototype ...............................................................................................

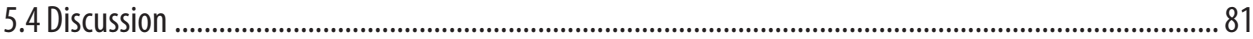

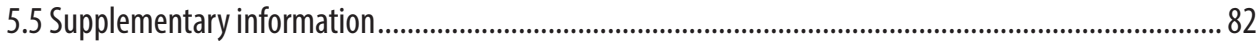

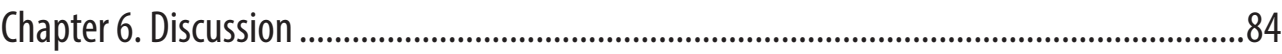

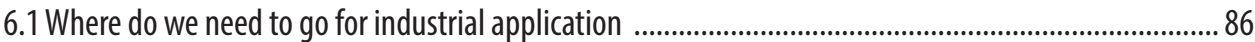

Qualitative evaluation of current technologies and BESs for metal recovery.......................................................86

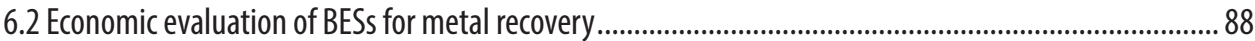

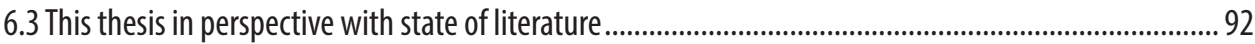

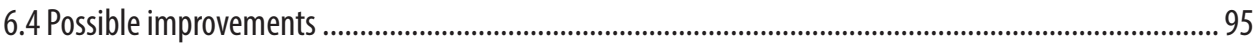

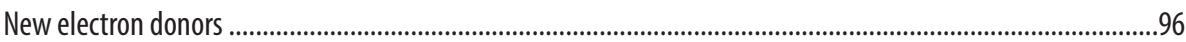

New electron acceptors: .............................................................................................................................97

Future perspectives in cell configuration and up-scaling.............................................................................97

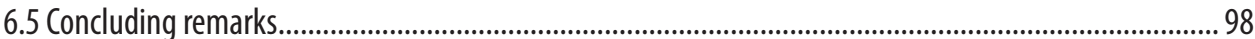

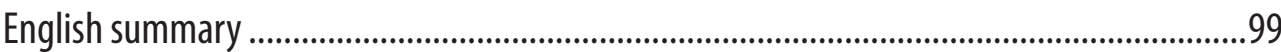

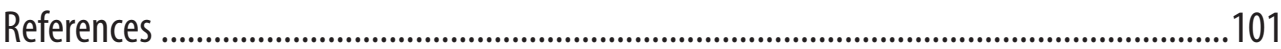

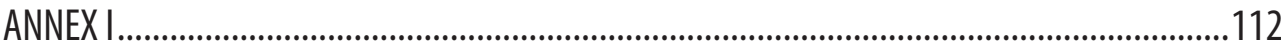

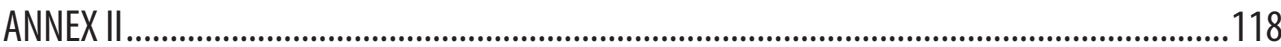

Model business case scenario for evaluation of different electron donors on copper recovery:.................... 118

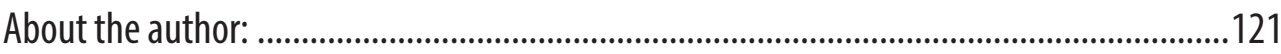

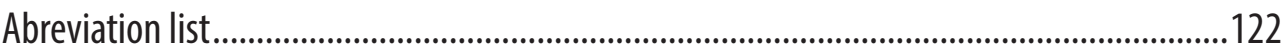

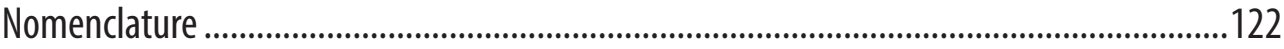

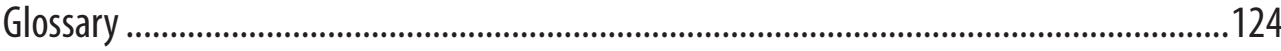




\section{Chapter 1: Introduction}


Heavy metals, like copper, zinc and nickel are essential micronutrients for life. Also, these metals form the basis for many industries, for example, they are used as catalyst, pesticides, fertilizers, but also form key components for electronic industry and construction materials. These metals need to be extracted from mineral ores, after which they can be transformed into a product that has the required characteristics or recycled to have a new use. Metal production processes require energy and cause negative environmental impacts, depending on which extraction and production technology is used. Current technologies for the production of metals are based on a series of processes: first of all the mineral is mined, then this mineral is processed to concentrate the metal, followed by a melting and extraction process, to finally end up in a refining process by smelting or electroplating ${ }^{1}$.

Due to the increasing demand for metals, in combination with the depletion of metal ore reserves, metal scarcity is expected to occur for several metals in the coming decades. Henckens et al. (2014) conclude that for 17 metals, including copper, lead, zinc and cadmium the current extraction rate is not sustainable in connection with the consumption rate in the industry ${ }^{2}$. Mining companies are already turning to lower grade minerals for metal extraction to provide sufficient resources. The extraction of lower grade minerals leads to an increase in production cost and an increase in production of wastes. One of the clearest examples is copper. Copper was a fundamental component of making bronze, and it started to be exploited 7000 years ago. Today it is an essential element of construction, wiring, heat dissipation, plumbing and the main component on printed circuit boards due to its malleability, heat and electrical conductivity. The before mentioned scarcity is responsible for the rise in copper price from 3000 /ton in December 2008 to its historical maximum of 8200\$/ton in February $2013^{3} .2500$ million tons of new ores have been estimated based on geological data and estimation models by Johnson et al. (2014) $)^{4}$. However, as many other authors defend most of these materials are not accessible for mining purposes. To attend the global demand, which is rated around 20 million tons per year, we should find alternatives. ${ }^{2,3,5}$

An alternative to the mining of ore is to recycle metals directly from scrap or to recover them before they are released into the environment again through remediation and production technologies. Figure 1.1 shows the possible cycles of metal processing, including the recycling and recovery of metals after use. Metal extraction and production release metal polluted wastes that can have harmful effects on the environment. Therefore, it is crucial to remove these metals from the waste streams in order to reduce environmental impacts. Ideally, removal of these metals is combined with recovery, so that the metal can be reused. 


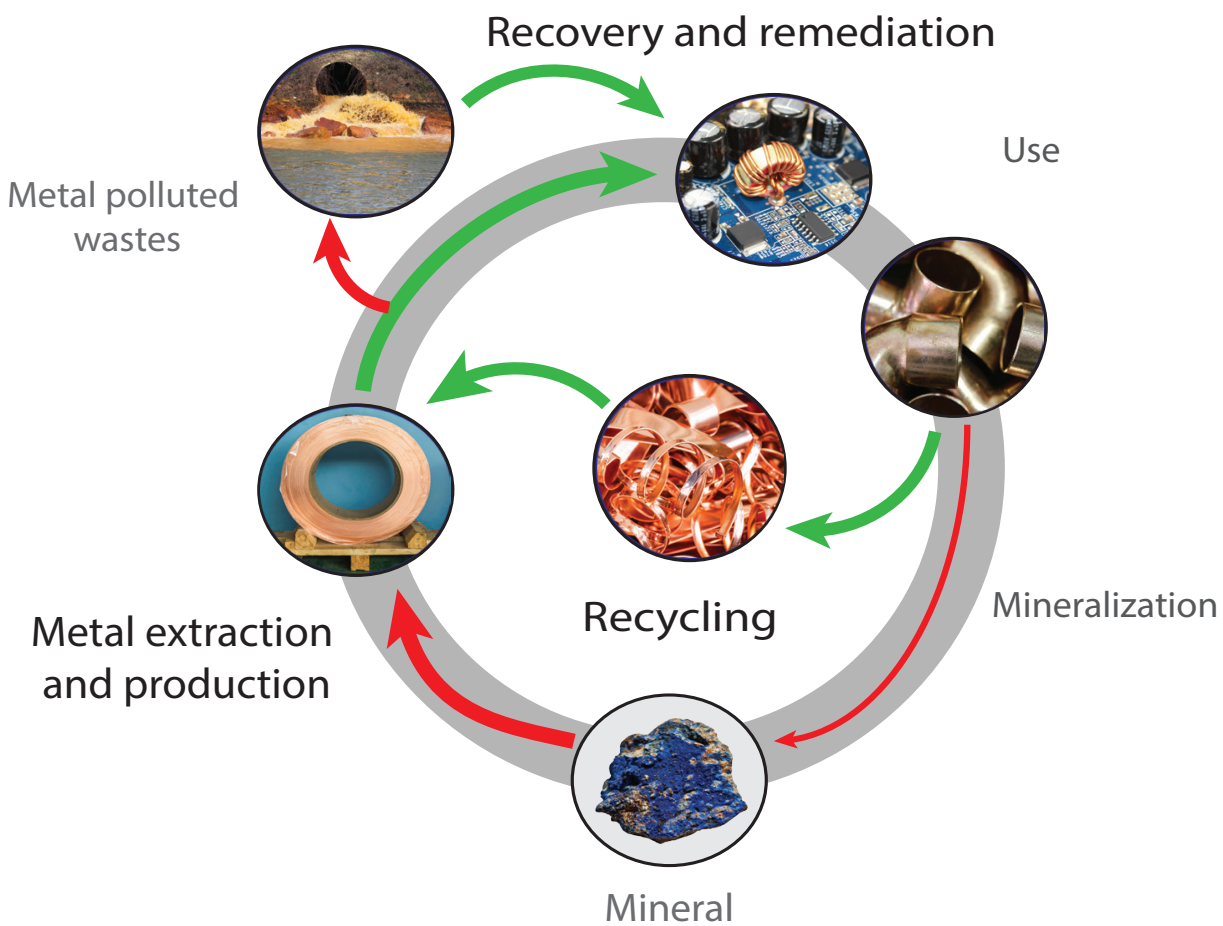

Figure 1.1. Metal recovery can be used at different steps of the copper cycle (production, recycling, and remediation).

\subsection{State-of-the-art technologies for metal recovery}

State-of-the-art technologies for metal recovery can be divided into two groups: remediation technologies and recovery technologies. Remediation focuses on extracting the heavy metals from wastewater, ashes or soils and concentrating them into a product that is not harmful to the environment. The existing remediation technologies are chemical precipitation, bioprecipitation, flocculation or sedimentation, ion-exchange and adsorption, and membrane filtration. The recovery technologies focus on extraction and converting them into a useful metal product. The recovery technologies are electrochemical metal precipitation known as cementation, and electro-winning.

\section{Chemical precipitation}

Chemical precipitation makes use of the low solubility of metals when combined with a suitable anion. Chemical metal precipitation is extensively used in industry because of the high removal efficiencies; that can reach up to $99.9 \%$. There are three different techniques: Hydroxide precipitation, sulfide precipitation, and chelation. All of them need high amounts of chemicals to clean the water. Furthermore, the purpose is to reduce the levels of pollutants and keep them in insoluble solid phase. In some cases, metals are recovered in a post- 
treatment process or by reintroducing the precipitates combined with the mineral ${ }^{6}$.

\section{Bioprecipitation}

Bioprecipitation is a process based on sulfate and sulfur reduction to produce sulfides and precipitate the heavy metals as sulfide compounds.

\section{lon-exchange and adsorption}

Ion-exchange is a wastewater treatment based on the chemisorption of the metallic ions on a resin or in a zeolite. These treatments are fast and reach high removal efficiencies. Most common cation exchangers are resins with sulfonic groups $\left(-\mathrm{SO}_{3} \mathrm{H}\right)$ or carboxylic acid groups $(-\mathrm{COOH})$. Besides resins, zeolites represent a cheaper alternative to polymeric resins, but the research is still in laboratory scale 7,8 . The downside of these processes is that, to recover the metals, you have to desorb the metal from the resin with acid or base.

Adsorption is similar to ion-exchange technology; adsorption is based on trapping the pollutants inside the porous cavities, while ion exchange technology relies on the electrostatic attraction of the ionized groups. The general purposes of the adsorber are to capture heavy metals in the adsorbent and then remove it from wastewater and desorb the metal to obtain a concentrated phase. The process is usually followed by solvent extraction and then electrowinning. Commonly, active carbon is used for heavy metal adsorption, but it is largely a non-selective removal agent. Many efforts are taken to produce, at lab-scale, lowcost adsorbers, bio-adsorbers or develop ionic liquid technology for selective removal of the metals, and to reuse the adsorber ${ }^{9,10}$. There is a third possibility call absortion that is based on chemically bond the pollutant; this takes place in nature when heavy metals are chemically bound to clays ${ }^{11}$. However, this technique is not used due the complexity in its extraction process.

\section{Membrane filtration}

The membrane filtration technique consist on using the porosity to separate the water from the pollutants and concentrate them. Today, there are filtration membranes to remove water efficiently and concentrate a heavy metal solution. There are four different techniques: ultra-filtration, reverse osmosis, nano-filtration, and electrodialysis. These techniques have metal removal efficiencies between $45 \%$ and $99 \%{ }^{8}$. These techniques need to be combined with other treatments to remove the heavy metals from the liquid phase. Filtration can be enhanced with chelators, coagulants or adsorbers. Today, development is on-going of a combination of electrodialysis and high selective membranes to recover metals selectively 7,8,12-15. Membrane filtration market is rapidly expanding due to improvements in membrane fabrication and the use of new materials.

\section{Coagulation processes}

Coagulation is the process of formation of big flocks of particles by adding a chemical like poly-aluminium chloride or ferric chloride. The coagulant absorbs particles in suspension. 
There are two possible phenomena: if the result is a dense colloid, it is separated by filtration, or by sedimentation; if the resulting colloid has a density lower than water, it is separated by flotation and the process is called flocculation ${ }^{16}$. Coagulation and flocculation followed by sedimentation, filtration or flotation are employed commonly in wastewater treatment to remove a wide variety of pollutants in industrial and urban waste waters. New coagulants are now in the market to selectively remove heavy metals making use of electrostatic charge. The latest technique in coagulation is Electrocoagulation (EC). This technique has achieved a removal efficiency of $97.5 \%$ for nickel and $94 \%$ for cadmium, or $94 \%$ for lead, current densities of 20 to $100 \mathrm{~A} / \mathrm{m}^{2}$ and voltages from 5 to $15 \mathrm{~V}^{17-19}$.

\section{Electrochemical treatment}

Besides Electrocoagulation, Electrowinning (EW) is a common technique to recover and produce metals Electrowinning is based on applying a current between two electrodes immersed in the plating solution. The purpose is to plate the desired metal on the cathode. This technique can be selective for almost all the heavy metals. This technique has removal efficiencies over 99\%. However, EW needs a considerable energy input to drive metal precipitation. For example, the energy consumption is $2.1 \mathrm{kWh} / \mathrm{kg}$ copper to achieve a $97 \%$ removal efficiency. The high value of the metals makes electrowinning an economic process ${ }^{20}$.

In practice, the presence of complexing agents and smoothers reduces the efficiency of the process but improves the quality (purity) of the product.

\section{Cementation}

Cementation is a process commonly used in metal plating industry to purify a metal liquor and remove the non-desired metals from the solution. As an example Zinc industry uses zinc dust to removed copper, cadmium or lead from the plating liquor before it enters the plating bath. This process produces a cake made of a mixture of different metals that finally is sold as low-grade metal.

\subsection{Bioelectrochemical Systems; state-of-the-art}

Bioelectrochemical systems (BESs) have been proposed as a clean alternative to the stateof-the-art technologies for wastewater treatment. A BES is an electrochemical cell where the anode has electroactive bacteria attached to an electrode surface, and can be used to produce, remove and remediate metals from polluted waters. This system is basically similar to electrowinning process, but this technology uses a different anode reaction.

The fact that microorganisms could exchange electrons with an electrode was discovered by the botanist M.C. Potter in $1911^{21}$. In the 1980s, Bennetto et al. showed that it was possible to use redox mediators to extract electrons from microbial metabolism ${ }^{22}$. However, it was only in 1999 that Kim et al. ${ }^{23}$ showed that electrons could be directly harvested without 
redox mediators. Many possible applications have been developed during the following decades. On the one hand, a variety of substrates for the bioanode have been tested: acetate, starch, domestic wastewaters, urine, brewery waste waters, chocolate industry wastewaters ${ }^{24}$. On the other hand, many reduction reactions are possible at the cathode: for example oxygen reduction, hydrogen production, caustic and peroxide production, but also, metal plating. 23,25,26. Ter Heijne et al. (2010) were the first to use a BES, with acetate as an electron donor, and $\mathrm{Cu}^{2+}$ as the electrode acceptor in the cathode. They showed the possibility to remove copper from wastewater and production of pure plated copper, in combination with electricity production (Figure 1.2). ${ }^{27}$

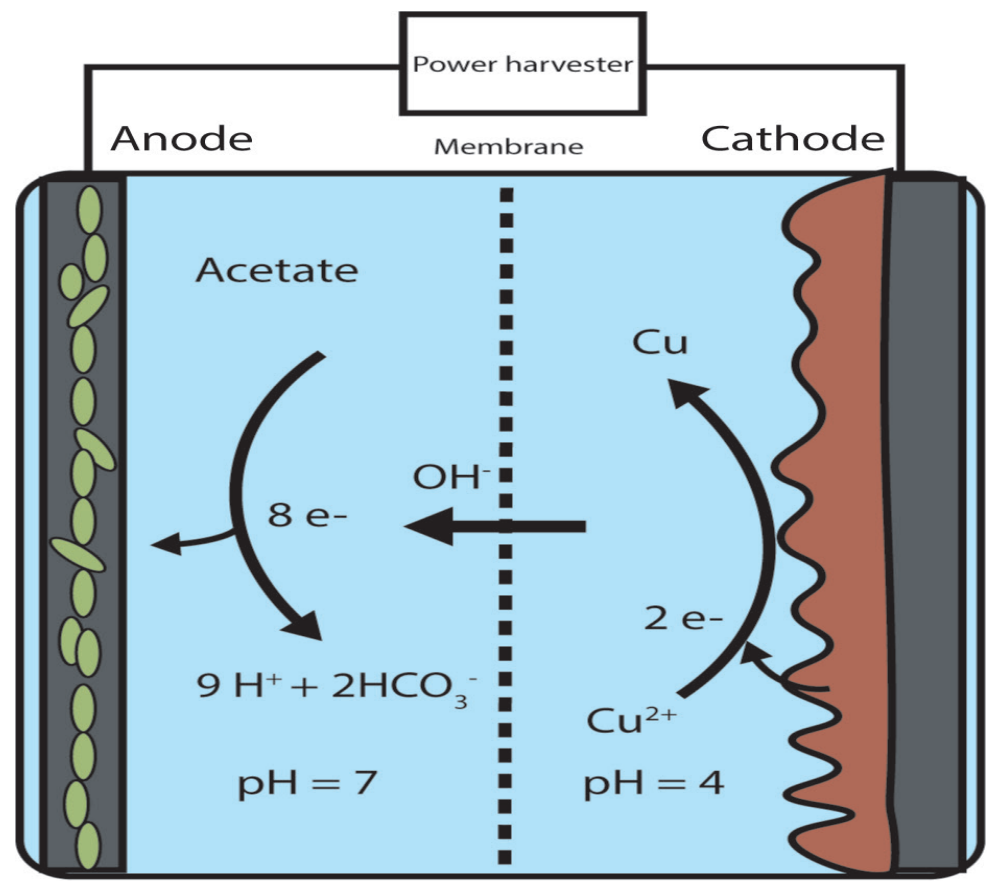

Figure 1.2. Diagram of BES and configuration for copper recovery using acetate as an electron donor.

The novelty of the application of BES for the recovery of metal waste was that this provides an energy-efficient alternative to conventional electrowinning processes, because the electron donor (wastewater) provides (part of) the energy to drive the reduction reaction ${ }^{27-32}$.

After this proof of principle, multiple other metals have been shown to act as electron acceptor in the cathode: $\mathrm{Fe}(\mathrm{III}), \mathrm{Cu}(\mathrm{II}), \mathrm{Ag}$ (I), $\mathrm{Hg}$ (II), Ni (II) or Zn (II). Both electrolytes are separated by a membrane which allows for the selective transfer of charged species from anolyte to the catholyte or vice-versa (Figure 1.2) ) $^{2533}$ 


\section{Thermodynamics of BESs}

As explained in the previous paragraph, in a BES, two half-reactions occur simultaneously, an oxidation and a reduction reaction. In an oxidation process, a reactant is oxidized releasing electrons to the electrode, and these electrons travel to the second electrode, where they reduce another reactant. In the overall reaction species $\mathrm{A}$ is oxidized to $\mathrm{C}$ and species $\mathrm{B}$ are reduced to species $\mathrm{D}$.

$$
v A \quad v B \leftrightarrows v C \quad v D
$$

The energy input or output is determined by the Gibbs free energy change of the reaction that can be calculated by equation 1.1 .

$$
\Delta G_{r}^{\varnothing}=-R T \ln \left\{\frac{a_{C}^{v_{C}} \cdot a_{D}^{v_{D}}}{a_{A}^{v_{A}} \cdot a_{B}^{v_{B}}}\right\}
$$

where $\Delta G_{r}^{\varnothing}$ is the gibbs free energy of this reaction at standard conditions ( 1 atm, $273 \mathrm{~K}, 1$ $\mathrm{M}), \mathrm{R}$ is the gas constant $(8.31 \mathrm{~J} / \mathrm{K} \cdot \mathrm{mol}), \mathrm{T}$ is the temperature $(\mathrm{K})$, and a is the activity of the different species.

In a diluted system, like in BES, the Gibbs free energy change can be calculated by equation 2

$$
\Delta G_{r}=\Delta G_{r}^{\varnothing}-R T \ln \left\{\frac{[C]^{\nu_{C}} \cdot[D]^{v_{D}}}{[A]^{v_{A}} \cdot[B]^{v_{B}}}\right\}
$$

where $[\mathrm{X}]$ is the concentration of $\mathrm{mol} / \mathrm{L}$ of the species in solution and $V \mathrm{x}$ is the stoichiometric coefficient for the species in the reaction.

In thermodynamically reversible conditions, the maximum work of the process that is related to the Gibbs free energy of the overall reaction can be calculated as the cell voltage by equation (1.3)

$$
E_{r}=-\frac{\Delta G_{r}}{\mathrm{nF}}
$$

where $E_{r}$ is cell potential measured in $(\mathrm{V}), \Delta G_{r}$ is the Gibbs free energy of the overall reaction, $\mathrm{n}$ is the number of electrons transferred during the process, and $\mathrm{F}$ is Faraday 
constant $(96485 \mathrm{~mol} / \mathrm{C})$.

At the anode, the oxidation of substrate produces electrons at a certain energy level; that is expressed as the anode potential. This anode potential depends on the substrate to be oxidized, and the concentration of substrate and products. As an example, the potential of the oxidation of acetate (Oxidation half-reaction) can be calculated with the Nernst equation according to equation 1.4.

$$
\begin{gathered}
\mathrm{CH}_{3} \mathrm{COO}^{-}+4 \mathrm{H}_{2} \mathrm{O} \rightarrow 2 \mathrm{HCO}_{3}^{-}+8 e^{-}+9 \mathrm{H}^{+} \\
E_{\text {anode }}=E_{\mathrm{HCO}_{3}^{-} / A c^{-}}^{0}-\frac{R \cdot T}{8 \cdot F} \cdot \ln \left(\frac{\left[\mathrm{CH}_{3} \mathrm{COO}^{-}\right]}{\left[\mathrm{HCO}_{3}^{-}\right]^{2} \cdot\left[\mathrm{H}^{+}\right]^{9}}\right)
\end{gathered}
$$$$
\text { Oxidation half-reaction }
$$

where $E_{\mathrm{HCO}_{3}^{-} / \mathrm{Ac}^{-}}^{0}$ is the standard potential for bicarbonate/acetate (V) obtained from the standard Gibbs free energy from equation $1.3, \mathrm{R}$ is the gas constant $(8.31 \mathrm{~J} / \mathrm{K} . \mathrm{mol}), \mathrm{T}$ is the temperature $(\mathrm{K})$, F is Faraday constant $(96485 \mathrm{~mol} / \mathrm{C}),\left[\mathrm{CH}_{3} \mathrm{COO}^{-}\right]$is the acetate concentration in solution $(\mathrm{mol} / \mathrm{L}),\left[\mathrm{HCO}_{3}{ }^{-}\right]$is the bicarbonate concentration in solution $(\mathrm{mol} / \mathrm{L})$, and $\left[\mathrm{H}^{+}\right]$is the proton concentration $(\mathrm{mol} / \mathrm{L})$.

At the cathode, electrons are used to reduce a metal. The cathode potential depends on the free metal ion concentration and on the species in solution that are involved in the reactions (eq. 1.2). The cathode potential for the general case of most of the metals can be calculated according to.

$$
\begin{aligned}
& M^{n+}+(n-m) e^{-} \leftrightarrow M^{m+} \quad \text { Reduction half-reaction } \\
& E_{c a t}=E_{M^{m+} / M^{n+}}^{0}-\frac{R \cdot T}{(n-m) \cdot F} \cdot \ln \left[\frac{\left[\mathrm{M}^{n+}\right]}{\left[M^{m+}\right]}\right]
\end{aligned}
$$

where $E_{M^{m+} / M^{n+}}^{0}$ is the standard reduction potential of the target metal to recover $(\mathrm{V}) ;\left[\mathrm{M}^{\mathrm{m}+}\right.$ ] is the concentration of the oxidized metal ion and $\left[\mathrm{M}^{\mathrm{n}+}\right]$ is the concentration of the reduced metal ion in solution $(\mathrm{mol} / \mathrm{L})$.

The overall reaction, when acetate oxidation is coupled to copper (II) reduction is:

$$
\mathrm{CH}_{3} \mathrm{COO}^{-}+4 \mathrm{H}_{2} \mathrm{O}+4 \mathrm{Cu}^{2+} \leftrightarrow 2 \mathrm{HCO}_{3}^{-}+4 \mathrm{Cu}+9 \mathrm{H}^{+}
$$

Reaction 3 
The difference between cathode and anode potential at actual conditions defines the theretical cell voltage of the BES (eq. 3), and the energetics of the overall reaction.

$$
E_{B E S}=E_{c a t}-E_{a n}=E_{\mathrm{Cu}^{2+} / \mathrm{Cu}}^{0}-E_{{\mathrm{Ac} / \mathrm{HCO} \mathrm{O}^{-}}^{-}}^{0}-\frac{R \cdot T}{8 \cdot F} \cdot \ln \left(\frac{\left[\mathrm{HCO}_{3}^{-}\right]^{2} \cdot\left[\mathrm{H}^{+}\right]^{9}}{\left[\mathrm{CH}_{3} \mathrm{COO}^{-}\right] \cdot\left[\mathrm{Cu}^{2+}\right]^{4}}\right)
$$

\section{Performance indicators in a BES}

The primary tool to assess the performance of a BES is by recording polarization curve, where the current is plotted versus cell voltage. From this polarization curve, it is possible to extract the relevant parameters to compare the efficiency and performance of these systems. The open circuit voltage $\left(\mathrm{V}_{\mathrm{oc}} ; \mathrm{V}\right)$ indicates the maximum voltage that the system can reach, and is the point where the system is in equilibrium. Peak current density $\left(J_{\text {peak }} ; \mathrm{A} / \mathrm{m} 2\right)$ is the current produced by short circuit, where the cell voltage is equal to zero. The produced power by the system is the product of the voltage and the current. The maximum power density $\left(\mathrm{P}_{\max } ; \mathrm{W} / \mathrm{m}^{2}\right)$ is extracted from the polarization curve values using equation 1.7 to calculate its maximum. ${ }^{5}$ :

$P=V \cdot J$

where $P$ is the power density $\left(\mathrm{W} / \mathrm{m}^{2}\right), \mathrm{V}$ is the voltage $(\mathrm{V})$ and $\mathrm{J}$ is the current density $\left(\mathrm{A} / \mathrm{m}^{2}\right)$.

From the polarization curve, the internal resistance $\left(\mathrm{R}_{\mathrm{int}}\right)$ can be calculated by determining the slope of the polarization curve at the maximum power point. This magnitude represents the energy losses of an electrochemical device when current flows from cathode to anode.

The removal efficiency is the fraction of component removed, and is calculated from the initial and final concentration of the component in solution using the following equation 1.8:

$\eta_{r}(\%)=\frac{C_{t}-C_{0}}{C_{0}} \cdot 100$

were $C_{t}$ is the concentration measured after a defined time and $C_{0}$ is the initial concentration. This parameter shows the amount of metal removed from the wastewater.

The Coulombic efficiency at the anode expresses which part of the electrons in the substrate (acetate) is recovered as electrical current (equation 1.9). 
$\eta_{\text {anode }}(\%)=\frac{\int_{0}^{t} I \cdot d t}{\int_{0}^{t}\left(C_{t}-C_{0}\right) \cdot n \cdot Q \cdot F \cdot d t} \cdot 100 \%$

where $\mathrm{Ct}$ is the electron donor concentration in the reactor, $\mathrm{C}_{0}$ is the electron donnor concentration in the influent, $\mathrm{I}$ is the current, $\mathrm{n}$ is the number of electrons transferred by the reaction, $\mathrm{Q}$ is the volumetric flow of the influent and $\mathrm{F}$ is the Faraday constant.

The cathode coulombic efficiency expresses which part of the electrons ends up in the recovered metal, and is calculated using equation 1.10,

$\eta_{\text {cathode }}(\%)=\frac{\int_{0}^{t}\left(C_{t}-C_{0}\right) \cdot n \cdot Q \cdot F \cdot d t}{\int_{0}^{t} I \cdot d t} \cdot 100 \%$

where $\mathrm{C}_{\mathrm{t}}$ is the electron acceptor concentration, $\mathrm{C}_{0}$ is the electron acceptor concentration in the influent, $\mathrm{I}$ is the current across the external resistor, $\mathrm{n}$ is the number of electrons transferred by the reaction, $\mathrm{Q}$ is the volumetric flow of the influent and $\mathrm{F}$ is the Faraday constant.

Figure 1.3 shows the indicators to study the electrochemical performance of a BES that combines oxidation of acetate to the reduction of copper. This figure is known as polarization curve, where the voltage is presented as a function of current. Power curve, maximum power, open circuit voltage $\left(\mathrm{V}_{\mathrm{oc}}\right)$, peak current $\left(\mathrm{J}_{\text {peak }}\right)$ and internal resistance are shown. The maximum power density reported for this MFC was $0.43 \mathrm{~W} / \mathrm{m}^{2}$ at a current density of $1.8 \mathrm{~A} /$ $\mathrm{m}^{2}$ (ter Heijne et al., 2010) ${ }^{27}$. The values at maximum power of current density and voltage are expressed as $\mathrm{J}_{\max }$ and $\mathrm{V}_{\max }$ respectively.

The main advantage of using BESs for metal recovery compared to existing technologies is the fact that electrons can be released at high energy level at the anode, making the combination with metal reduction at the cathode thermodynamically more favorable. In the case of electroplating, these electrons are produced from water while in BESs these electrons can be generated from an organic substrate. The oxidation reaction of water to oxidize requires a minimum of $0.817 \mathrm{~V}$ vs. NHE and the reaction involves 4 electrons and $4 \mathrm{H}^{+}$making it kinetically not favorable, needing a catalyst (Fig.1.5). The minimum energy necessary to plate copper using water as an electron donor can be calculated from thermodynamics and is equal to $2.11 \mathrm{kWh} / \mathrm{kg}$ of $\mathrm{Cu}$. 


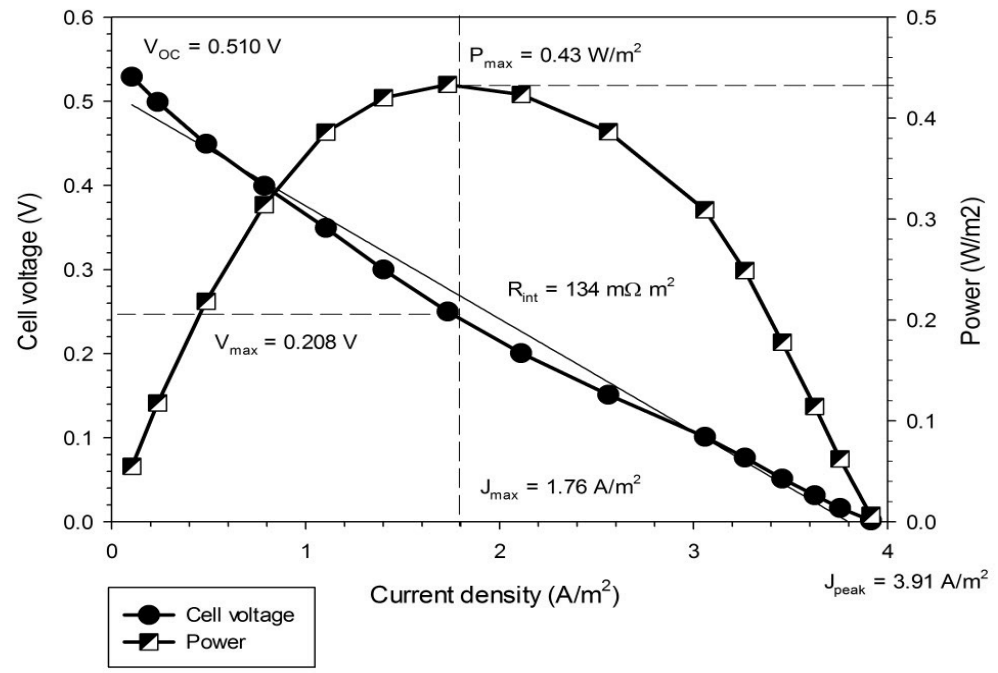

Figure 1.3. Cell voltage and power density versus current density, based on data from ter Heijne et al. (2010) for copper recovery.

$\Delta \mathrm{G}(\mathrm{eV} / \mathrm{mol}$ e-) $\mathrm{E} v \mathrm{~N} \mathrm{NHE}(\mathrm{V}) \mathrm{pH}=7$

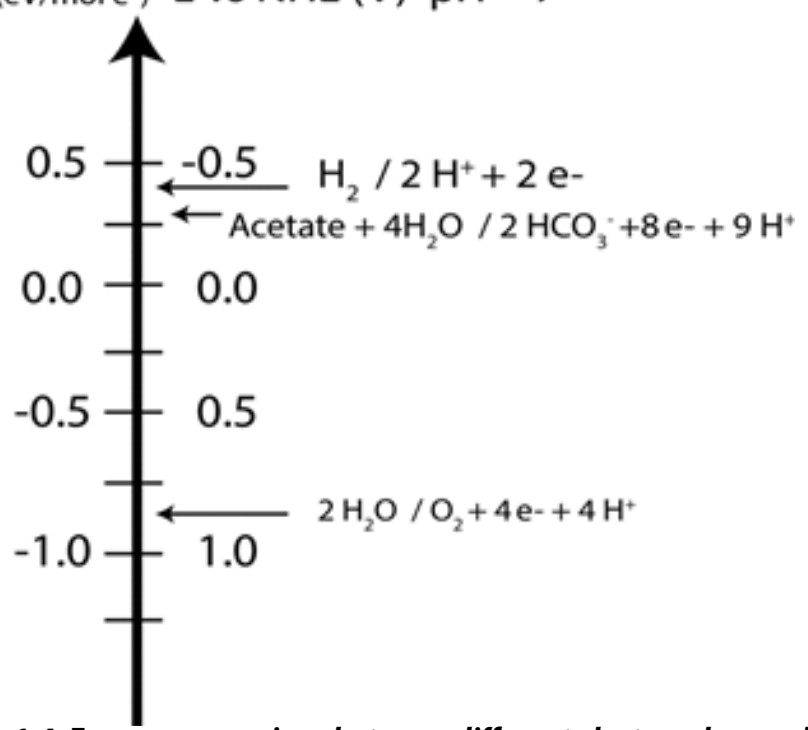

Figure 1.4. Energy comparison between different electron donors: hydrogen, acetate, and water. 
The oxidation of acetate to $\mathrm{CO}_{2}$ occurs at a potential of $-0.284 \mathrm{~V}$ vs. NHE, meaning that the electrons delivered to the electrode have a higher energy level than the electrons released from water oxidation. Acetate oxidation can occur at low overpotentials compared to water oxidation and uses a biological self-sustaining catalyst. When acetate is used as electron donor to recover copper, electricity is produced instead of consumed, with maximum energy production of $0.574 \mathrm{kWh} / \mathrm{Kg}$ of $\mathrm{Cu}$, based on thermodynamics.

\section{Electron acceptors (Cathode)}

To remove metals from wastewaters, they should be reduced from their ionic species to their elemental nature or be adsorbed or precipitated, as seen in previous pages (1.1). Figure 1.5 shows an overview of possible reactions for a BES recovering metals at the cathode. On the left side, the potential (energy level) of the oxidation reaction with acetate is depicted, while on the right side an overview of different cathode reduction reactions is shown. In this figure, the ions with a standard reduction potential (energy level) that is more positive than the potential of acetate oxidation, have a positive cell potential, meaning that the reaction is spontaneous, and electricity can be produced (MFC). The ionic species that have a standard reduction potential that is more negative than acetate require an addition energy input and thus an applied cell voltage(MEC). Figure 1.5 shows, that theoretically, metals like nickel, lead, copper, silver, and mercury can be reduced with power production in an MFC. The other metals, Cobalt, Cadmium, and Zinc, need an external power input and work as an MEC.

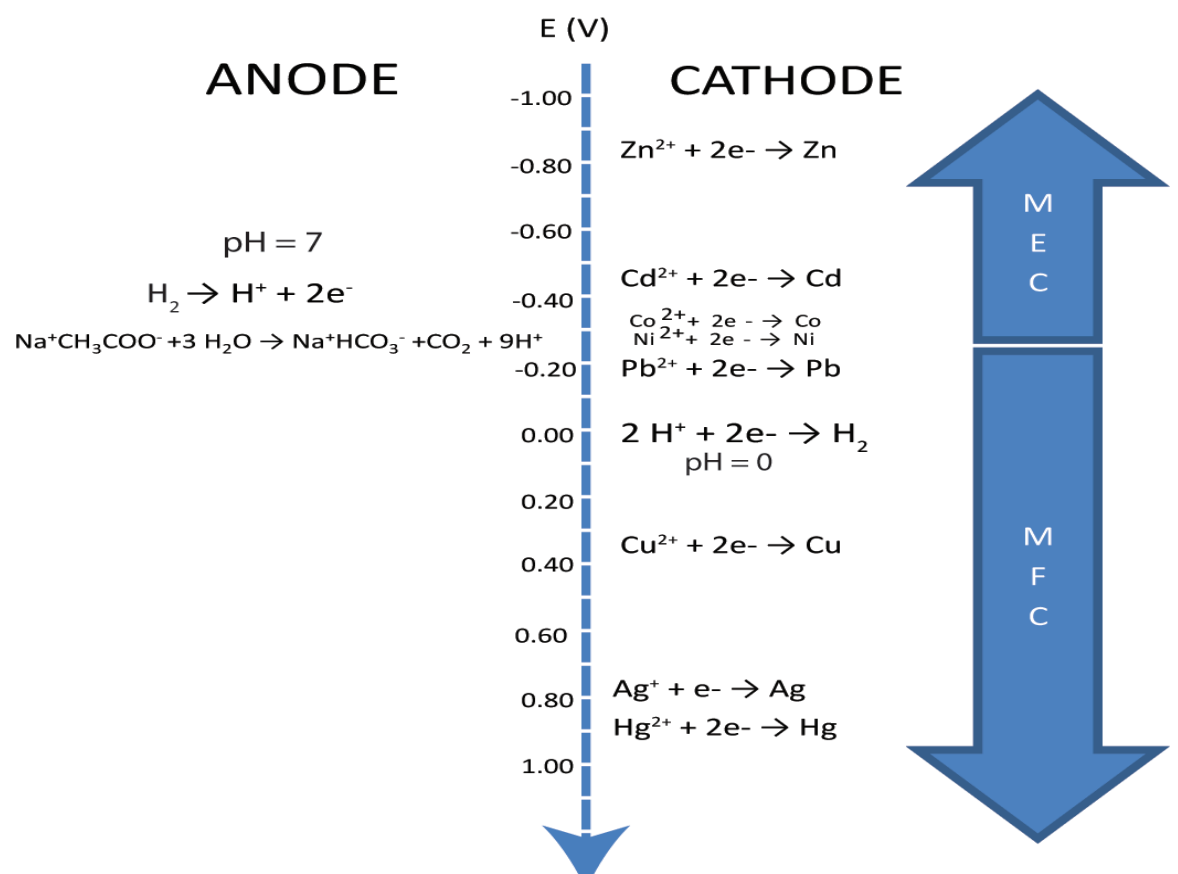

Figure 1.5. Energy diagram with reduction potentials vs. NHE. 
Bioelectrochemical metal recovery with microbial fuel cells

Table 1.1. MFC comparison between different studies and cathode configurations

\begin{tabular}{|c|c|c|c|c|c|c|}
\hline Metal & $\mathrm{V}_{\mathrm{OC}}$ & $\begin{array}{c}J_{\text {peak }} \\
\left(\mathrm{A} / \mathrm{m}^{2}\right)\end{array}$ & $\begin{array}{c}\mathrm{P}_{\max } \\
\left(\mathrm{W} / \mathrm{m}^{2}\right)\end{array}$ & $\begin{array}{l}\text { specific } \\
\text { surface }\end{array}$ & $\begin{array}{c}\text { Removal } \\
(\%)\end{array}$ & Authors \\
\hline Silver & 0.89 & 0.3 & 0.11 & 45 & 75 & $\begin{array}{l}\text { Hu-Chun } \\
\text { Tao et al. } \\
(2012)^{34}\end{array}$ \\
\hline Gold & 1.4 & 0.198 & 0.042 & 4 & & $\begin{array}{l}\text { Kalathil S. et. } \\
\text { al }(2013)^{35}\end{array}$ \\
\hline Chromium & 1.09 & 1.5 & 0.453 & 4.5 & 99 & $\begin{array}{l}\text { Wang G. et. } \\
\text { al. }(2018)^{29}\end{array}$ \\
\hline Vanadium & 0.997 & 5.5 & 0.97 & & 15 & $\begin{array}{c}\text { Zhang } \\
\text { Baogang et. } \\
\text { al. }(2012)^{36}\end{array}$ \\
\hline Copper & 0.61 & 6.2 & 0.8 & 66 & 99.88 & $\begin{array}{c}\text { Heijne et. al. } \\
(2010)^{27}\end{array}$ \\
\hline
\end{tabular}

Tables 1.1 and 1.2 show an overview of the first studies reporting the removal or recovery of a certain metal by using a BES as MFC (Table 1.1) or MEC (Table 1.2), using a bioanode that oxidizes organic material. In the different columns, these tables show the main performance indicators discussed previously, together with the specific surface (relation between the surface of the anode and the volume of the cell) and the removal efficiency. Table 1.1 shows the power produced and the current densities achieved for each case. Vanadium and copper achieved the highest rates compared to the other studied metals. Chromium and Copper showed the highest removals. Those two parameters are important for the feasibility of the technology, because it shows how fast and how efficient these metals are removed from the wastewaters. The voltage and the power are also relevant to understand how efficient the process is from an energetic point of view. Copper and Chromium are the most studied metals in BESs, but other metals can be used such as silver, gold and mercury ${ }^{27-31,37-39}$. Wang et al. (2008) published one of the first papers on MFC technology in which $\mathrm{Cr}$ (VI) in wastewaters was reduced to a less toxic aqueous species. For Chromium, Vanadium and Mercury the main target is the removal of these pollutants to improve water quality. The reduction of copper is especially interesting because of the high removal efficiency, high purity of the precipitated metal, and the production of electricity ${ }^{27}$. 
Table 1.2. MEC comparison between different authors and cathode configurations

\begin{tabular}{|c|c|c|c|c|c|c|}
\hline Metal & $\mathrm{V}_{\text {in }}$ & $\begin{array}{c}J_{\text {peak }} \\
\left(\mathrm{A} / \mathrm{m}^{2}\right)\end{array}$ & $\begin{array}{c}\mathrm{P}_{\max } \\
\left(\mathrm{W} / \mathrm{m}^{2}\right)\end{array}$ & $\begin{array}{l}\text { specific } \\
\text { surface }\end{array}$ & $\begin{array}{c}\text { Removal } \\
(\%)\end{array}$ & Authors \\
\hline Cobalt & 0.25 & 0.2 & 0.05 & 6 & 92.7 & $\begin{array}{l}\text { Huang L et } \\
\text { al. }(2013)^{40}\end{array}$ \\
\hline Nickel & 1.1 & $304\left(\mathrm{~A} / \mathrm{m}^{3}\right)$ & $33\left(\mathrm{~W} / \mathrm{m}^{3}\right)$ & 46.7 & 67 & $\begin{array}{l}\text { Qin B et. } \\
\text { al. }(2012)^{41}\end{array}$ \\
\hline Lead & 0.6 & 1.689 & 1.01 & 33 & 47.5 & \multirow{3}{*}{$\begin{array}{l}\text { Modin O. } \\
\text { et. al. (2012) } \\
28\end{array}$} \\
\hline Cadmium & 0.6 & 1.689 & 1.01 & 33 & 62 & \\
\hline Zinc & 0.8 & 1.689 & 1.35 & 33 & 44.2 & \\
\hline
\end{tabular}

Table 1.2 shows the non-spontaneous reactions in which power is used to recover nickel, cobalt, lead, cadmium and zinc using an MEC. In all these cases, an extra voltage is required (overpotentials) to plate the metal. In general, the cathode overpotentials are higher than those for MFCs. Reasons are the slow kinetics of the plating reactions, for example for $\mathrm{Nicke}^{41}$, and the presence of other competing reactions like hydrogen evolution, that reduce the efficiency of the process. These competing reactions result in lower removal efficiencies for MECs compared to MFC processes.

Modin et al. (2012) ${ }^{28}$ showed that for lead and cadmium, the recovery has lower energy demand than electrowinning processes. Cobalt reduction (Huang et al. (2013) ${ }^{42}$ can be achieved at much lower power consumption and higher removal efficiencies compared to the other metals nickel, lead, and cadmium.

\section{Membranes in BES operations}

Membranes are used in BES to keep anolyte and catholyte physically separated but in electrical contact. On one hand, in BESs the bioanode can be sensitive to the presence of metallic ions, reducing the efficiency or killing the biofilm. Furthermore, the metal stream can also get contaminated with unwanted compounds coming from the anolyte, a reason to keep both streams separated physically, but with the capacity to transfer charge between them. On the other hand, membranes play a major role in energy losses in the system due to transport resistance for ions. Transport resistance is the kinetic barrier to movement of ions through the membrane bulk. The transport resistance is dependant of ion concentration gradient between compartments. However, counter-ions can also move into the bulk of the membrane to compensate charge. ${ }^{43}$ 
Three different types of membranes have been employed in BES: Cation Exchange Membranes (CEM), Anion Exchange Membranes (AEM), and Bipolar Membranes (BP). Figure 1.6 shows a schematic representation of how these ion exchange membranes work.

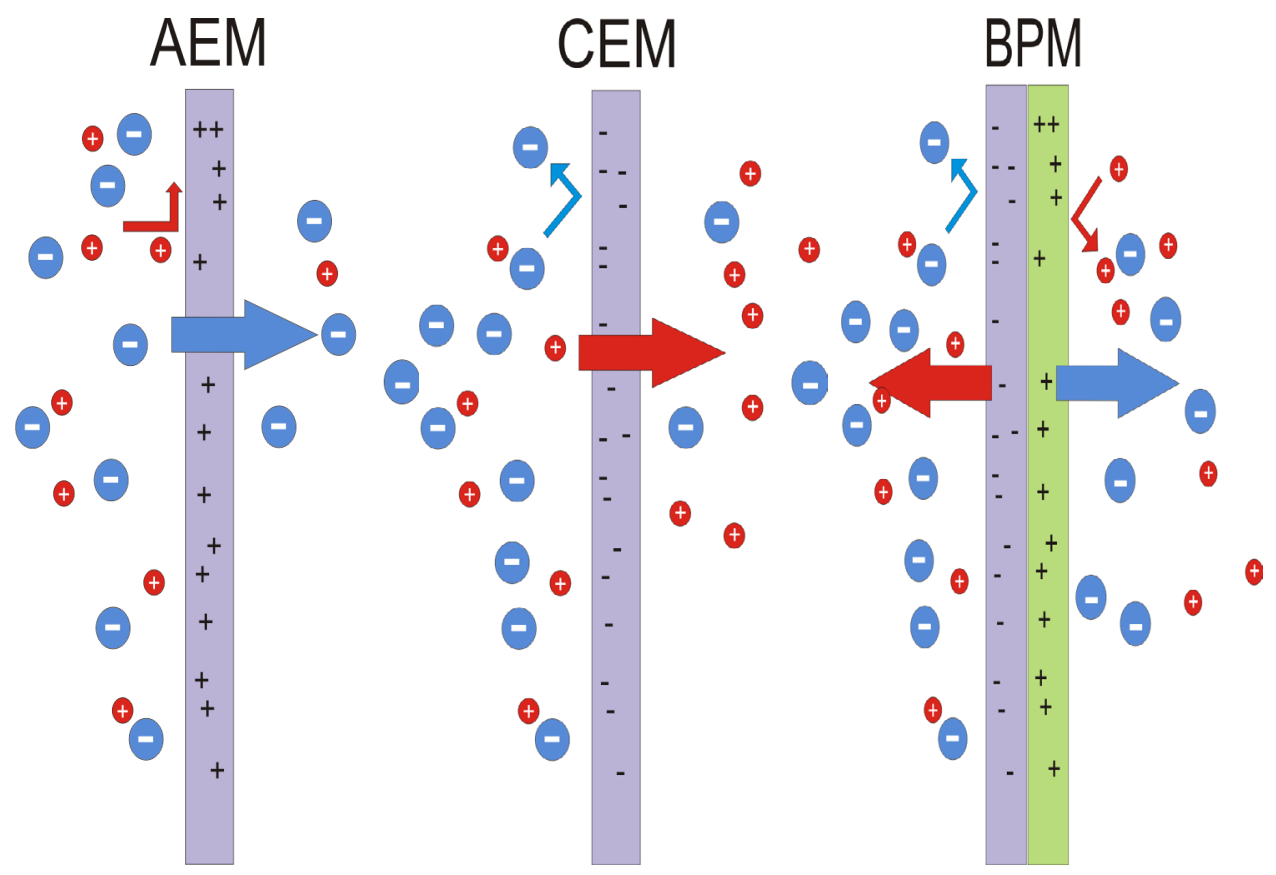

Figure 1.6 Schematic representation of Cation Exchange Membranes (CEM), Anion Exchange Membranes (AEM) and Bipolar Membranes (BPM) charge transport.

Anion exchange membranes are positively charged and allow mainly anions to go through. Cation exchange membranes work allowing cations to be transported because the membrane is negatively charged. The bipolar membrane consists of a combination of an AEM and CEM. The BPM generates anions and cations by dissociation of water in the interface between negatively charged layer and the positive charge layer. ${ }^{44}$

\subsection{Aim of this thesis}

This thesis aims to improve the performance of BESs for copper recovery, and describes the critical steps that are required to move BESs for metal recovery closer to practice.

Chapter 2 shows how a reduction in internal resistance results in a step forward in the power production and current density of an MFC that couples acetate oxidation to copper reduction with an anion exchange membrane. This chapter also identifies limitations of the technology. One of these constraints is the availability of organic electron donor. In remote areas, the technology can be attractive in places where organic electron donors are available. 
In many places that have metal-containing waste streams, however, no such organic electron donors are available. Therefore, Chapter 3 investigated hydrogen as electron donor for copper recovery. Hydrogen is available as a waste stream in metal production industry. We show that hydrogen can be oxidized biologically at a bio-anode, and can be combined with copper recovery while producing electricity. One of the limitations that limited power production was mass transfer of hydrogen from gas phase to the biofilm. In Chapter 4, we studied the use of a gas diffusion electrode to improve mass transfer of hydrogen at a bio-anode. Finally, Chapter 5 focuses on the use of a bipolar membrane for copper recovery. Because considerable energy losses occur in a bipolar membrane, we investigated if carbon dioxide could be used as a charge carrier, resulting in lower energy losses. In Chapter 6, the improvements are discussed with relation to existing technologies, and an outlook for practical application is given. 


\title{
Chapter 2. High Rate Copper and energy recovery in Microbial Fuel \\ Cells
}

\begin{abstract}
Bioelectrochemical Systems (BESs) are a novel, promising technology for the recovery of metals. The prerequisite for upscaling from laboratory to industrial size is that high current and high power densities can be produced. In this study we report the recovery of copper from a copper sulfate stream $\left(2 \mathrm{~g} / \mathrm{L} \mathrm{C \textrm {Cu } ^ { 2 + } )}\right.$ using a laboratory scale BES at high rate. To achieve this, we used a novel cell configuration to reduce the internal voltage losses of the system. At the anode, electroactive microorganisms produce electrons at the surface of an electrode, which generates a stable cell voltage of 485 $\mathrm{mV}$ when combined with a cathode where copper is reduced. In this system, a maximum current density of $23 \mathrm{~A} / \mathrm{m}^{2}$ in combination with a power density of $5.5 \mathrm{~W} / \mathrm{m}^{2}$ was produced. XRD analysis confirmed $99 \%$ purity in copper of copper deposited onto cathode surface. Analysis of voltage losses showed that at the highest current, most voltage losses occurred at the cathode and membrane, while anode losses had the lowest contribution to the total voltage loss. These results encourage further development of BESs for bioelectrochemical metal recovery.
\end{abstract}

Content of this chapter based on the publication:

Rodenas Motos, P., ter Heijne, A., van der Weijden, R., Saakes, M., Buisman, C.J.N., Sleutels, T.H.J.A., 2015. High Rate Copper and energy recovery in Microbial Fuel Cells. Front. Microbiol. 6, 527. 


\subsection{Introduction}

Heavy metals pose a serious problem when they are released into the environment due to their toxicity for humans and its negative effect on biodiversity ${ }^{45}$. Therefore, removal and recovery of heavy metals, remediation of polluted sites, and decontamination of waste streams is needed in heavy metal and mining industries. Today, the conventional method to recover metals, such as copper, is by electrowinning, which uses electric power to electrochemically reduce dissolved metals to their metallic form. As metals are becoming more scarce and expensive ${ }^{46,47}$, the revenues compensate for the electricity costs. However, considerable amounts of electrical energy are still required in electrolysis cells $(2.23 \mathrm{~kW} \mathrm{~h} /$ $\mathrm{kg}$ of Copper $)^{48}$. In comparison, Bioelectrochemical Systems (BES) can provide the energy by the bioelectrochemical degradation of organic compounds present in waste waters, for instance, acetate (electron donor), at a so called bioanode. By coupling this bioanode to a metal reducing cathode, waste water treatment can be coupled to the recovery of heavy metals in a clean and sustainable way. When additional energy is harvested from these two reactions, the system is known as a Microbial Fuel Cell (MFC). It is also possible to add extra electrical energy to drive and accelerate a reduction reaction at the cathode, in that case, the system is known as a Microbial Electrolysis Cell (MEC) ${ }^{49}$. The anode and the cathode compartment are generally separated by a membrane to simultaneously avoid mixing of the electrolytes and allowing ions to pass selectively, so charge neutrality is maintained.

In 2010 ter Heijne et al. showed the proof of principle of this concept where they combined bioelectrochemical oxidation of acetate with the reduction of copper ${ }^{27}$. In their system, electricity was produced while copper was removed and plated onto a solid electrode. A maximum current density of $3.2 \mathrm{~A} / \mathrm{m}^{2}$ was achieved in a setup with a flat plate graphite electrodes and a Bipolar Membrane (BPM). Since then ,other studies have reported MFCs in which copper was reduced at the cathode, reaching current densities ranging from $0.9-7$ $\mathrm{A} / \mathrm{m}^{2}$ with, for example, an increased surface area of the anode compared to the cathode ${ }^{28,50}$.

To make BESs practical and economically suitable to replace existing technologies, higher current densities are required. To reach high current densities, it is essential to reduce the voltage losses by reducing the internal resistance. Sleutels et al. (2012) analyzed the effect of the internal resistance on the practical applicability of BES. A resistance below $40 \mathrm{~m} \Omega \mathrm{m}^{2}$ was considered acceptable for BES applications to achieve sufficiently high current and power densities to make BESs economic ${ }^{25,51,52}$.

On the other hand, copper recovery is a highly valuable application for BES research. The recovery of valuable products allows for higher internal resistances compared to the recovery of energy alone ${ }^{25}$. Copper recovery as a cathode reaction can potentially lead to high current densities due to its low overpotential. It is therefore, a suitable cathode reaction to demonstrate that MFCs can be operated at high current densities. 
The main objective of this study was to increase the current and power density of a copper reducing MFC. Our approach was to reduce the internal resistance compared to previous studies by four changes: (i) decreasing the distance between electrodes, (ii) use an Anion Exchange Membrane (AEM), (iii) use a copper plate as cathode, and (iv) use carbon felt as anode material.

First, the distance between anode and cathode was reduced from $3 \mathrm{~cm}$ to $0.5 \mathrm{~cm}^{27}$. Second, an AEM is known to have lower internal resistance than other membranes when applied in MEC ${ }^{43,53}$ ). As the bipolar membrane resulted in high energy losses; the internal resistance was expected to be reduced by using an AEM. Third, cathode material was changed from graphite paper to copper, which is a material conventionally used in copper electroplating. Fourth, anode material was replaced from graphite paper to carbon felt to achieve high specific surface area for electroactive biofilm growth. To make this anode material available for microbial activity, the solution was forced via a perpendicular flow through this felt as shown by Sleutels et. al. ${ }^{54,55}$.

We operated this new cell design at different current densities and analyzed its performance in terms of power production and voltage losses.

\subsection{Materials and Methods}

\section{Research set up.}

The cell used in these experiments was similar to the one used by Kuntke et al $2014^{56}$. This cell was built using $10 \times 10 \mathrm{~cm}^{2}$ metallic copper plates as cathode and $10 \times 10 \mathrm{~cm}^{2}$ carbon felt of $1.5 \mathrm{~mm}$ thickness as anode. A Ralex ${ }^{\circledR}$ Anion Exchange Membrane (MEGA a.s., Stráž pod Ralskem, Czech Republic) was placed in between the anode and cathode compartment. To force the electrolyte to flow perpendicular through the electrodes, $1.2 \mathrm{~mm}$ spacer (64\% open; PETEX 07-4000/64, Sefar BV, Goor, The Netherlands) was placed between the membrane and the electrodes in both compartments (Figure 2.1). The anolyte was forced to flow towards the membrane through the electrode ${ }^{55}$. The anode, cathode, spacer material and membrane were kept in place by bolting them in between two PMMA endplates.

The anode compartment was controlled at $30{ }^{\circ} \mathrm{C}$ via a water flow through the outer wall in the anode recirculation bottle. The cathode temperature was only measured and it was oscillating between $20-23{ }^{\circ} \mathrm{C}$. Nitrogen was flushed continuously through anolyte and catholyte to keep anaerobic conditions in anode and cathode compartments. Anode and cathode potentials were measured against $\mathrm{Ag} / \mathrm{AgCl} 3 \mathrm{M}$ reference electrode (ProSense, Oosterhout, Netherlands; $201 \mathrm{mV}$ vs. Standard Hydrogen Electrode). Voltage losses across the membrane were measured as the voltage difference between the two reference electrodes placed in catholyte and anolyte. Cell voltage and potentials of cathode, anode and membrane 
were continuously recorded together with $\mathrm{pH}$ and temperature in both compartments using a data logger (Endress+Hauser Messtechnik GmbH+Co., Rhein, Germany).

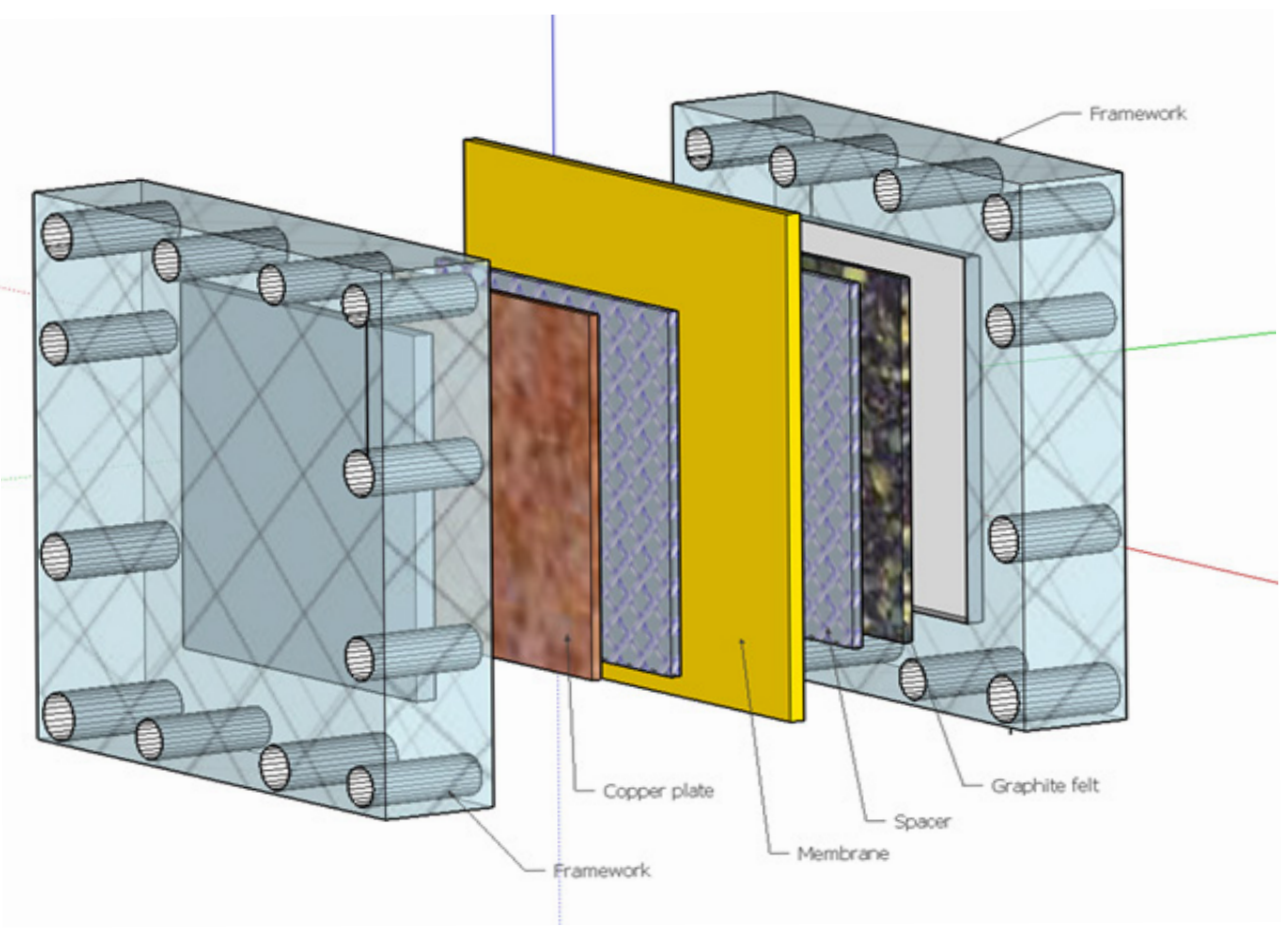

Figure 2.1. Cell design 3D view with copper electrode (brown), membrane (yellow), spacer (clear blue patterned), graphite felt (black with white dots) and framework (transparent).

\section{Start-up and operation.}

At the beginning of the experiment a $2 \mathrm{~g} / \mathrm{L} \mathrm{Cu}^{2+}$ solution was prepared dissolving $\mathrm{CuSO}_{4}$ $5 \cdot \mathrm{H}_{2} \mathrm{O}$ as catholyte. The anode influent $(2 \mathrm{~mL} / \mathrm{min})$ consisted of synthetic waste water solution containing $20 \mathrm{mM}$ acetate, phosphate buffer $(10 \mathrm{mM}, \mathrm{pH}$ 7), nutrients and vitamins as described in ter Heijne (2008) ${ }^{57}$. The anode was fed with an excess of acetate to make sure the current production was not limited by substrate availability. Acetate was measured over time to ensure an excess of electron donor in the anode to produce current. Any competing processes at the anode for example methanogens were taken into consideration. Anolyte and catholyte had a constant recirculation rate of $200 \mathrm{~mL} / \mathrm{min}$. The total catholyte volume was $10 \mathrm{~L}$. The cathode $\mathrm{pH}$ was controlled at $\mathrm{pH} 3$ in the anode with a $0.1 \mathrm{M} \mathrm{H}_{2} \mathrm{SO}_{4}$ solution. No supporting electrolyte was used. The conductivity of the solution was not measured during the experiment, only was measured at the beginning of the experiment, and the values are 9.2 $\mathrm{mS} / \mathrm{cm}$ for the catholyte and $6.2 \mathrm{mS} / \mathrm{cm}$ for the anolyte. The presence of an excess of acetate and sulfate (transported from the cathode) in the anolyte resulted in sulfate reduction (due to 
sulfate reducing bacteria $)^{58}$ and a consequent consumption of protons. Hence, acid addition was required in the anode compartment. It should be noted that addition of chemicals to control the $\mathrm{pH}$ is not a sustainable solution for practical applications but it was used here to be able to study the maximum performance of the system for copper removal. The cell started up at a constant resistance of $1 \mathrm{k} \Omega$. The resistor was switched to a lower value (stepwise using $1 \mathrm{k} \Omega, 500 \Omega, 250 \Omega$ and $100 \Omega$ ) after the anode potential had stabilized at a value of -450 $\mathrm{mV}$ vs Ag/AgCl. During this growing period of two weeks stable conditions were ensured using buffer solution as catholyte for oxygen reduction and measuring stable voltages over the entire cell. During the measurements that are reported in the results section below, the resistances were lowered sequentially from $1 \mathrm{k} \Omega$ to $0.5 \Omega$ and catholyte was changed to copper sulphate solution. For each resistance steady state values over a period of $24 \mathrm{~h}$ were used to calculate the polarization curve.

\section{Analyses.}

Copper concentration was measured using ICP-OES Perkin Elmer Optima 5300 (Perkin Elmer, Groningen, Netherlands). The consumed acetate during the experiment was tracked every $24 \mathrm{~h}$ measuring TOC (Total Organic Carbon) and IC (Inorganic Carbon) that was correlated with the concentration of acetate and bicarbonate using Shimadzu TOC-L CPH combustion TOC analyzer (Shimadzu Benelux, 's-Hertogenbosch, Netherlands). The gas composition in the headspace of the cells was also examined with a gas chromatographer (Varian Inc. (Part A) - CP-4900 Micro-GC).

The deposited copper on the electrode was scratched with a knife from the surface, weighed in a test tube and dissolved in $5 \mathrm{~mL}$ of $33 \% \mathrm{HNO}_{3}$. Then, $5 \mathrm{~mL}$ of Mili-Q water was added to dilute the solution. Then the solution obtained was diluted 1000 times again and measured by ICP-OES Perkin Elmer Optima 5300 to determine the amount of copper plated on the electrode.

\section{Calculation.}

The theoretical cell voltage $\left(\mathrm{E}_{\text {emf }}\right.$ in $\left.\mathrm{V}\right)$ can be calculated from the Gibbs free energy change of the overall reaction occurring at the cathode and anode, while the practical value can be directly measured at open cell conditions

$$
E_{\text {emf }}=\frac{-\Delta G_{r}}{n F}
$$

where, $\Delta \mathrm{Gr}$ is the Gibbs free energy of the overall reaction $(\mathrm{kJ} / \mathrm{mol}), \mathrm{n}$ is the number of electrons transferred in the reaction, $\mathrm{F}$ is Faraday constant $(96485 \mathrm{C} / \mathrm{mol})$.

The contribution of the partial voltage losses to the total voltage loss inside the cell can be calculated according to 


$$
E_{C E L L}=E_{\text {emf }}-\varphi_{\text {Cath }}-\varphi_{\text {Anod }}-\varphi_{\text {mem }}-\varphi_{\text {ion }}
$$

where $\mathrm{E}_{\mathrm{CELL}}$ is the voltage measured during cell operation $(\mathrm{V}), \varphi_{\mathrm{Cath}}$ is the measured cathode overpotential (theoretical cathode potential-measured cathode potential) $(V), \varphi_{\text {Anod }}$ is the measured anode overpotential (theoretical anode potential-measured anode potential) (V), $\varphi_{\text {mem }}$ is the voltage lost across the membrane (cathode ref potential-anode ref potential)(V), and $\varphi_{\text {ion }}$ is the voltage lost due to the ionic resistance of the solutions (V).

\subsection{Results and discussion}

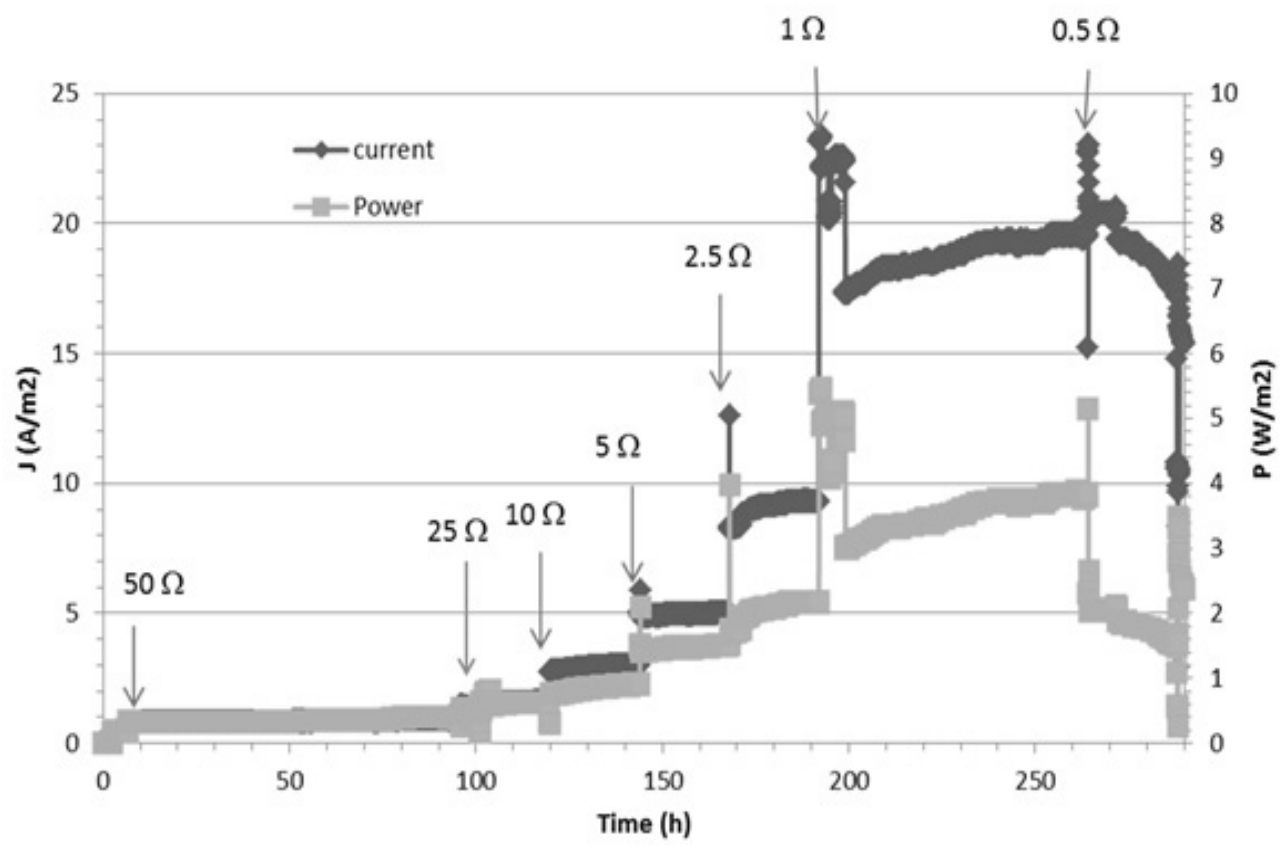

Figure 2.2. Evolution of current density (black) and the power density (grey) is shown versus time during the entire range of the experiment. The arrows indicate when resistances were changed.

\section{Current and power output.}

Figure 2.2 shows the current and power density generated over the entire experimental period. The arrows indicate the moment at which the value of the external resistance was lowered. The current density increased from $0.5 \mathrm{~A} / \mathrm{m}^{2}$ at an external resistance of $100 \Omega$ up to a stable value of $19 \mathrm{~A} / \mathrm{m}^{2}$ at an external resistance of $1 \Omega$. The peak current density was 23 $\mathrm{A} / \mathrm{m}^{2}$ and at this maximum current density, the peak power density was $5.5 \mathrm{~W} / \mathrm{m}^{2}$ When the resistor was further decreased to $0.5 \Omega$, the current density did not increase further, and 
the power output dropped from 4.0 to $2.0 \mathrm{~W} / \mathrm{m}^{2}$. Figure 2.3 shows the polarization curve of the MFC, summarizing the whole experimental period, using the average values for cell voltage, current and power density at each external resistor. The Open Circuit voltage (OCV) measured the first day was $485 \mathrm{mV}$, which is lower than the theoretical value of $575 \mathrm{mV}$.

During the whole period only $60 \%$ of the total amount of acetate was consumed by the biofilm, from this amount only the $26 \%$ was used to produce electricity. The detection of methane and sulphide in the head space of the recirculation bottle let us conclude that acetate was used for methane production and sulphate reduction by methanogens and sulphate reducers competing for the substrate with the electrogenic bacteria.

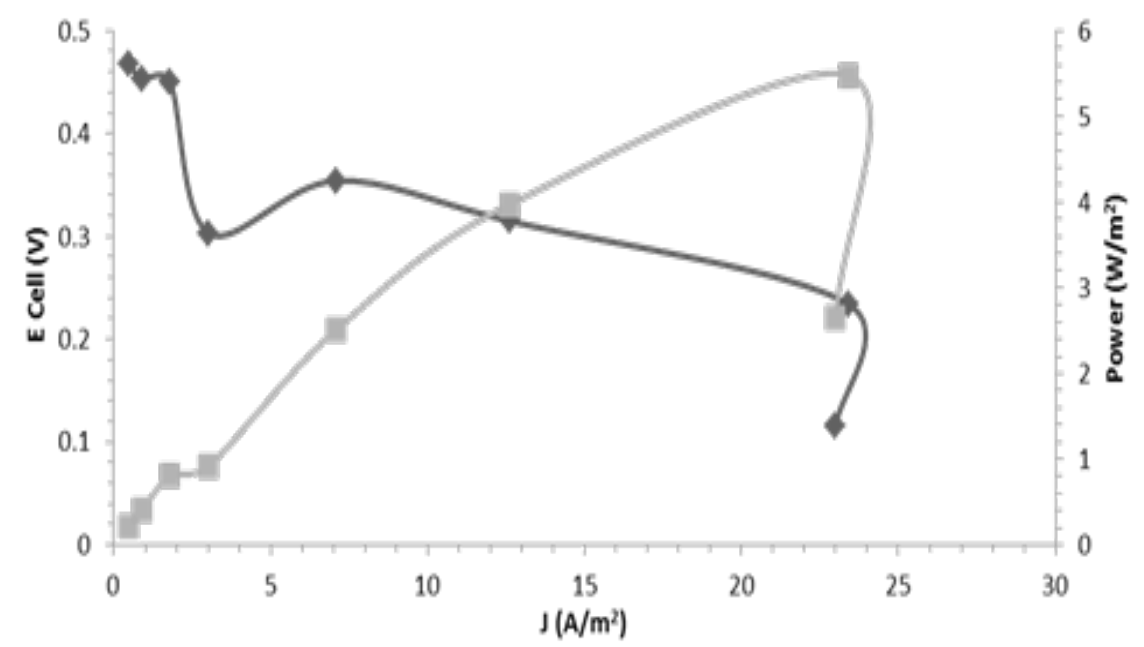

Figure 2.3. Polarization curve of the copper reducing MFC. The potential is represented versus current density (black) and the power is shown versus current density (grey).

\section{Analysis of the performance.}

To analyze the reason for the drop in power production in more detail, we have analyzed the separate contributions of anode, cathode and voltage losses across the membrane throughout the experimental period. Figure 2.4 shows the relative contribution of the voltage losses for these three main components of the system: at every external resistance. The voltage loss over the membrane was measured using the reference electrode inserted in the anode and cathode compartment. Then, the ionic resistance of the electrolyte (anode and cathode) is measured as part of the membrane voltage loss. Note that Figure 2.4 shows the contribution of the three components, the three of them summing up to $100 \%$. This was done to illustrate the differences with time more clearly. Obviously, at a high external resistance the produced current was lowest while at a decreasing external resistor the produced current increased 
(Figure 2.2). So overall, the internal resistance of the system decreased with time.

With an increase in current density, the contribution of anode overpotential to the total voltage losses decreased considerably from $68 \%$ to $23 \%$. We observed an increase in anode voltage from -450 to $-400 \mathrm{mV}$ vs $\mathrm{Ag} / \mathrm{AgCl}$ for the first steps with high external resistances. However, when current reached its maximum values, the anode potential raised only to -350 $\mathrm{mV}$ vs $\mathrm{Ag} / \mathrm{AgCl}$. Apparently the biofilm was not affected by the high protons production rate that is associated with the current production. Instead an increase in the voltage loss over the membrane was observed. At increasing current densities voltage losses across the membrane increased from $-50 \mathrm{mV}$ on first day to $180 \mathrm{mV}$ on ninth day. This value of $-50 \mathrm{mV}$ was result of the difference in chemical potential between anolyte and catholyte due to the difference in composition of these electrolytes. Sulphate was transported through the membrane from catholyte to anolyte. This chemical potential contributes positively to the cell potential. At the highest current reached, the dominant losses occurred at the cathode, approximately around $50 \%$ of total losses contribution between $10 \Omega$ external resistance and $1 \Omega$ external resistance. The increase in current density at lower external resistance was also reflected in an increase of the cathode overpotential Cathode potential went down from $50 \mathrm{mV}$ during first day to -60 $\mathrm{mV}$ vs $\mathrm{Ag} / \mathrm{AgCl}$ at the end of the experiment due to the decrease in Copper concentration.

An increase in the membrane voltage losses is likely at higher current densities since more ions need to be transported in the same time period. Additionally, the increase in membrane voltage losses can also be related to scaling. At the end of the experiment, when the cell was disassembled, precipitates were found in the catholyte and on the membrane surface. Figure $2.5 \mathrm{c}$ shows the SEM images of scaling in the cathode and on the membrane. Analysis of these structures with EDX shows the presence of copper, sulfur and phosphor, which lead us to believe that the precipitates are copper sulfates, copper sulfides and copper phosphates. Scaling is more likely to occur when divalent ions (like Copper and sulphate in this system) are present. Scaling is a serious issue that may limit the transport of ionic species from one compartment to the other, and thereby limiting performance of these systems. Prevention of this scaling is an important aspect of further study. 


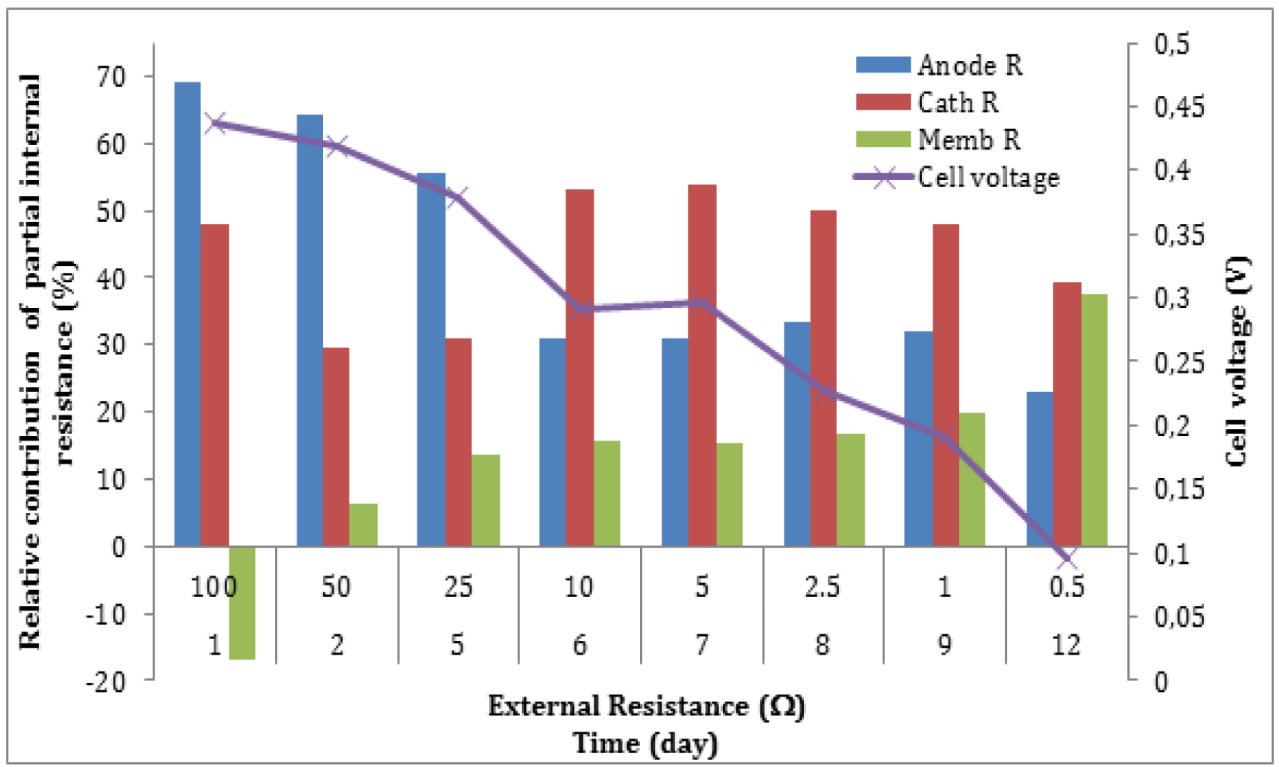

Figure 2.4. Contribution of the cell components (anode, cathode and membrane) to the total voltage loss in the system at different external resistors. Also the cell voltage is shown for each external resistor.

\section{Performance comparison to previous studies.}

To improve MFC performance the cell design was improved compared to previous studies ${ }^{27}$ by modifying the electrode materials, the membrane, and the distance between electrodes and mass transport within the system. Table 2.1 compares the performance of the MFC described in this study to other studies that used copper reduction as cathode reaction. Main differences between this and other studies are: cell configuration, type of membrane and different electrode materials. For example, all studies list in table 2.1 except Modin et al. (2012)and present study used carbon electrodes as cathode instead metal electrodes. The maximum current density in short circuit conditions produced by Modin et al. (2012) cell, was $7 \mathrm{~A} / \mathrm{m}^{2}$ for $128 \mathrm{~cm}^{2}$ of anode felt surface using a small cathode surface of $1 \mathrm{~cm}^{2}$, and using also an AEM. Even though, ter Heijne et al. (2010) achieved $3.2 \mathrm{~A} / \mathrm{m}^{2}$ using graphite paper electrodes with a surface of $20 \mathrm{~cm}^{2}$ and a $\mathrm{BPM}^{27}$. Cheng et al. (2013) achieved $1.2 \mathrm{~A} / \mathrm{m}^{2}$ using a carbon fiber brush anode and a carbon rod cathode. On the other hand, this study achieved a current density of $23 \mathrm{~A} / \mathrm{m}^{2}$ for $100 \mathrm{~cm}^{2}$ of anode graphite felt surface and $100 \mathrm{~cm}^{2}$ copper cathode and using AEM.

Although previous studies reported considerable current densities, the power production was not always equivalent due to, either short circuit conditions or high internal resistance. However, in this study the produced power density was $5.5 \mathrm{~W} / \mathrm{m}^{2}$, which is considerably 
higher than the reported before with power densities ranging between 0.2 to $0.8 \mathrm{~W} / \mathrm{m}^{2}$. This achievement is explained as a result of the low voltage losses of this MFC compared to other MFC configurations.

\section{Copper removal and analysis of the deposited copper.}

Samples from catholyte were taken and analyzed 5 times per week. Interestingly, during the first 100 hours, we found out a slight increase in copper concentration from $2.0 \mathrm{~g} / \mathrm{L}$ to $2.2 \mathrm{~g} / \mathrm{L}$. In this time period, the current density was still low, below $1 \mathrm{~A} / \mathrm{m}^{2}$. Only when current density exceed $1.0 \mathrm{~A} / \mathrm{m}^{2}$, copper concentration started to drop and showed a steady decrease to 0.2 $\mathrm{g} / \mathrm{L}$ after 24 hours. A possible reasonable explanation for the increase in copper concentration may be that the copper electrode itself was oxidized to copper (II) under acidic conditions ( $\mathrm{pH} 3)$. In order to check that copper oxidation occurs at acidic $\mathrm{pH}$, a parallel experiment at open circuit in the same acidic conditions and copper concentration was performed. Here, a loss in weight of the electrode of 1.72 gr of copper was observed after 24 hours. This confirmed that the copper electrode can be oxidized under acidic conditions and explains the increase in copper concentration at low current densities (below $1 \mathrm{~A} / \mathrm{m}^{2}$ ). Finally, it is important to mention that no copper was detected in the anode during any of the experiments.

After one month of operation, the cell was disassembled and the copper layer on the cathode was analyzed for purity. Figures 2.5a and 2.5b show the SEM images of the copper deposited on top of the copper cathode. Copper exhibited dendritic formations, which are likely a result of the high current densities. These dendrites crossed the spacer and touched the membrane surface. This is a point of attention because these structures might damage the membrane. Analysis of the Copper electrode by nitric acid leaching showed that the composition of the deposited copper on the cathode has a copper purity of $99.4 \% \pm 1.0 \%$ with $0,3 \%$ in zinc. XRD analysis confirmed the copper purity of the copper deposited onto the electrode.

\subsection{Implications}

High current density and power production were achieved in this improved cell design compared to the proof of principle by ter Heijne et al. (2010). The current was enhanced from $3.2 \mathrm{~A} / \mathrm{m}^{2}$ to $23 \mathrm{~A} / \mathrm{m}^{2}$ while the power density increased from $0.8 \mathrm{~W} / \mathrm{m}^{2}$ to $5.5 \mathrm{~W} / \mathrm{m}^{2}$.

State of the art technologies like solvent extraction and electrowinning SX/EW consume $2.716 \mathrm{kWh} / \mathrm{Kg}$ of $\mathrm{Cu}^{2+}$. On the contrary, this study produced a constant power of $3.7 \mathrm{~W} / \mathrm{m}^{2}$ equivalent to an energy production of $0.081 \mathrm{kWh} / \mathrm{Kg}$ of $\mathrm{Cu}$. It should be mentioned that, the energy required to operate the system was not taken into account here. Also, $2.056 \mathrm{~kg}$ of acetate is required per kilogram of copper, which can be considered as a waste product.

The current density can be improved even further by supplying an external voltage to the 


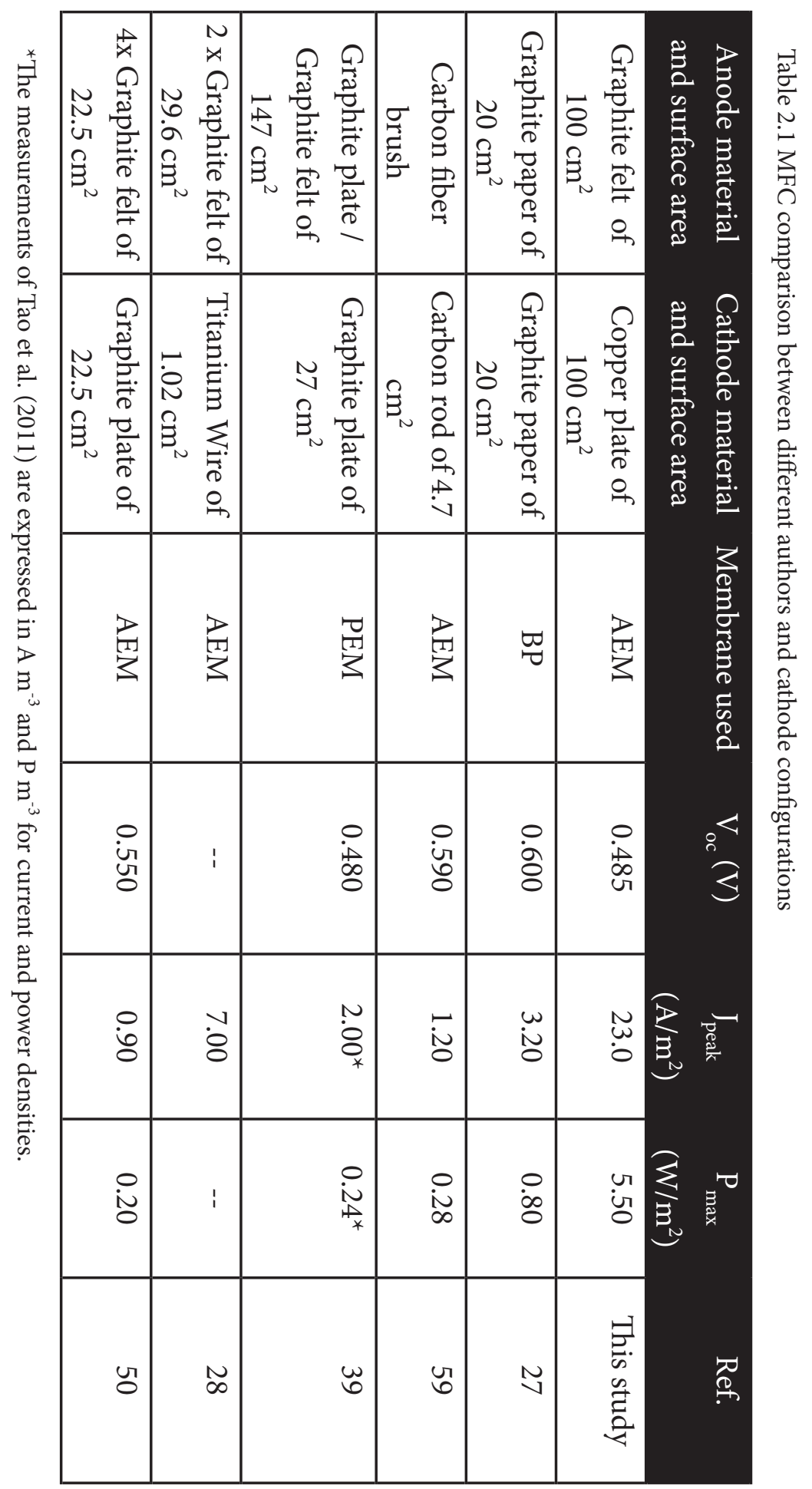




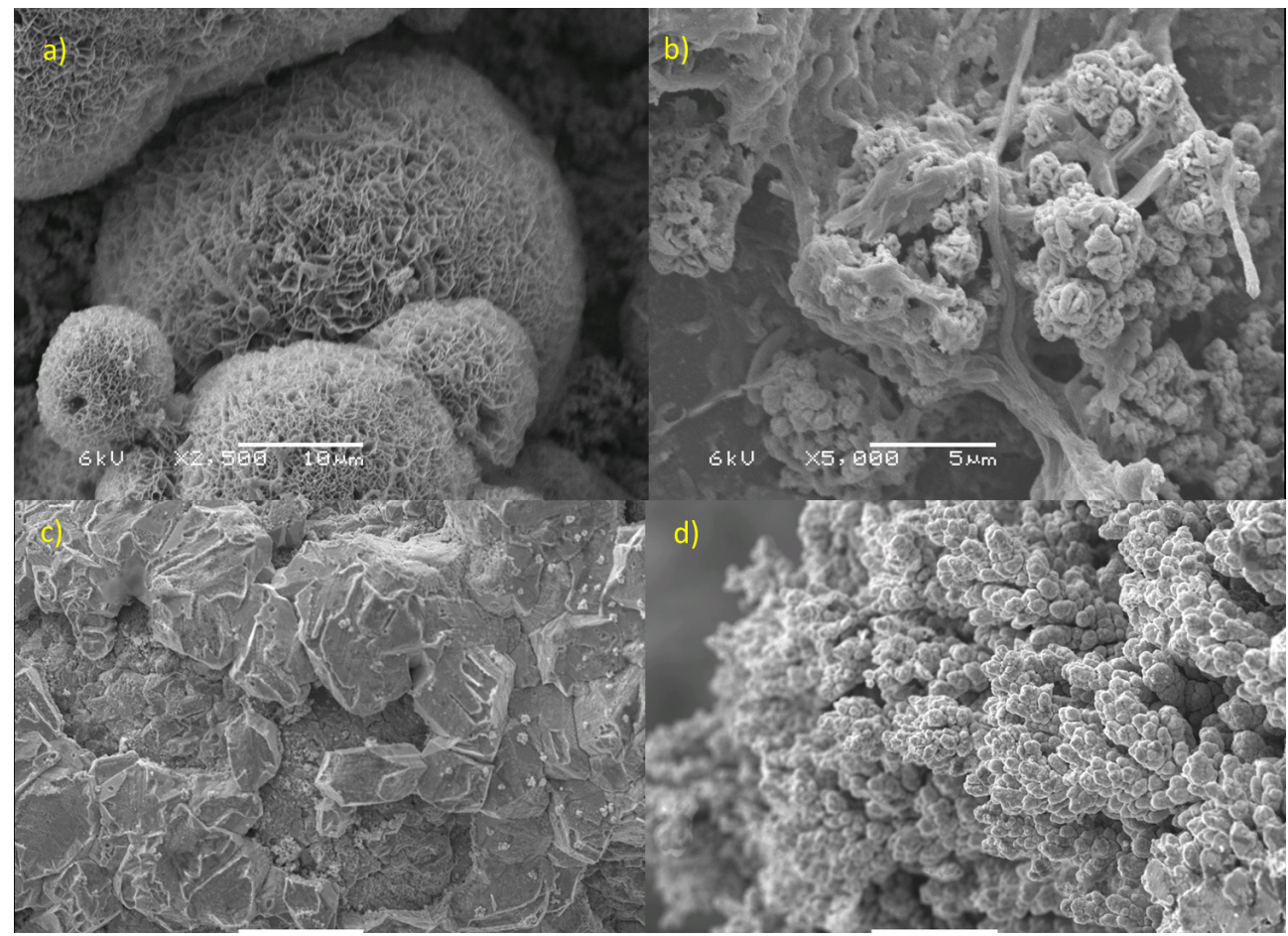

Figure 5 a) SEM image of crystalline scaling from cathode side on AEM, b) SEM image of biofilm on anode side of AEM. c) SEM image of smooth copper deposited on flat copper surface d) SEM image of the dendrites formed on cathode surface,

system. Although the produced current and removed amount of copper will be higher, this would go at the expense of energy input.

Analysis of the voltage losses showed that anode was the main contribution to the voltage losses in the system at low current densities, but when currents were higher the cathode and the membrane started to limit the system. Consequently, the transport of ionic species through the system and membrane should be studied in more detail, as well as the scaling on the membrane surface related to the ion transport are an important aspect that needs attention in the future.

Several challenges remain to be solved before this technology becomes practically applicable. The use of a copper electrode, which is normally used in electro-winning, may pose difficulties in MFCs. Those difficulties are typically the slow reaction rates and the fact that copper actually dissolves. Further research on copper deposition at low current densities with other metallic electrodes, such as stainless steel or titanium, would give more insights on this system performance. 


\section{Chapter 3. Hydrogen as electron donor for copper removal in bio- electrochemical systems}

Abstract

Hydrogen gas is an attractive alternative electron donor since it is produced in large quantities as a side product in the metallurgical industry. Aim of this study was to demonstrate that microbial anodic hydrogen oxidation on a non-catalyzed graphite electrode can be coupled with cathodic copper reduction in a BES to simultaneously recover copper and produce power. The strategy was first to grow an anodic biofilm on acetate, then replace the acetate with hydrogen as electron donor, and finally combine hydrogen oxidation with copper reduction in the cathode. The maximum current density was 1.8 $A / m^{2}$ at $-250 \mathrm{mV}$ anode potential vs $\mathrm{Ag} / \mathrm{AgCl}$. When coupled with $\mathrm{Cu}^{2+}$ reduction, the maximum power density was $0.25 \mathrm{~W} / \mathrm{m}^{2}$ at a current density of $0.48 \mathrm{~A} / \mathrm{m}^{2}$. Anode overpotentials were higher compared to acetate oxidation, probably a result of limited hydrogen solubility and transfer.

This chapter has been published in:

Ntagia, E., Rodenas, P., Ter Heijne, A., Buisman, C.J.N., Sleutels, T.H.J.A., 2016. Hydrogen as electron donor for copper removal in bioelectrochemical systems. Int. J. Hydrogen Energy 41. 


\subsection{Introduction}

Significant volumes of heavy metal containing wastewaters are produced continuously at metal producing or electroplating companies. Heavy metals have been proven highly toxic for human, microbial and plant life ${ }^{61,62}$. Because heavy metals, even at low concentrations have negative effects on the environment, there is a need to remediate metal containing waste streams. Moreover, metal resources are finite, making their recycling crucial, since their production and transportation results in high energy consumption and arises unwanted and highly pollutant gas, solid and liquid emissions ${ }^{1,63}$.

Conventional heavy metal removal technologies include electrochemical, chemical precipitation and ion-exchange. Although these technologies are applied in practice and a large scale their economic and environmental impact could still be improved by reduction of the high operational costs due to chemicals and energy consumption and the reduction of excessive production of hazardous wastes. This improvement could possibly also be achieved by the removal of these heavy metals in bioelectrochemical systems (BES). ${ }^{1,45}$. In order to improve economic revenue and environmental impact of heavy metal treatment, we propose the removal of metals with BES. In BES the costs for chemicals and also for energy are minimized, and even power is produced in some cases; the biological oxidation of organic substrates provides part of required energy input. Three basic components comprises a BES: an anode, where substrate is oxidized and electrons are entering an electrical circuit, a cathode where a reduction reaction takes place and electrons are leaving the electrical circuit and, in most of the cases, an ion-exchange membrane that keeps the anolyte and catholyte separated and prevents substrate/product crossover ${ }^{64}$.

Several metals have been demonstrated as electron acceptors in BES cathodes such as silver ${ }^{65,66}$, iron ${ }^{17,67,68}$, nickel ${ }^{41}$, zinc ${ }^{28}$ and copper ${ }^{27,28,37,39,50,59,69}$. A common feature in all these studies is that the electron donor in the anodic compartment is an organic substrate. Electrochemically active bacteria are efficient oxidizers of organic substrates such as glucose, ethanol, glycerol, cellulose feedstocks, sewage sludge and aromatic compounds, but also inorganic such as hydrogen and sulfur compounds ${ }^{24,70,71}$. The use of organic substrates limits application of BESs to certain locations were organic wastewaters are available, but in reality organic waste streams are not ubiquitous. At the same time, mining and metal industries, being the ones most interested in metal recovery, produce large amounts of hydrogen as a side product of their electroplating activities ${ }^{72,73}$. Hydrogen is also produced in reduction furnace operations $^{74}$ and as a side product of electro-catalytic treatment for acidity in mine waters ${ }^{75,76}$.

Hydrogen can be used as electron donor in chemical fuel cells where it reacts with oxygen to produce electric current. The drawbacks of fuel cells is that they utilize noble metal catalysts like platinum, which are expensive and rare materials, and often operate at extreme conditions ${ }^{77,78}$. Microorganisms could serve as an alternative catalyst for the hydrogen 
oxidation reaction. Production of current by hydrogenotrophic anodophilic bacteria in MECs has already been reported by a number of researchers ${ }^{79-81}$. Rozendal et al. $(2008)^{82}$ used hydrogen as electron donor in order to grow a bioanode, which was after start-up changed to a hydrogen producing biocathode by reversing the polarity of the electrode. Moreover, Wang et al. $(2014)^{83}$, succeeded in perchlorate reduction in a bioelectrochemical reactor utilizing autotrophic hydrogen oxidizing bacteria. Both studies did not analyze the performance of a hydrogen oxidizing biofilm on the anode.

The main objective of this study was to explore the feasibility to utilize hydrogen as electron donor in combination with electrochemically active microorganisms at the anode for the recovery of copper at the cathode of a bioelectrochemical system. The strategy was to first to grow an anodic biofilm on acetate, then replace the acetate with hydrogen as electron donor and finally couple the hydrogen oxidation to copper reduction in the cathode. The performance of this system was studied by analyzing current as a function of anode potential, and, when coupled to copper reduction, power production.

\subsection{Materials and methods}

\section{Experimental set up.}

Two identical cells (biotic and abiotic control) with a surface area of $22 \mathrm{~cm}^{2}$ were constructed, as described by ter Heijne et al $(2008)^{57}$. Each of them comprised of two graphite plates (Müller \& Rössner GmbH \& Co., Troisdorf, Germany) serving as anode current collector and cathode. The anode material was graphite foil $\left(1.0 \mathrm{~g} / \mathrm{cm}^{3}\right.$ density, $99 \%$ purity; Coidan Graphite Products Ltd., York, UK), which was pressed on the anode current collector.

Two plexiglass plates with a single flow channel as middle compartments contained anolyte and catholyte and were separated by a Ralex anion exchange membrane (MEGA a.s.,Stráž pod Ralskem, Czech Republic). Two additional plexiglass plates served as temperature control (30 ${ }^{\circ} \mathrm{C}$ ) on the outside of the cell.

Temperature and $\mathrm{pH}$ were continuously logged (Endress + Hauser, Liquiline data logger) through pH electrodes (Endress + Hauser, CPS41 D) that were placed in the recirculation of anolyte and catholyte. In the headspace of each of the recirculation bottles, a gas sampling point was placed. The outgoing gas flow was measured using a bubble counter (MilliGascounter, Type MGC-1, Ritter, Bochum, Germany).

\section{Electron donor and electrolyte composition}

The anode of both cells was first fed with an acetate containing solution $(20 \mathrm{mM})$ at a rate of $2 \mathrm{~mL} / \mathrm{min}$. This solution furthermore contained the following buffer and nutrients: 0.68 
$\mathrm{g} / \mathrm{L} \mathrm{KH}_{2} \mathrm{PO}_{4}, 0.87 \mathrm{~g} / \mathrm{L} \mathrm{K}_{2} \mathrm{HPO}_{4}, 0.74 \mathrm{~g} / \mathrm{L} \mathrm{KCl}, 0.58 \mathrm{~g} / \mathrm{L} \mathrm{NaCl}, 0.28 \mathrm{~g} / \mathrm{L} \mathrm{NH}_{4} \mathrm{Cl}, 0.1 \mathrm{~g} / \mathrm{L} \mathrm{MgSO}_{4} .7$ $\mathrm{H}_{2} \mathrm{O}, 0.1 \mathrm{~g} / \mathrm{L} \mathrm{CaCl} 2 \cdot 2 \mathrm{H}_{2} \mathrm{O}$ and $0.1 \mathrm{~mL} / \mathrm{L}$ of a trace element mixture ${ }^{84}$.

The anolyte chamber was operated in a continuous mode and the catholyte in a batch mode. The anolyte was recirculated at $200 \mathrm{~mL} / \mathrm{min}$ via two recirculation bottles of $0.5 \mathrm{~L}$ each. The catholyte was recirculated with the same rate in a $1 \mathrm{~L}$ bottle, which was shared by both the biotic and abiotic cell.

During stage 1, the bioanode was tested on acetate and hydrogen, and the catholyte consisted of $10 \mathrm{mM}$ of phosphate buffer solution ( $\mathrm{pH}$ 7). In stage 2, the bioanode was coupled to copper reduction, and the catholyte consisted of $1 \mathrm{~g} / \mathrm{L} \mathrm{Cu}^{2+}$ (prepared from $\mathrm{CuCl}_{2}$ and deionized water; $\mathrm{pH}=4$ ).

The cathode was kept anaerobic by flushing with nitrogen gas.

In the second stage both cells were fed with hydrogen gas as electron donor. This hydrogen gas inflow was controlled with a mass flow controller (Bronkhorst HICH-TECH BV, Ruurlo, Nederland) at 3, 10 and $30 \mathrm{~mL} / \mathrm{min}$. Hydrogen was sparged in the recirculation bottles and continuously recirculated through the headspace of the recirculation bottles with a vacuum pump to achieve saturation of the anolyte with hydrogen. Buffer and nutrients remained the same when the hydrogen gas served as electron donor.

\section{Experimental strategy}

The biotic cell was inoculated with a mixed microbial culture from an active MFC utilizing acetate as electron donor. The abiotic cell was not inoculated and served as control. This cell was tested under the same hydrogen flows as for the biotic cell and with the anode potential ranging from -400 to $-200 \mathrm{mV}$.

Table 3.1 gives an overview of the two experimental stages. First, the cell was started with acetate as electron donor and during the experiment the acetate was first partly and later fully replaced with hydrogen. For both cells the anode potential was controlled with a potentiostat ranging from $-400 \mathrm{mV}$ to $-200 \mathrm{mV}$ (50 mV steps), in order to see the response of current generation as a function of the anode potential. When a stable current was reached, the acetate concentration was decreased stepwise to 10 and $5 \mathrm{mM}$ acetate. For these last two concentrations of acetate the anolyte was flushed with $3 \mathrm{~mL} / \mathrm{min} \mathrm{H} 2$ at the same time. Next, only hydrogen was provided to the cells as a sole electron donor with a flow of 3, 10 and 30 $\mathrm{mL} / \mathrm{min}$ were tested.

In the second experimental stage, hydrogen oxidation at the anode was combined with copper reduction at the cathode. The potentiostat was replaced by an external resistor and the resistance was stepwise reduced when the current reached a stable value; 1000, 500, 250, $100,75,50 \Omega$. The hydrogen flow provided during these experiments was $30 \mathrm{~mL} / \mathrm{min}$, while the catholyte was a copper solution replaced regularly to keep copper concentration constant 
during the experiment. The copper concentration was checked twice every day to be sure that concentration was close to $1 \mathrm{~g} / \mathrm{L}$, and never lower than $0,7 \mathrm{~g} / \mathrm{L}$.

Finally, bicarbonate was added as carbon source in addition to hydrogen as electron donor $\left(30 \mathrm{~mL} / \mathrm{min}_{2}\right)$. Again, the anode potential was controlled with a potentiostat between -400 and $-200 \mathrm{mV}$ in $50 \mathrm{mV}$ steps.

The biotic cell was inoculated again a few times during the experiment when a sharp drop in current was observed. At these points the system was also supplied with additional acetate. The experiment was only resumed when the supplied acetate was completely depleted, as confirmed by IC measurements.

\section{Electrochemical control}

The anode potential was controlled with a potentiostat (BANK ELEKTRONIK, WENKING POTENTIOSTAT KP 3A5V). Since the anode potential was controlled and the cathode was anaerobic, the cell voltage was negative, such that hydrogen gas was produced in the cathode. The potentials of the cell compartments were controlled and measured versus $\mathrm{Ag} / \mathrm{AgCl} 3 \mathrm{M} \mathrm{KCl}$ reference electrodes (Qis, QM711X - Reference electrode, Epoxy, Refillable, $4 \mathrm{~mm}$ ) that were placed in the electrolyte, for both the anodic and the cathodic compartment. All potentials are reported versus the $\mathrm{Ag} / \mathrm{AgCl}$ reference electrode (+0.201 vs SHE).

The cell voltage, anode, cathode and membrane potential (defined as the potential difference between the two reference electrodes), as well as the current produced were recorded every minute on a data logger (Endress + Hauser RSG40). Chronoamperometry tests were conducted in order to check the current production of the abiotic cell with different hydrogen flows and anode potential control, using Autolab equipment (Metrohm Autolab B.V., PGSTAT 302N). 


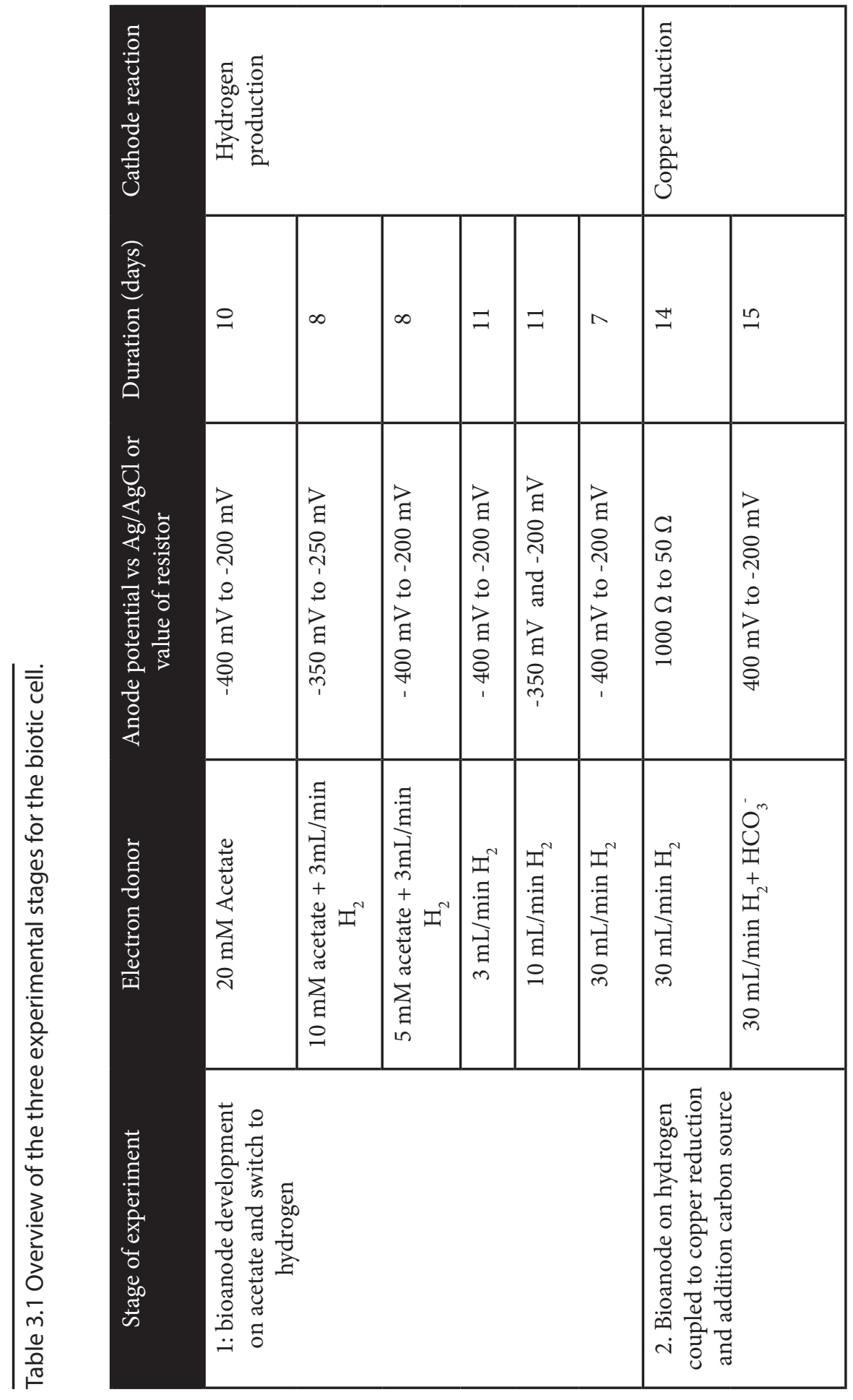




\section{Electrochemical control.}

The anode potential was controlled with a potentiostat (BANK ELEKTRONIK, WENKING POTENTIOSTAT KP 3A5V). Since the anode potential was controlled and the cathode was anaerobic, the cell voltage was negative, such that hydrogen gas was produced in the cathode. The potentials of the cell compartments were controlled and measured versus $\mathrm{Ag} / \mathrm{AgCl} 3 \mathrm{M} \mathrm{KCl}$ reference electrodes (Qis, QM711X - Reference electrode, Epoxy, Refillable, $4 \mathrm{~mm}$ ) that were placed in the electrolyte, for both the anodic and the cathodic compartment. All potentials are reported versus the $\mathrm{Ag} / \mathrm{AgCl}$ reference electrode (+0.201 vs SHE).

The cell voltage, anode, cathode and membrane potential (defined as the potential difference between the two reference electrodes), as well as the current produced were recorded every minute on a data logger (Endress + Hauser RSG40). Chronoamperometry tests were conducted in order to check the current production of the abiotic cell with different hydrogen flows and anode potential control, using Autolab equipment (Metrohm Autolab B.V., PGSTAT 302N).

\section{Analytical procedures and calculations:}

The acetate concentration in the cells was measured using ion chromatography (Metrohm 761 Compact IC equipped with a conductivity detector and a Metrosep Organic Acids 6.1005.200 ion exclusion column) and the bicarbonate concentration was determined using a total carbon analyzer (Shimadzu TOC-VCPH). The gas composition in the headspace of the cells was also examined with a gas chromatographer (Varian Inc. (Part A) - CP-4900 Micro-GC).

When the catholyte was changed to the copper solution, the current and power production were calculated according to

$$
\begin{gathered}
I=\frac{V_{\text {cell }}}{R_{\text {ext }} \cdot A_{a n}} \\
P=\frac{V_{\text {cell }}^{2}}{R_{\text {ext }} \cdot A_{\text {an }}}
\end{gathered}
$$

where Vcell is the cell voltage, Rext is the external resistance $(\Omega)$, Aan is the projected surface area of the anode $\left(0.0022 \mathrm{~m}^{2}\right)$. 


\subsection{Results and discussion}

\section{Hydrogen as electron donor for an electroactive biofilm.}

The performance of the anodic biofilm with acetate and hydrogen as electron donors is summarized in Figure 3.1.

Initially an acetate solution $(20 \mathrm{mM})$ was used to achieve fast growth of an electroactive anodic biofilm and a stable current. The performance of this bioanode was analyzed at controlled anode potentials in steps of $50 \mathrm{mV}$ (every 50 hours) ranging from -400 to $-200 \mathrm{mV}$. The bioanode produced a maximum current of $3.98 \mathrm{~A} / \mathrm{m}^{2}$ at $-250 \mathrm{mV}$. After that, the acetate concentration was stepwise decreased while an inflow of hydrogen was introduced to the system. When the acetate concentration decreased to $10 \mathrm{mM}$ and $3 \mathrm{~mL} / \mathrm{min} \mathrm{H}_{2}$ was flushed in the anolyte, the maximum current density was $1.80 \mathrm{~A} / \mathrm{m}^{2}$ at $-250 \mathrm{mV}$. When the acetate concentration was decreased further to $5 \mathrm{mM}$, the maximum current density was $0.92 \mathrm{~A} / \mathrm{m}^{2}$ at an anode potential of $-250 \mathrm{mV}$.

In the next experimental stage, after depletion of acetate, the anolyte was provided only with hydrogen at a flow of $3 \mathrm{~mL} / \mathrm{min}$. The maximum current density was $0.67 \mathrm{~A} / \mathrm{m}^{2}$ at an anode potential of $-250 \mathrm{mV}$. This was the highest current obtained during this experimental cycle. Increase of the anode potential to $-200 \mathrm{mV}$ led to a slight decrease in current density $\left(0.62 \mathrm{~A} / \mathrm{m}^{2}\right)$. These results show that also in absence of acetate, hydrogen can be used as electron donor for the bioanode.

Nevertheless, the produced current with hydrogen as electron donor was a factor 6 lower than with only acetate. A possible limitation of current production from hydrogen is the availability of hydrogen gas for the microorganisms, due to its low solubility. To test if hydrogen was limiting, after 11 days, the hydrogen inflow into the anolyte was increased from $3 \mathrm{~mL} / \mathrm{min}$ to $10 \mathrm{~mL} / \mathrm{min}_{2}$ gas. For $-200 \mathrm{mV}$ (the only anode potential measured at this $\mathrm{H}_{2}$ flow), the bioanode now produced $1.84 \mathrm{~A} / \mathrm{m}^{2}$. A further increase of the $\mathrm{H}_{2}$ gas flow to 30 $\mathrm{mL} / \mathrm{min}$ and repeating the experiments at anode potentials in the range of -350 to $-200 \mathrm{mV}$ did not lead to a further increase in current density. The maximum current density at this hydrogen flow was $1.57 \mathrm{~A} / \mathrm{m}^{2}$ at an anode potential of $-200 \mathrm{mV}$. 


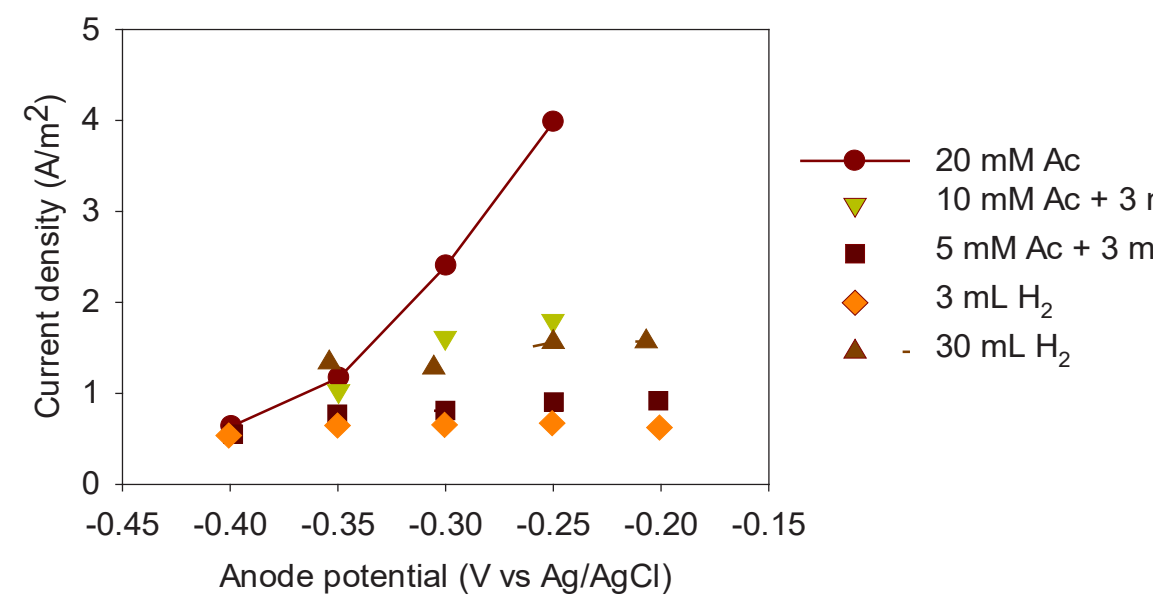

Figure 3.1. Performance of biotic cell when shifting from acetate to $\mathrm{H} 2$ as electron donor

\section{Abiotic control experiments.}

Hydrogen can be oxidized in the absence of microorganisms at noble metal based catalysts like Pt. Possibly, it can also be oxidized on a plain graphite electrode. To verify if the biological catalysis, and not the graphite electrode, was responsible for hydrogen oxidation, the current produced in an abiotic cell was compared to the current produced in the biotic cell. In Figure 3.2 the current density obtained from the biotic cell is compared with the current produced from the abiotic cell, at an anode potential of $-200 \mathrm{mV}$ and at different hydrogen inflows. The current density in the abiotic cell was much lower than the current produced in the biotic experiment at all flow rates. Some negative current was measured for the abiotic cell, meaning that a reduction reaction, instead of an oxidation reaction, occurred at $-200 \mathrm{mV}$ electrode potential, due to the potentiostatic control of the cell.

According to these results, it can be concluded that the electroactive biofilm oxidized hydrogen at the graphite electrode.

\section{Cathodic copper reduction coupled with anodic hydrogen oxidation.}

Finally, experiments were conducted where the electrons from hydrogen oxidation at the bioanode were used to reduce copper at the cathode. The anolyte was continuously flushed with $30 \mathrm{~mL} / \mathrm{min}_{2}$, in order to operate at high hydrogen concentration, while the catholyte was a copper solution $\left(\left[\mathrm{Cu}^{2+}\right]=1 \mathrm{~g} / \mathrm{L}\right)$. Copper concentration was replenished regularly so that copper concentration was always $>0.7 \mathrm{~g} / \mathrm{L}$.

Figure 6A shows the performance of the system in a polarization and power curve. During the experiment the external resistor was stepwise reduced: 1000, 500, 250, 100, 75 and $50 \Omega$. 
The initial cell voltage and current density obtained with $1 \mathrm{k} \Omega$ were $0.61 \mathrm{~V}$ and $0.28 \mathrm{~A} / \mathrm{m}^{2}$, respectively, giving a power density of $0.17 \mathrm{~W} / \mathrm{m}^{2}$. The maximum power density obtained was $0.25 \mathrm{~W} / \mathrm{m}^{2}$. At that point the cell voltage was $0.53 \mathrm{~V}$ and the current density was $0.48 \mathrm{~A} / \mathrm{m}^{2}$. The highest current density was $0.66 \mathrm{~A} / \mathrm{m}^{2}$ in combination with a power density of $0.24 \mathrm{~W} /$ $\mathrm{m}^{2}$.

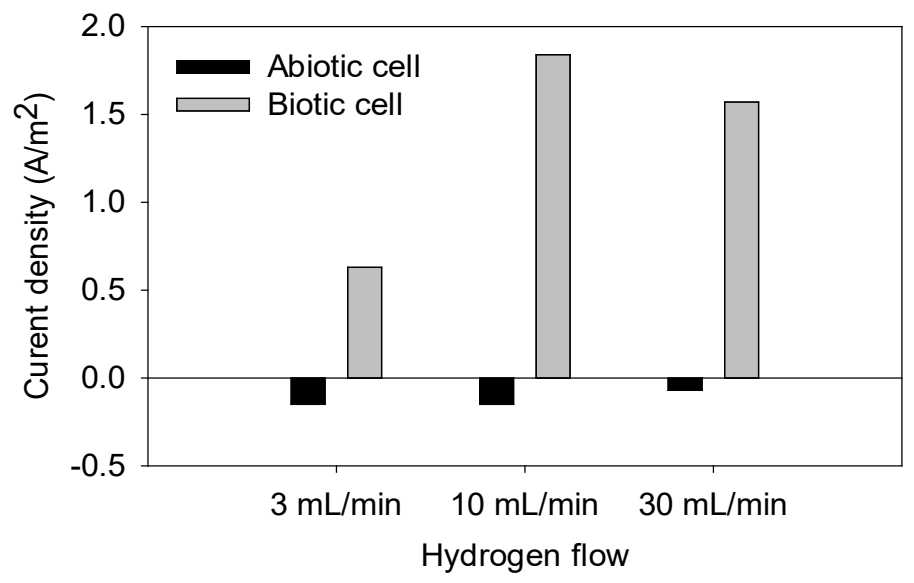

Figure 3.2. Abiotic cell vs biotic cell performance at an anode potential of $-0.200 \mathrm{~V}$ at different hydrogen inflow rates.

The following equations show the potentials for acetate and hydrogen oxidation, copper reduction and the overall cell voltages.

Acetate oxidation

$$
\mathrm{CH}_{3} \mathrm{COO}^{-}+4 \mathrm{H}_{2} \mathrm{O} \rightarrow 2 \mathrm{HCO}_{3}^{-}+9 \mathrm{H}^{+}+8 \mathrm{e}^{-} \quad \mathrm{E}_{\mathrm{an}}=-0.496 \mathrm{~V} \text { at } \mathrm{pH} 7
$$

Hydrogen oxidation

$$
\mathrm{H}_{2} \rightarrow 2 \mathrm{H}^{+}+2 \mathrm{e}-\quad \mathrm{E}_{\mathrm{an}}=-0.554 \mathrm{~V} \text { at } \mathrm{pH}=7
$$

Copper reduction

$$
\mathrm{Cu}^{2+}+2 \mathrm{e}-\rightarrow \mathrm{Cu}(\mathrm{s}) \quad \mathrm{E}_{\mathrm{cat}}=0.082 \mathrm{~V} \text { at } \mathrm{pH}=3
$$

Overall

$$
\begin{array}{ll}
\mathrm{CH}_{3} \mathrm{COO}^{-}+4 \mathrm{H}_{2} \mathrm{O}+4 \mathrm{Cu}^{2+} \rightarrow 2 \mathrm{HCO}_{3}^{-}+9 \mathrm{H}^{+}+8 \mathrm{e}-+4 \mathrm{Cu}(\mathrm{s}) & \mathrm{E}_{\text {cell }}=0.578 \mathrm{~V}( \\
\mathrm{H}_{2}+\mathrm{Cu}^{2+} \rightarrow 2 \mathrm{H}^{+}+\mathrm{Cu}(\mathrm{s}) & \mathrm{E}_{\text {cell }}=0.636 \mathrm{~V}(3.7
\end{array}
$$

Figure $3.3 \mathrm{~B}$ shows the anode, cathode and membrane potential and their contribution to the total cell voltage. The maximum cell voltage close to the open circuit voltage was 0.608 $\mathrm{V}$; which is very close to the theoretical open cell voltage of $0.636 \mathrm{~V}$ for copper reduction combined with hydrogen oxidation (equation 3.5). The anode potential close to open circuit 
was $-0.468 \mathrm{~V}$, slightly more positive than the theoretical potential (equation 3.2). The cathode potential was quite stable throughout the range of measured current densities varying between 0.097-0.141 V, close to the theoretical potential of copper reduction (equation 3.3). The copper concentration in the catholyte decreased in the course of the experiment, indicating that indeed copper was recovered at the cathode. Copper recovery and its efficiency was not further analyzed in this study, but has been analyzed by others ${ }^{85}$.

As can be seen from this figure, both the membrane and cathode potential are stable over the whole current range. The drop in cell voltage at higher current densities is caused by increase in anode potential. This increase in anode potential is most likely caused by limited transport of hydrogen towards the biofilm. Even though the gas flow was increased hydrogen supply to the biofilm might be limited due to its limited solubility in water at atmospheric pressure.
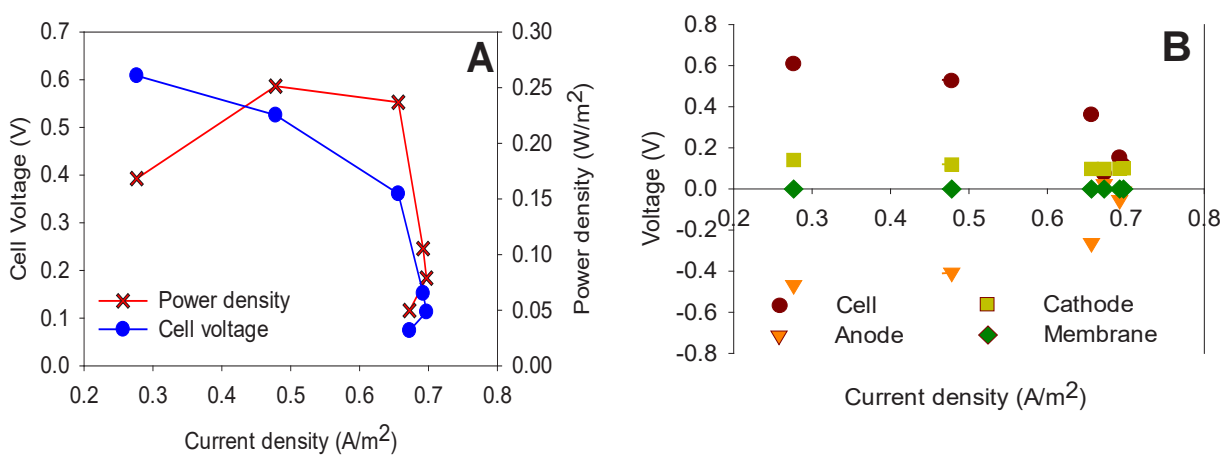

Figure 3.3 (A) Power and polarization curve for hydrogen oxidation coupled to copper recovery and (B) contribution of the anode, cathode and membrane potential to the cell voltage at $30 \mathrm{~mL} /$ $\min \mathrm{H}_{2}$ flow.

\section{Perspectives and long term performance.}

The results presented here show the proof of principle for the use of hydrogen as electron donor for the recovery of copper in BESs. The current and power densities obtained in this study $\left(0.48 \mathrm{~A} / \mathrm{m}^{2}\right.$ in combination with $\left.0.25 \mathrm{~W} / \mathrm{m}^{2}\right)$ are in the same order as previous investigations of copper removal in BESs. However, all previous studies used an organic electron donor while here for the first time hydrogen was used. Tao et al. produced $0.26 \mathrm{~W} /$ $\mathrm{m}^{2}$ power density at $0.86 \mathrm{~A} / \mathrm{m}^{2}$ current density ${ }^{39}$, using glucose as electron donor. Ter Heijne et al obtained a maximum power density for acetate oxidation coupled to copper reduction of $0.43 \mathrm{~W} / \mathrm{m}^{2}$ at a current density of $1.7 \mathrm{~A} / \mathrm{m}^{2}$ in exactly the same cell configuration as used in this study ${ }^{27}$.

Second, our analysis of overpotentials shows that the anode overpotential for hydrogen oxidation is higher than for acetate oxidation. A probable reason for this higher overpotential 
is limited hydrogen availability due to its low solubility, even at higher flow rates. A future configuration should avoid these limitations, for example through more efficient gas transport and elevated gas pressure.

Finally, the long term performance of this system should be investigated Hydrogen acts only as an electron donor, while microorganisms require also a carbon source for growth. In the final stage of our experiment, we observed a slow decrease in current density, with limitations in carbon source as a possible reason. To test the effect of carbon source, we provided the cell with bicarbonate and were able to run it under stable conditions $\left(\sim 1.2 \mathrm{~A} / \mathrm{m}^{2}\right)$ for over two weeks (data not shown). It should be further investigated what the minimum requirement of carbon source is and if an inorganic source is sufficient for these microorganisms to survive for long periods of time. For example, Jeremiasse et al showed that a hydrogen producing biocathode required two times lower startup time with acetate compared to a biocathode starting on bicarbonate ${ }^{86}$. When adding a carbon source, either in the form of acetate or bicarbonate, care should be taken not to produce methane instead of electricity, since both acetate and bicarbonate are suitable substrates for methanogens. In the present research, already small amounts of methane $(\max 4 \%)$ were detected in the headspace.

\subsection{Conclusions}

With a BES, biologically catalyzed hydrogen oxidation at the anode can be coupled with copper reduction Results show a maximum current density of $0.67 \mathrm{~A} / \mathrm{m}^{2}$ combined with a power density of $0.25 \mathrm{~W} / \mathrm{m}^{2}$ when hydrogen is used as single electron donor Further research and optimization of the system could lead to a novel practical application for BESs for metal recovery. 


\section{Chapter 4. Gas Diffusion Elec- trodes improve hydrogen gas mass transfer for a hydrogen oxidizing bioanode coupled}

\section{to copper recovery}

\section{Abstract}

In previous chapter, it has been demonstrated that hydrogen gas can be used by a bioanode as an electron donor to recover copper in Bioelectrochemical Systems (BESs). The oxidation of hydrogen gas to protons produced a current density of $0.48 \mathrm{~A} / \mathrm{m}^{2}$ and combined with $\mathrm{Cu}^{2+}$ reduction at the cathode produced $0.11 \mathrm{kWh} / \mathrm{kg} \mathrm{Cu}\left(0.25 \mathrm{~W} / \mathrm{m}^{2}\right)$. The main factor limiting current production was the mass transfer of hydrogen gas to the biofilm due to the low solubility of hydrogen gas in the anolyte. Here, we improved the mass transfer of hydrogen gas to the bioanode by the use of a gas diffusion electrode (GDE). With the GDE, hydrogen gas was oxidized to produce a current density of $2.9 \mathrm{~A} /$ $\mathrm{m}^{2}$ at an anode potential of $-0.2 \mathrm{~V} \mathrm{vs} \mathrm{Ag} / \mathrm{AgCl}$. Addition of bicarbonate to the influent led to the production of acetate, in addition to current. At a bicarbonate concentration of $50 \mathrm{mM}$, the current density increased to $10.7 \mathrm{~A} / \mathrm{m}^{2}$ at an anode potential of $-0.2 \mathrm{~V}$ vs $\mathrm{Ag} / \mathrm{AgCl}$. This increase in current density could be due to oxidation of the formed acetate, in addition to oxidation of hydrogen gas, or enhanced growth of hydrogen gas oxidizing bacteria as a result of the availability of acetate as carbon source. The effect of mass transfer was further assessed through enhanced mixing of the anolyte, and in combination with the addition of bicarbonate (50 $\mathrm{mM}$ ) the current density increased further to $17.1 \mathrm{~A} / \mathrm{m}^{2}$. Hydrogen gas may offer opportunities as electron donor for bioanodes, with acetate as potential intermediate, at locations where excess hydrogen gas and no organics are available. 


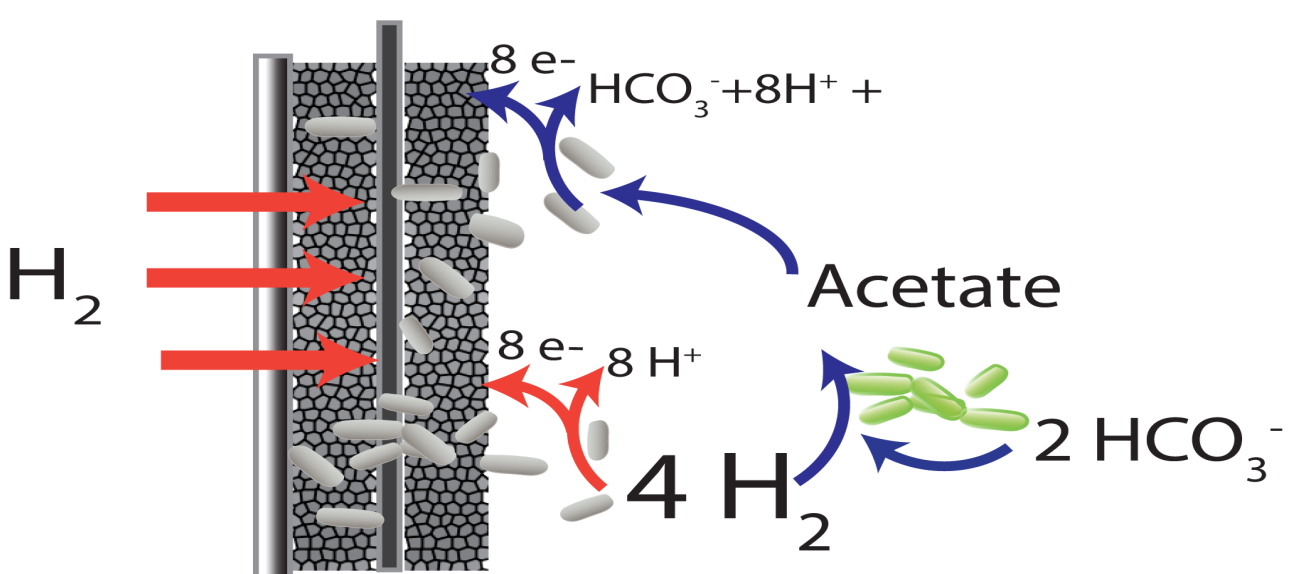

\section{Synopsis}

Microbial hydrogen fuel cells are a source of clean energy without expensive catalyst that leads to innovative applications

This chapter has been submitted in:

ACS Sustainable Chemistry \& Engineering

Gas Diffusion Electrodes improve hydrogen gas mass transfer for a hydrogen oxidizing bioanode coupled to copper recovery Manuscript ID: sc-2016-02890x Submitted on 29 November 2016 


\subsection{Introduction}

For the electrochemical removal or recovery of heavy metals, like e.g. copper, from wastewater, an electron donor is required. A suitable electron donor is water, which is oxidized to yield oxygen, protons, and electrons. The reduction of copper in combination with water oxidation, however, requires a theoretical minimum energy input of $0.10 \mathrm{kWh} / \mathrm{kg}$ $\mathrm{Cu}$. In practice, industrial copper plating even requires $2.7 \mathrm{kWh} / \mathrm{kg} \mathrm{Cu}$ when water is used as electron donor due to a high overpotential for this reaction ${ }^{60}$. Previously it has been shown that Bioelectrochemical Systems (BESs) can be used for the recovery of metals, using the organic matter in wastewater as an electron donor. The oxidation of organics like acetate, gives an energetic advantage over water oxidation and even results in electricity production combined with copper recovery ${ }^{27}$. Rodenas et al. (2015) (Chapter 2) achieved an energy recovery of 0.081 $\mathrm{kWh} / \mathrm{kg} \mathrm{Cu}\left(5.5 \mathrm{~W} / \mathrm{m}^{2}\right)$ by using acetate as an electron donor at a current densitiy of $23 \mathrm{~A} /$ $\mathrm{m}^{2}{ }^{69}$. These current densities are low, however, when compared to the electroplating industry $\left(100 \mathrm{~A} / \mathrm{m}^{2}\right)^{87}$. Besides the lower current densities, another disadvantage of using wastewater as electron donor is that organics are not commonly available in hydrometallurgical or mining industries. However, these industries often produce hydrogen gas, that is considered a waste stream. Previous research showed that hydrogen gas can be used as alternative to acetate as an electron donor at the bioanode in BESs ${ }^{88}$. Hydrogen gas was oxidized directly by bacteria on a graphite anode, eliminating the need for an expensive catalyst, which would be needed for electrochemical oxidation of hydrogen gas. When coupled to copper reduction, electricity was produced, resulting in energy recovery of $0.11 \mathrm{kWh} / \mathrm{kg} \mathrm{Cu}\left(0.25 \mathrm{~W} / \mathrm{m}^{2}\right)^{88}$ (Chapter 3$)$. The energy losses at the anode were partly explained by the limited solubility of hydrogen gas in water, causing mass transfer limitations. Enhancing mass transfer would result in higher current densities and higher energy recovery. Therefore, the aim of this study was to improve mass transfer of hydrogen gas to a bioanode by the use of a gas diffusion electrode (GDE) to reduce the anode overpotentials and thereby increase the current density produced from this hydrogen gas.

The gas diffusion electrode (GDE) consisted of an electrode material, in this case graphite felt, in combination with a porous teflon layer. This teflon layer allowed gas $\left(\mathrm{H}_{2}\right)$ to diffuse from the gas chamber into anode, and at the same time retains the anolyte in the anode chamber due to its hydrophobic nature. GDEs rely on the gas molecules to react directly at the electrode surface while the produced ions are released into the electrolyte. Their use for oxygen reducing cathodes is well established ${ }^{89}$. The main advantage of GDEs is that the fuel for the electrode reactions (hydrogen or oxygen gas) does not need to be dissolved into the electrolyte and can, therefore, be transferred faster to the electrode. The electrolyte is required not only to have a watery environment for the microorganisms, but also provides micronutrients and allows ions to be transported to the membrane. 


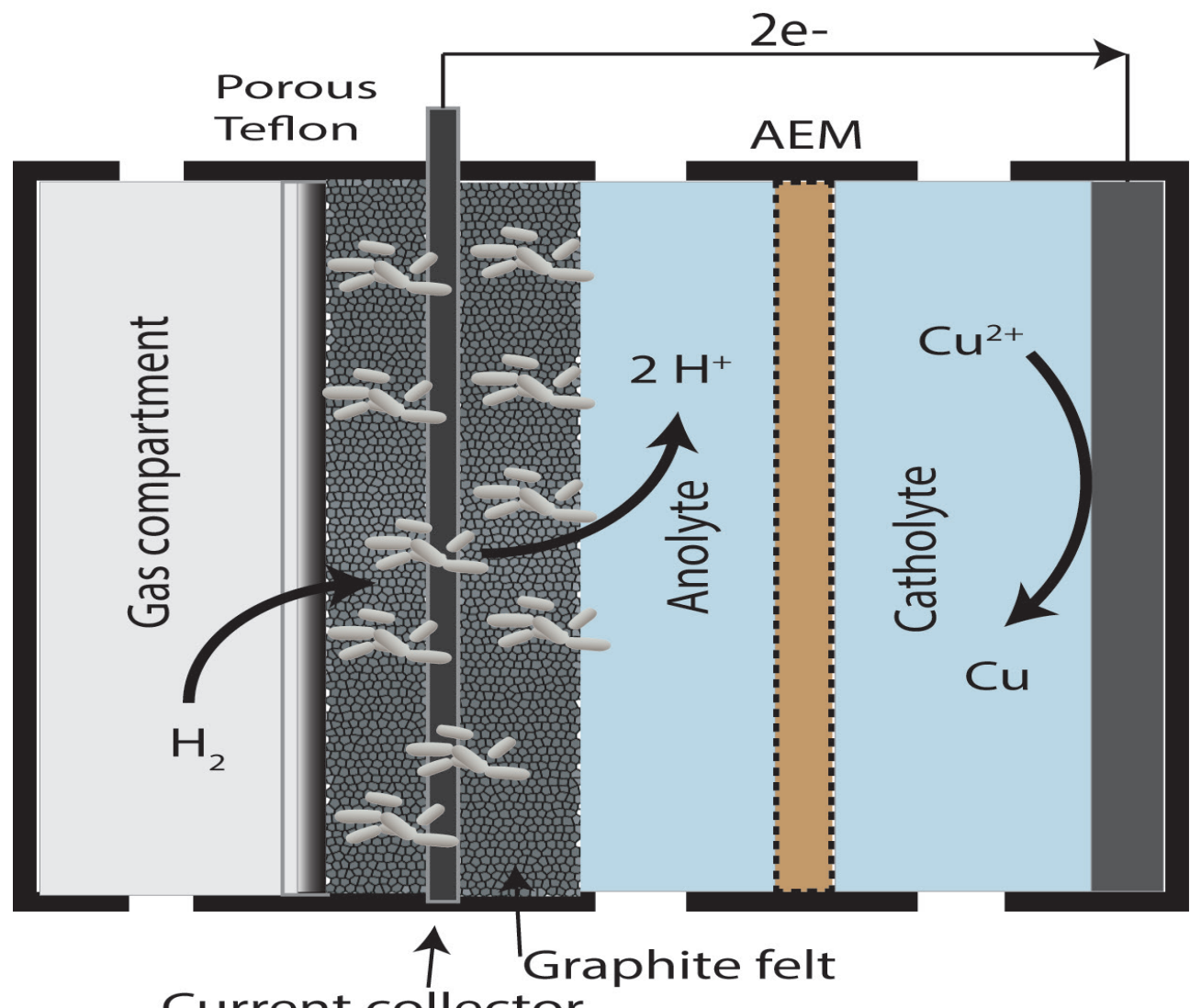

Figure 4.1. Schematic representation of the experimental set-up with the gas diffusion electrode. The system contains from left to right the gas compartment where the hydrogen gas is fed to the system, hydrofobic layer (porous teflon) which allows the hydrogen gas to diffuse directly to the biofilm, electrode with biofilm, Pt current collector, anolyte, membrane which keeps the anolyte and catholyte separated and allows ions to be transported, catholyte and cathode are depicted.

In this study, we analyzed the performance of a GDE for use as a hydrogen-fed bioanode using polarization tests. We assessed the effect of enhanced mass transfer through mixing and investigated the mechanisms of electricity production through addition of bicarbonate. 


\subsection{Materials and methods}

\section{Experimental set up.}

The cell (biotic and abiotic control) was constructed, as described by ter Heijne et al. $(2008)^{57}$. Two plexiglass plates with a single flow channel contained anolyte and catholyte and were separated by a Ralex anion exchange membrane with a surface area of $22 \mathrm{~cm}^{2}$ (MEGA a.s.Stráž pod Ralskem, Czech Republic). One additional plexiglass plate with flow channel served as gas chamber and was placed adjacent to the anode (Figure 4.1).

The cathode material was graphite foil $\left(1.0 \mathrm{~g} / \mathrm{cm}^{3}\right.$ density, $99 \%$ purity; Coidan Graphite Products Ltd., York, UK), which was pressed on the cathode current collector made of stainless steel. The anode consisted of a gas diffusion electrode made of a porous Teflon layer (POREX ${ }^{\bullet}$ Porous PTFE Porex Technologies GmbH, Germany) and two layers of graphite felt of $2 \mathrm{~mm}$ thickness on each side of a $510 \mu \mathrm{m}$ Pt current collector mesh. This GDE was separated from the membrane by a spacer $560 \mu \mathrm{m}$ (PETEX, Sefar BV, Goor, Netherlands) and a $3 \mathrm{~mm}$ rubber between the GDE and membrane. to allow a flow of anolyte (Figure 4.1).

Temperature and $\mathrm{pH}$ were continuously recorded (Endress + Hauser, Liquiline data logger) through pH electrodes (Endress + Hauser, CPS41 D) that were placed in the recirculation of anolyte and catholyte. Potentials were measured and recorded vs. $\mathrm{Ag} / \mathrm{AgCl}$ reference electrodes, placed in anolyte and catholyte $(+0.204 \mathrm{~V}$ vs NHE; QR400X QiS ProSense B.V. The Netherlands). Cell voltage was recorded simultaneously.

\section{Electron donor and electrolyte composition.}

The anolyte chamber was operated in a continuous mode and the catholyte in a batch mode. The anolyte was recirculated at $100 \mathrm{~mL} / \mathrm{min}$ via a recirculation bottle of $0.5 \mathrm{~L}$. The catholyte was recirculated at the same rate via a $1 \mathrm{~L}$ bottle. The anode influent $(1.5 \mathrm{~mL} /$ min) consisted of. $0.68 \mathrm{~g} / \mathrm{L} \mathrm{KH}_{2} \mathrm{PO}_{4}, 0.87 \mathrm{~g} / \mathrm{L} \mathrm{K}_{2} \mathrm{HPO}_{4}, 0.74 \mathrm{~g} / \mathrm{L} \mathrm{KCl}, 0.58 \mathrm{~g} / \mathrm{L} \mathrm{NaCl}, 0.28 \mathrm{~g} / \mathrm{L}$ $\mathrm{NH} 4 \mathrm{Cl}, 0.1 \mathrm{~g} / \mathrm{L} \mathrm{MgSO}_{4} \cdot 7 \mathrm{H}_{2} \mathrm{O}, 0.1 \mathrm{~g} / \mathrm{L} \mathrm{CaCl}_{2} \cdot 2 \mathrm{H}_{2} \mathrm{O}$ and $0.1 \mathrm{~mL} / \mathrm{L}$ of a trace element mixture ${ }^{84}$.

The catholyte consisted of a $1 \mathrm{~g} / \mathrm{L} \mathrm{Cu}^{2+}$ solution (prepared from $\mathrm{CuCl}_{2}$ and deionized water; $\mathrm{pH}=3$ ). The cathode was kept anaerobic by flushing with nitrogen gas.

The cell was inoculated with $10 \mathrm{~mL}$ of effluent from a running microbial fuel cell fed with acetate containing a mixed culture enriched with Geobacter sp.

\section{Experimental strategy.}

The experimental strategy consisted of 4 steps: (1) start-up and characterization of the cell with acetate as electron donor, (2) hydrogen as an electron donor at two different inflow rates (3) assesment of mass transfer through changes in circulation speed of the anolyte and (4) addition of bicarbonate to the anode influent. 
During all steps of the strategy the anode potential was changed through a programmed sequence from -0.45 to $-0.20 \mathrm{~V}$ vs. $\mathrm{Ag} / \mathrm{AgCl}$, in steps of $50 \mathrm{mV}$, each step lasting 120 minutes. This anode potential was controlled using an AUTOLAB 302N (Metrohm Autolab B.V., PGSTAT 302N).

During start-up , the bioanode was fed with $10 \mathrm{mM}$ acetate. After current had stabilized (23 days), the current was characterized at different anode potentials. In the second phase, hydrogen gas was used as an electron donor instead of acetate. First, the cell was fed with $3 \mathrm{~mL} / \mathrm{min} \mathrm{H}_{2}$ inflow using a mass flow controller (Bronkhorst HICH-TECH BV, Ruurlo, Nederland), which was later increased to $10 \mathrm{~mL} / \mathrm{min}$. Under these different hydrogen inflow rates, the effect of anolyte recirculation rate was studied. Anolyte recirculation rate was changed from $50 \mathrm{~mL} / \mathrm{min}$ to 100,150 , and $200 \mathrm{~mL} / \mathrm{min}$, and for each flow rate. Finally, the bicarbonate concentration in the influent was changed from 0 to $50 \mathrm{mM}$ to study its effect on current density.

\section{Analytical procedures.}

The bicarbonate concentration in the cells was determined using a total carbon analyzer (Shimadzu TOC-VCPH) and the acetate concentration was measured using ion chromatography (Metrohm 761 Compact IC equipped with a conductivity detector and a Metrosep Organic Acids 6.1005.200 ion exclusion column).

\subsection{Results and discussion}

\section{Improved hydrogen mass transfer led to an increase in current production}

To assess the improvement in hydrogen gas oxidation at a bioanode by using a GDE, current densities at different anode potentials were evaluated. Figure 4.2 shows the produced current density with acetate and hydrogen gas as an electron donor at different hydrogen gas inflow and anolyte recirculation rates.

For acetate, the maximum current density was $6.8 \mathrm{~A} / \mathrm{m}^{2}$ at $-0.30 \mathrm{~V}$ anode potential, which is comparable to values reported in the literature ${ }^{2,9,69}$. For hydrogen gas as electron donor supplied at $3 \mathrm{~mL} / \mathrm{min}$, the maximum current density was $1.5 \mathrm{~A} / \mathrm{m}^{2}$ at $-0.20 \mathrm{~V}$ anode potential, for the highest anolyte recirculation speed of $200 \mathrm{~mL} / \mathrm{min}$. For hydrogen gas supplied at 10 $\mathrm{mL} / \mathrm{min}$, an increase in current density was observed, with a maximum current density of $2.9 \mathrm{~A} / \mathrm{m}^{2}$ at $-0.20 \mathrm{~V}$ anode potential at $200 \mathrm{~mL} / \mathrm{min}$ anolyte recirculation. From the figures, three trends can be seen: First, an increase in hydrogen gas inflow rate led to higher current production due to better mass transfer from the gas phase to biofilm. Second, the current density increased at higher overpotentials for both inflow rates. Third, an increase in the 
recirculation speed of the anolyte resulted in the higher current, which indicates that mass transfer limitations arise from dissolved species in the anolyte. The transport of protons away from the biofilm may be limiting the current density, as has been observed for acetate oxidation ${ }^{55,90}$
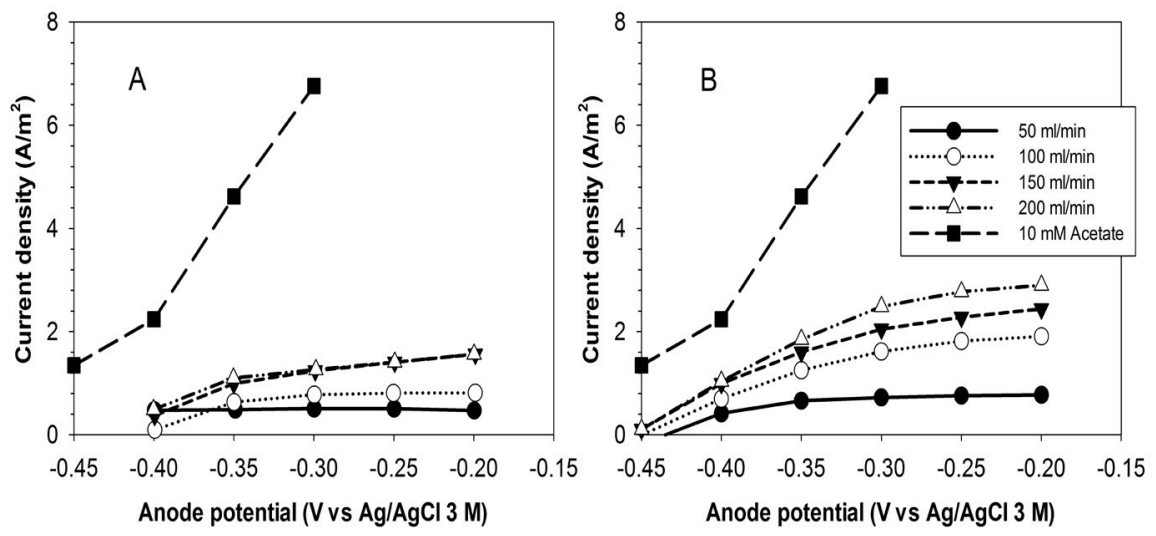

Figure 4.2. Current density production is given at an inflow of hydrogen gas of $3 \mathrm{ml} / \mathrm{min}(A)$ and 10 $\mathrm{ml} / \mathrm{min}$ (B) for anolyte circulation speed of $50,100,150$ and $200 \mathrm{ml} / \mathrm{min}$.

To assess the improvement in hydrogen gas oxidation at a bioanode by using a GDE, current densities at different anode potentials were evaluated. Figure 4.2 shows the produced current density with acetate and hydrogen gas as an electron donor at different hydrogen gas inflow and anolyte recirculation rates. For acetate, the maximum current density was $6.8 \mathrm{~A} / \mathrm{m}^{2}$ at $-0.30 \mathrm{~V}$ anode potential, which is comparable to values reported in the literature ${ }^{2,9,69}$. For hydrogen gas as electron donor supplied at $3 \mathrm{~mL} / \mathrm{min}$, the maximum current density was 1.5 $\mathrm{A} / \mathrm{m}^{2}$ at $-0.20 \mathrm{~V}$ anode potential, for the highest anolyte recirculation speed of $200 \mathrm{~mL} / \mathrm{min}$. For hydrogen gas supplied at $10 \mathrm{~mL} / \mathrm{min}$, an increase in current density was observed, with a maximum current density of $2.9 \mathrm{~A} / \mathrm{m}^{2}$ at $-0.20 \mathrm{~V}$ anode potential at $200 \mathrm{~mL} / \mathrm{min}$ anolyte recirculation. From the figures, three trends can be seen: First, an increase in hydrogen gas inflow rate led to higher current production due to better mass transfer from the gas phase to biofilm. Second, the current density increased at higher overpotentials for both inflow rates. Third, an increase in the recirculation speed of the anolyte resulted in the higher current, which indicates that mass transfer limitations arise from dissolved species in the anolyte. The transport of protons away from the biofilm may be limiting the current density, as has been observed for acetate oxidation ${ }^{55,90}$.

Control experiments performed without biofilm on graphite felt with platinum as current collector revealed that no current was produced in the used potential range (data not shown). 
Compared to the previous study that used hydrogen gas oxidation at the bio-anode 88 , the current density improved roughly 2 -fold, with reported currents of $0.84 \mathrm{~A} / \mathrm{m}^{2}$ for an hydrogen gas inflow of $3 \mathrm{ml} / \mathrm{min}$ and $1.8 \mathrm{~A} / \mathrm{m}^{2}$ for a hydrogen gas inflow of $10 \mathrm{ml} / \mathrm{min}$. Ntagia et al (2016) achieved $0.62 \mathrm{~A} / \mathrm{m}^{2}$ at an anode potential of $-0.25 \mathrm{~V}$ for $3 \mathrm{ml} / \mathrm{min}_{2}$ inflow while this study already achieved $1.2 \mathrm{~A} / \mathrm{m}^{2}$ performing under same conditions. Thus, the supply of hydrogen gas via a gas diffusion electrode led to an improvement in current density.

Although the performance for hydrogen gas oxidation at the bioanode improved compared to the previous study, performance was still much lower when compared to acetate oxidation at bioanodes. This fact does not only reflect in the current density produced at different anode potentials but also becomes visible in the open circuit potentials. Theoretically, for hydrogen gas oxidation, the equilibrium potential is $-0.62 \mathrm{~V}$ at $\mathrm{pH} 7$, while for acetate the equilibrium potential is $-0.50 \mathrm{~V}$ at $\mathrm{pH} 7$. The measured open circuit potential for acetate, during startup and first characterization phase, was -0.48 , which is close to the theoretical value. For hydrogen gas oxidation, however, the measured open circuit potential was around $-0.45 \mathrm{~V}$; a value much further from thermodynamic equilibrium. Thus, the overpotential for hydrogen gas oxidation is much higher than for acetate oxidation.

\section{Effect of bicarbonate addition on bioanode performance.}

As bioanode performance for hydrogen gas oxidation was considerably lower than bioanode performance for acetate oxidation, we investigated if the production of electricity from hydrogen could be improved by acetate as an intermediate component. To study if acetate could be a suitable intermediate for electricity generation, we investigated bio-anode performance at different bicarbonate concentration $(1 \mathrm{mM}$ to $50 \mathrm{mM})$ and $10 \mathrm{~mL} / \mathrm{min}_{2}$ supply.

Figure 4.3 shows the effect of different bicarbonate concentrations on current density at different anode potentials. With increasing bicarbonate concentrations, we observed an increase in current density. The current densities increased to $8.2 \mathrm{~A} / \mathrm{m}^{2}$ for $50 \mathrm{mM}$ bicarbonate and $6.9 \mathrm{~A} / \mathrm{m}^{2}$ for acetate at $-0.30 \mathrm{~V}$. During these polarization tests, acetate was detected in the anolyte. After 1 day of operation, the acetate concentration was $0.049 \mathrm{mM}$ for $1 \mathrm{mM}$ bicarbonate, $0.13 \mathrm{mM}$ for $10 \mathrm{mM}$ bicarbonate, and $1.9 \mathrm{mM}$ for $50 \mathrm{mM}$ bicarbonate, showing that acetate was produced from $\mathrm{H}_{2}$ and bicarbonate.

The results presented in Figure 4.2 were obtained when the cell was fed with $1 \mathrm{mM} \mathrm{HCO}_{3}^{-}$ , which raises the question if acetate was also formed as intermediate in those experiments. Therefore, an additional experiment was performed where no $\mathrm{HCO}_{3}{ }^{-}$was fed to the bioanode. In this case, the maximum current density was $0.53 \mathrm{~A} / \mathrm{m}^{2}$ at an anode potential of $-0.20 \mathrm{~V}$ (Figure 4.3), showing that hydrogen gas oxidation can occur in the absence of bicarbonate (and acetate) which is in accordance with the findings by Ntagia et al. (2016). 


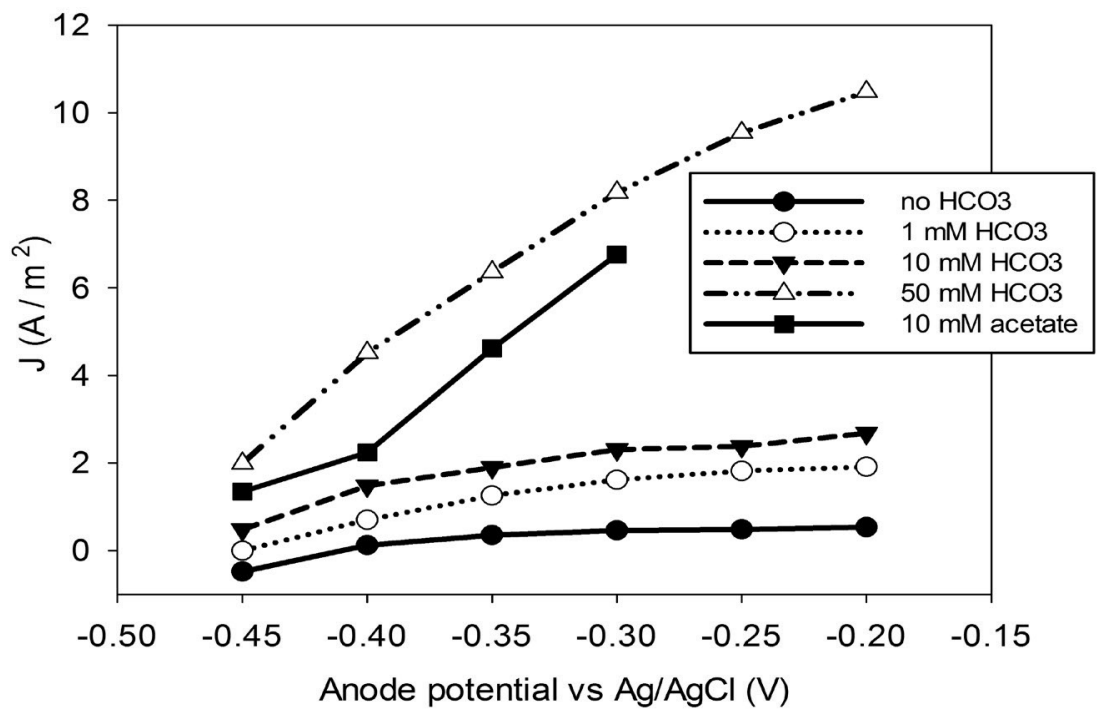

Figure 4.3 Current density as a function of a controlled anode potential fed with hydrogen gas at various bicarbonate concentrations in the anolyte and compared with acetate as a reference measurement.

\section{Improved mass transfer in anolyte led to higher current density.}

To study the current produced from hydrogen gas at different bicarbonate levels, polarization tests were performed at different recirculation rates. Figure 4.4 shows the relation between recirculation speed, bicarbonate concentration and current density at $-0.20 \mathrm{~V}$ anode potential. This figure shows an increase in current density with increasing recirculation rate for the three bicarbonate concentrations, and shows that enhanced mass transfer in solution improves the conversion rate. This could be due to improved mass transfer of hydrogen gas to the bioanode and an improved mass transfer of the produced acetate to the biofilm, as well as improved mass transfer of protons away from the biofilm. At a recirculation rate of the anolyte of $200 \mathrm{~mL} / \mathrm{min}$, the current density achieved a maximum of $17 \mathrm{~A} / \mathrm{m}^{2}$ at $-0.200 \mathrm{~V}$ and $50 \mathrm{mM}$ bicarbonate. 


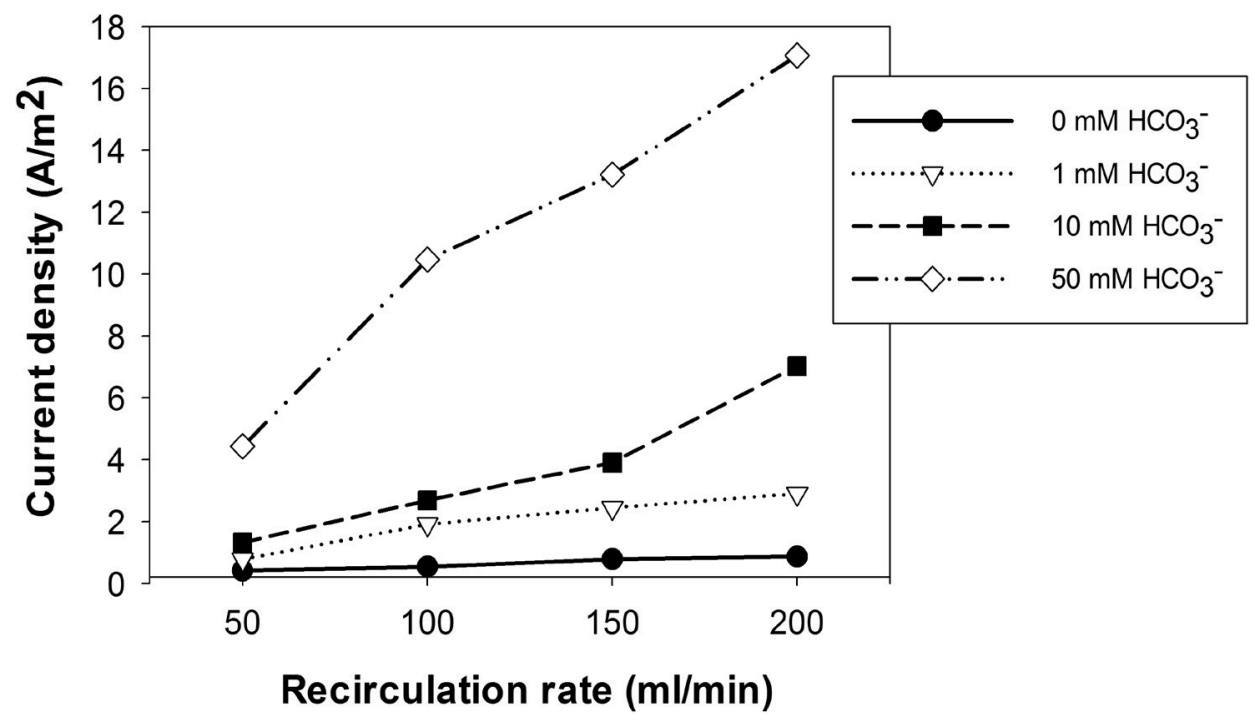

Figure 4.4 Current density at $-0.200 \mathrm{~V}$ vs. $\mathrm{Ag} / \mathrm{AgCl}$ anode potential at different bicarbonate concentrations as a function of the recirculation speed of the anolyte.

\section{Mechanisms for current production from hydrogen and bicarbonate.}

The overall experiment was set up to improve the performance of a hydrogen oxidizing bioanode by improving the mass transfer by use of a gas diffusion electrode. The inoculum was taken from an acetate-oxidizing bioanode from an active MFC, with Geobacter as the expected dominant electro-active species. This inoculum was used because it is known that Geobacter species can oxidise both acetate and $\mathrm{H}_{2}{ }^{88}$. Interestingly, after increasing bicarbonate levels, acetate was produced and detected in our bioanode even though the bioanode was inoculated with an enriched culture of electrogens and not with specific acetogenic microorganisms. It has been suggested, though, that a specific inoculum is required for acetate production in biocathodes ${ }^{91}$. According to our results, under certain conditions, being sufficiently high $\mathrm{H}_{2}$ pressure and a sufficiently high $\mathrm{HCO}_{3}{ }^{-}$concentration, acetate formation will take place even if the reactors was not inoculated with specific acetogens. Due to the presence of both acetate and hydrogen gas, it is difficult to determine the mechanisms through which the electrons are released to the anode. Four possible scenarios can be distinguished:

In the first scenario, bicarbonate serves as carbon source, while hydrogen gas serves as electron donor, while the formed acetate has no effect on the generated current. This scenario would require the presence of autotrophic electroactive cultures where bicarbonate is the 
carbon source for the biomass. Ntagia et al. (2016) showed that hydrogen gas was directly oxidized at a bioanode with no detectable organic compounds in the anolyte ${ }^{88}$, a finding that was also observed in this study at $0 \mathrm{mM}$ bicarbonate. However, the current density generated in Ntagia et al. could only be sustained for a limited period of time (two weeks) when no additional carbon source was added, showing that the activity of electroactive autotrophs was dependent on carbon availability. Therefore, the direct oxidation of hydrogen gas might have determined the generated current. However, the presence of acetate likely results in a different scenario.

In a second scenario, hydrogen gas is directly oxidized by the biofilm to generate current while the produced acetate functions as a carbon source for the hydrogen oxidizing bacteria, keeping the biomass population active on the electrode surface. For sulfate reducers it has been shown that the presence of organic compounds like lactate boosts the growth of the biomass increasing the activity of sulfate reducers $\left(6 \mathrm{~g} \mathrm{SO}_{4}^{2-} / \mathrm{L}\right.$ per day to $7.5 \mathrm{~g} \mathrm{SO}_{4}^{2-} / \mathrm{L}$ per day) and acetogens, while the presence of an excess of bicarbonate enhances methanogenesis 92,93. Furthermore, Visser (1995) observed that at increasing organic COD concentrations, e.g. acetate, an increase of hydrogen oxidation was observed ${ }^{94}$. Translated to a bioanode, this would mean that the hydrogen oxidizers would show better performance in presence of acetate, as growth rates are higher.

In the third scenario, hydrogen gas is first converted together with $\mathrm{HCO}_{3}{ }^{-}$into acetate by acetogens, after which acetate is oxidized at the bioanode by the electrogens to electricity ${ }^{95,96}$. Although direct oxidation of hydrogen at the anode is thermodynamically more favorable than the conversion of hydrogen gas to acetate, the acetogens have a spatial advantage compared to electrogens to use hydrogen, since they are not limited to the electrode and can live freely in solution.

In the fourth and final scenario, hydrogen gas and acetate are both used by the same microbial community to produce electricity. Geobacter can oxidize both substrates independently, while acetate can also be used as a carbon source for growth during hydrogen oxidation. This dual electron donor oxidation process has also been observed in BES when hydrogen and acetate are both present in solution ${ }^{97,98}$. In this study we showed that direct hydrogen gas oxidation without bicarbonate produced $0.65 \mathrm{~A} / \mathrm{m}^{2}$, while acetate oxidation alone produced $6.8 \mathrm{~A} / \mathrm{m}^{2}$, and a combination of hydrogen and bicarbonate resulted in $8.3 \mathrm{~A} /$ $\mathrm{m}^{2}$.

\subsection{Perspectives}

The extent to which acetate can act as an intermediate for current production from hydrogen gas, of course, depends on the availability of bicarbonate. In our experiments, acetate formation was already observed at $1 \mathrm{mM} \mathrm{HCO}_{3}^{-}$, Bicarbonate is available at concentrations 
between 1 to $5 \mathrm{mM}$ in groundwater ${ }^{99}$. At mining locations, it is common to find water with a high hardness ( 50 to $500 \mathrm{mM}$ )-that degasses $\mathrm{CO}_{2}$ slowly due to the acidification or solubilized suspended carbonates when $\mathrm{pH}$ decreases100. Regulations do not allow water hardness in concentrations over $5 \mathrm{mM}$ in surface or tap water. Therefore, mining water treatment should include processes to reduce carbonate and bicarbonate content ${ }^{101,102}$; its use for acetate production, in combination with use of $\mathrm{H}_{2}$ that is otherwise burned, could present a solution. Hydrogen gas may thus offer opportunities as electron donor for bioanodes in situations where excess hydrogen and no organics are available. Kinetics of hydrogen gas oxidation, however, remains slow, even when a gas diffusion electrode is used. Production of acetate from $\mathrm{H}_{2}$ and $\mathrm{HCO}_{3}{ }^{-}$might be an interesting route to improve kinetics of the conversion of hydrogen gas into electricity. 


\section{Chapter 5. Prototype of a scaled-up Bioelec- trochemical System for copper recovery}

Abstract

Scale-up of Bioelectrochemical Systems (BESs) from the laboratory to pilot scale is a challenging step in the development of the process since there are only few successful experiences to build on. In this paper, we present a prototype BESs for the recovery of copper, suitable for further upscaling to pilot scale. The cell design was based on electroplating baths to enable incorporation of this new technology in traditional electrowinning plants. Furthermore, the anode and cathode in this design could be replaced independently which enables flexible operation of the system. A $835 \mathrm{~cm}^{2}$ bioanode with $700 \mathrm{~cm}^{2}$ cathode electrochemical cell was studied. A current density of $1.2 \mathrm{~A} / \mathrm{m}^{2}$ was achieved with $48 \mathrm{~mW} / \mathrm{m}^{2}$ of power production. The contribution of each component (anode, electrolytes, cathode and membrane was evaluated through the analysis of the internal resistance distribution. This study shows that upscaling of BESs comes with serious additional challenges compared to lab scale systems that need to be solved before these systems can come to practical application. 


\subsection{Introduction}

Bioelectrochemical Systems (BESs) enable recovery of electrons from a wide range of substrates and utilize these electrons to produce electrical power, produce valuable products like hydrogen, acetate or methane or recover ammonia from urine ${ }^{56,82,103}$. Another interesting application is the recovery of metals at the cathode ${ }^{27}$. BESs for the recovery of metals have several advantages over traditional technologies like electroplating; the most important being the required energy input. The lead anodes used in electroplating are designed for the oxidation of water which requires a high energy input of $2.71 \mathrm{kWh} / \mathrm{Kg}$. By contrast, the anode in BESs the anode is made up of a bioanode that oxidizes organic matter from waste streams to produce an electric current. In the overall redox reactions of acetate oxidation and copper reduction, energy is generated instead of consumed ${ }^{69,85}$. Furthermore, an external power supply can be coupled to the cell to increase the current density while copper plating rate is increased.

The concept of copper recovery using BESs was first demonstrated by Ter Heijne et al (2010) and after several years of research, this application has reached a current density of 25 $\mathrm{A} / \mathrm{m}^{2}$ and a power production of $5.5 \mathrm{~W} / \mathrm{m}^{2} 69,85$. Copper was recovered at the surface of an electrode with a purity of $99 \%{ }^{69}$. The rate of copper recovery and the energy production are competitive with state of the art technologies, at least at lab scale. Therefore, it is clear that BESs have reached the point of scaling-up to test its viability for industrial application 104,105. Scaling up to pilot scale is an important step that bridges research between laboratory and industry. Laboratory scale cells work in optimized conditions that sometimes are not feasible for industrial use. For example, a pertinent challenge for electrochemical cells is to design scaled up systems with the same low internal resistance as the small scale devices ${ }^{105,106}$. Low internal resistance can be achieved by stacking electrodes and compartments close to each other allowing for short distances between electrodes.

For the recovery of metals using BESs, some other criteria next to the internal resistance are of importance. For instance, the recovered metals on the cathode have to be removed from the system while; the bioanode has to be kept separated from the metal stream due to toxicity issues for the electro-active biofilm. Therefore, the electrochemical baths used in electroplating industry were taken as a model for the design of the prototype of the pilot reactor. In this design, the bioanode was built as a separate module that can be immersed in between cathode electrodes in an electrochemical bath. This cell design enabled the anode module as well as the cathode plated to be substituted when required. It reduces the operational cost of opening and closing the reactor each time that maintenance is required. This bioanode design also takes into consideration the requirements for a BES to work adequately like high surface/ volume ratio to maximize the current output ${ }^{107,108}$. The maintenance is easier than other electrochemical cell designs like sandwich cells or tubular reactors due to the possibility to replace the modules independently without stopping the whole process. 
Here, we introduce a working prototype of a scaled-up BES for metal recovery of which the design can be translated directly into pilot scale. This prototype was evaluated through the contribution of each component (anode, electrolytes, membrane and cathode) to the total internal resistance. Finally, this study shows that upscaling of BESs comes with serious additional challenges compared to lab scale systems that need to be solved before these systems can come to practical application

\subsection{Materials and experimental procedure}

\section{Design of the prototype BES}

The BES consisted of a large cathode compartment, representing a traditional plating bath in which a separate module was placed containing the anode (Figure 5.1). The cathode chamber consisted of PTFE housing with a volume of $32 \mathrm{~L}$ and was placed on stirring plates to allow mixing of the catholyte. Two stainless steel plates served as the cathode electrodes. These cathodes could be lifted to be removed from the cathode chamber. Each cathode had a (submerged) working surface area of $700 \mathrm{~cm}^{2}$ (Figure 5.2).

The anode compartment was designed as a separate module that was inserted in between the cathodes (Figure 5.1). This anode module consisted of PTFE housing $(24.6 \times 34 \mathrm{~cm}$ ), in which four layers of carbon felt (surface area 1-2 $\mathrm{m}^{2} / \mathrm{g}$ Technical Fibre Products Ltd., Kendal, United Kingdom) were placed on both sides of a platinum coated titanium mesh (thickness 1 mm Magneto Special Anodes BV, Schiedam, The Netherlands) as current collector.

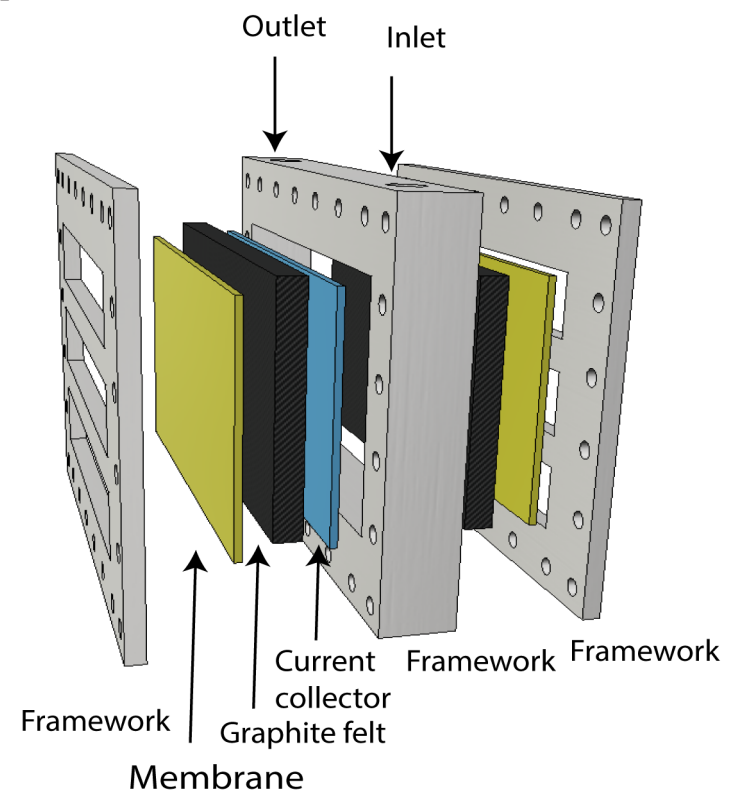

Figure 5.1. Schematic representation of the bioanode module housing 
On both sides of this anode an anion exchange membrane (Ralex, MEGA a.s., Czech Republic) was placed, making the anode a separate, closed module. The membrane had a projected surface area of $600 \mathrm{~cm}^{2}$ on each side .

To allow inflow and outflow of the anolyte, a spacer material (PETEX, Goor, The Netherlands) was placed in between the anode felt and the membrane. The spacer also allowed for a perpendicular flow of the anolyte through the anode. The anode module had a volume of $300 \mathrm{~mL}$. The anolyte was circulated over the anode module and an external circulation bottle $(1 \mathrm{~L})$ at a rate of of $500 \mathrm{~mL} / \mathrm{min}$. The total anolyte volume was $1.3 \mathrm{~L}$. The influent was fed to the circulation bottle at a rate of $4 \mathrm{~mL} / \mathrm{min}$ giving a theoretical hydraulic retention time (HRT) of $325 \mathrm{~min} .$. The anolyte temperature was kept at $30^{\circ} \mathrm{C}$ through a heat jacket around the anolyte circulation bottle. The rest of the system was run at room temperature $\left(23^{\circ} \mathrm{C}\right)$. Figure 5.2 shows the schematic design of the prototype with the recirculation bottle, pumps and electrical connection.

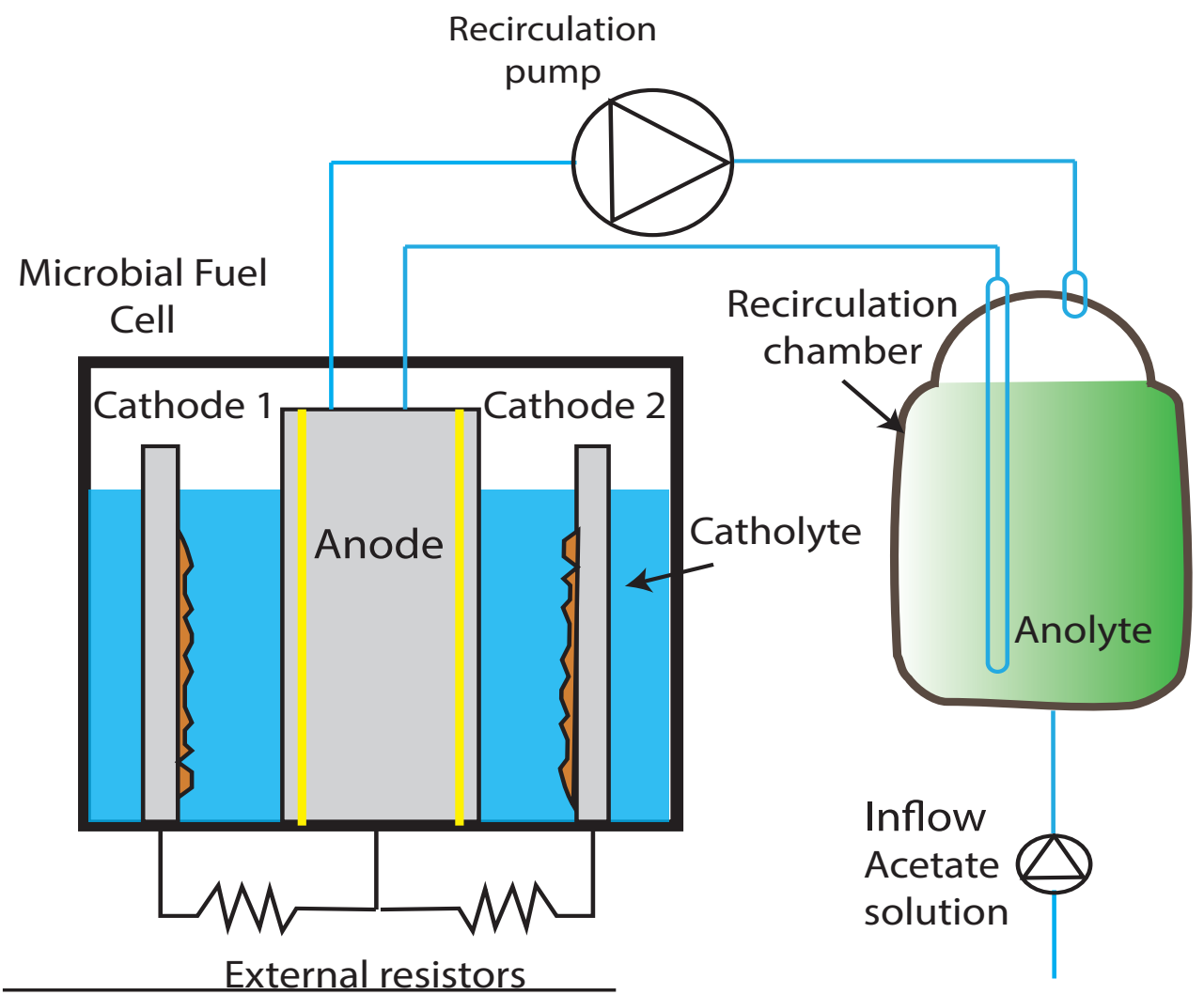

Figure 5.2. Scheme of the experimental setup 


\section{Medium \& microorganisms.}

The anode compartment was fed at a rate of $4 \mathrm{~mL} / \mathrm{min}$ with acetate solution $(20 \mathrm{mM})$ furthermore containing $0.68 \mathrm{~g} / \mathrm{L} \mathrm{KH}_{2} \mathrm{PO}_{4}, 0.87 \mathrm{~g} / \mathrm{L} \mathrm{K}_{2} \mathrm{HPO}_{4}, 0.74 \mathrm{~g} / \mathrm{L} \mathrm{KCl}, 0.58 \mathrm{~g} / \mathrm{L} \mathrm{NaCl}$, $0.28 \mathrm{~g} / \mathrm{L} \mathrm{NH}_{4} \mathrm{Cl}, 0.1 \mathrm{~g} / \mathrm{L} \mathrm{MgSO}_{4} \cdot 7 \mathrm{H}_{2} \mathrm{O}, 0.1 \mathrm{~g} / \mathrm{L} \mathrm{CaCl} \cdot 2 \mathrm{H}_{2} \mathrm{O}$ and $0.1 \mathrm{~mL} / \mathrm{L}$ of a trace element mixture 84 The system was inoculated with $200 \mathrm{ml}$ of effluent of a running MFC on acetate

During start-up, the catholyte compartment contained a buffer solution containing 0.68 $\mathrm{g} / \mathrm{L} \mathrm{KH}_{2} \mathrm{PO}_{4}, 0.87 \mathrm{~g} / \mathrm{L} \mathrm{K}_{2} \mathrm{HPO}_{4}$. Air was continuously supplied to the catholyte compartment to facilitate the oxygen reduction reaction.

During this start-up stage, two external resistors $(1000 \Omega)$ were connected in parallel to both cathode electrodes. After 12 days the cell produced a stable current of $100 \mathrm{~mA}$ and was considered ready for the experimental procedure.

\section{Experimental procedure}

After the start-up phase, three experiments were performed with different copper sulfate concentrations as catholyte $\left(1,0.5\right.$ and $\left.0.1 \mathrm{~g} / \mathrm{L} \mathrm{Cu}^{2+}\right)$. The $\mathrm{pH}$ of the solution was kept at 4 by the addition of $10 \mathrm{ml} \mathrm{H}_{2} \mathrm{SO}_{4} 0.5 \mathrm{M}$ every day into the catholyte. Two external resistors (1000 $\Omega$ ) were connected in parallel to both cathode electrodes, splitting the cell into two parallel cells sharing one anode. The resistance was stepwise decreased every 24 hours (except in the weekend) until the cell voltage reached $0 \mathrm{~V}$. During the 24 hours the current reached a stable value. During the experiments, the catholyte was flushed with nitrogen to ensure anaerobic conditions. To this end, floating plastic balls were placed on top of the catholyte to prevent air intrusion.

The potentials of the anode and the cathodes were measured using $\mathrm{Ag} / \mathrm{AgCl}$ reference electrodes (QM711X ProSense QiS, Oosterhout, The Netherlands) placed close to the cathode and in the anolyte outlet. These potentials were continuously recorded using a data logger (RSG40 Memo-graph, Endress + Hauser), together with the cell voltage (for both cathodes), the potential of both membranes, and the $\mathrm{pH}$ of the anolyte (Liquisys, Endress + Hauser).

Anolyte, Catholyte, and inflow were sampled three times per day to measure organic and inorganic carbon (total carbon analyzer Shimadzu TOC-VCPH), volatile fatty acids and anion concentrations were measured with by Ionic Chromatography (Metrohm 761 Compact IC equipped with a conductivity detector and a Metrosep Organic Acids 6.1005.200 ion exclusion column). Cations were analyzed by Induction Coupled Plasma (ICP) (ICP-OES Perkin Elmer Optima 5300). Dissolved oxygen (HQ40d Hach Company, Colorado, U.S.A.), ionic conductivity, temperature and $\mathrm{pH}$ of anolyte and catholyte were also measured (WTW $\mathrm{pH} /$ cond 340i/SET, Weilheim, Germany). 


\section{Calculations}

The Coulombic efficiencies (anodic and cathodic) and the recovery efficiencies were calculated using the following formulas. The anode Coulombic efficiency was calculated using

$\eta_{\text {anod }}(\%)=\frac{\int_{0}^{t} I \cdot d t}{\int_{0}^{t}\left(\left[A c^{-}\right]_{t}-\left[A c^{-}\right]_{0}\right) \cdot n \cdot Q \cdot F \cdot d t} \cdot 100$

were $[\mathrm{Ac}-]_{\mathrm{t}}$ is the acetate concentration $\left(\mathrm{mol} / \mathrm{L}\right.$ in the effluent in, $[\mathrm{Ac}-]_{0}$ is the acetate concentration $(\mathrm{mol} / \mathrm{L})$ in the influent, $\mathrm{I}$ is the current $(\mathrm{A})$ across the external resistor, $\mathrm{Q}$ is the volumetric flow $(\mathrm{L} / \mathrm{s})$ of the influent, $\mathrm{F}$ is the Faraday constant $(96485 \mathrm{C} / \mathrm{mol})$ and $\mathrm{n}$ is the number of electrons transferred during the reaction. The cathode Coulombic efficiency was calculated using

$$
\eta_{\text {cath }}(\%)=\frac{\int_{0}^{t}\left(\left[\mathrm{Cu}^{2+}\right]_{t}-\left[C u^{2+}\right]_{0}\right) \cdot n \cdot Q \cdot F d t}{\int_{0}^{t} I \cdot d t} \cdot 100
$$

were $\left[\mathrm{Cu}^{2+}\right]_{t}$ is the copper concentration $\left(\mathrm{mol} \mathrm{L}^{-1}\right)$ in the effluent, $\left[\mathrm{Cu}^{2+}\right]_{0}$ is the copper concentration $\left(\mathrm{mol} \mathrm{L}^{-1}\right)$ in the influent.

The copper recovery $\left(\eta_{\mathrm{r}}\right)$ was calculated as the coefficient between the mass of copper deposited on the cathode, $\mathrm{m}_{\mathrm{Cu} \text { deposited }}$ and the total initial mass of copper in solution $\mathrm{m}_{\mathrm{Cu} \text { initial }}$.

$\eta_{r}(\%)=\frac{m_{\text {Cu deposited }}}{m_{\text {Cu initial }}} \cdot 100$

The internal resistance $\left(\mathrm{R}_{\text {int }}\right)$ was calculated using:

$$
R_{i n t}=\frac{V_{O C}-V^{\prime}}{J^{\prime}}
$$

were $\mathrm{V}_{\mathrm{OC}}$ is the voltage at open circuit, $\mathrm{V}^{\prime}$ is the cell voltage at an specific point of the polarization curve and $J$ ' is the current at this specific point.

The contribution from each element to the internal resistance was calculated by:

Contribution $\%=\frac{\phi / J^{\prime}}{R_{\text {ext }}} \cdot 100$ 
were $\phi$ is the voltage loss in each component.

\subsection{Results and discussion}

\section{Electrochemical performance of the prototype}

The electrochemical performance of the prototype for the pilot BES was analyzed at three different copper concentrations $(1,0.5$ and $0.1 \mathrm{~g} / \mathrm{L})$ in the catholyte. In this prototype, the current produced by the bioanode is distributed in parallel to each of the cathodes 1 and 2 . After the start-up phase, two duplicate experiments were performed with an initial copper concentration of $1 \mathrm{~g} / \mathrm{L}$. Figure $5.3 \mathrm{~A}$ and B show this current density as a function of time for these two experiments. The arrows in these figures indicate when the external resistance, was changed.

For the first experiment at $1 \mathrm{~g} / \mathrm{L}(\mathrm{A})$, stable current densities were obtained for both cathodes until the external resistance was reduced to $10 \Omega$. For cathodes A1 and A2, the current densities dropped drastically at an external resistance of $5 \Omega$ This drop in current density was related to the limited inflow of acetate due to interrupted inflow of the influent; after feeding acetate, current increased again. The second experiment at $1 \mathrm{~g} / \mathrm{L}$ (B) showed stable current production at all external resistances

For the first experiment the maximum current density achieved by the bioanode was 0.78 $\mathrm{A} / \mathrm{m}^{2}$ and the current density was slightly higher for cathode $\mathrm{A} 1\left(0.78 \mathrm{~A} / \mathrm{m}^{2}\right)$ compared to cathode A2 $\left(0.43 \mathrm{~A} / \mathrm{m}^{2}\right)$. For the second experiment, the maximum current density was 1.2 $\mathrm{A} / \mathrm{m}^{2}$, which was higher than the current in the first experiment as a result of sufficient acetate supply. The second experiment cathode B2 also had a slightly higher current densities (1.2 A/ $\mathrm{m}^{2}$ ) compared to cathode B1 $\left(0.73 \mathrm{~A} / \mathrm{m}^{2}\right)$.

Figures 5.4A and 5.4B show the polarization curve calculated from the average values of current densities shown on figures 5.3A and 5.3B and the voltages for both cells at decreasing external resistance. Figure 5.4A shows that an average maximum current density of $0.70 \mathrm{~A} /$ $\mathrm{m}^{2}$ was obtained for cathode A2 while cathode A1 only reached $0.45 \mathrm{~A} / \mathrm{m}^{2}$. By contrast, the second experiment depicted in figure $5.4 \mathrm{~B}$ cathode $\mathrm{B} 1$ reached $0.72 \mathrm{~A} / \mathrm{m}^{2}$ and cathode $\mathrm{B} 2$ $1.16 \mathrm{~A} / \mathrm{m}^{2}$.

The experiments were repeated at lower copper concentrations $(0.5$ and $0.1 \mathrm{~g} / \mathrm{L})$. A reduction in copper concentration lead to a decrease in generated current densities to $0.47 \mathrm{~A} /$ $\mathrm{m}^{2}$ for cathode 1 and $0.48 \mathrm{~A} / \mathrm{m}^{2}$ for cathode 2 at $0.5 \mathrm{~g} / \mathrm{L}$ and to $0.21 \mathrm{~A} / \mathrm{m}^{2}$ for cathode 1 and $0.27 \mathrm{~A} / \mathrm{m}^{2}$ for cathode 2 at $0.1 \mathrm{~g} / \mathrm{L}$ (data available in supplementary information). Overall, the lower copper concentration increased the contribution of the cathode to the internal resistance. The current densities achieved for this prototype are similar to the current densities obtained at early stages of the research in this field on laboratory scale, but one order of 

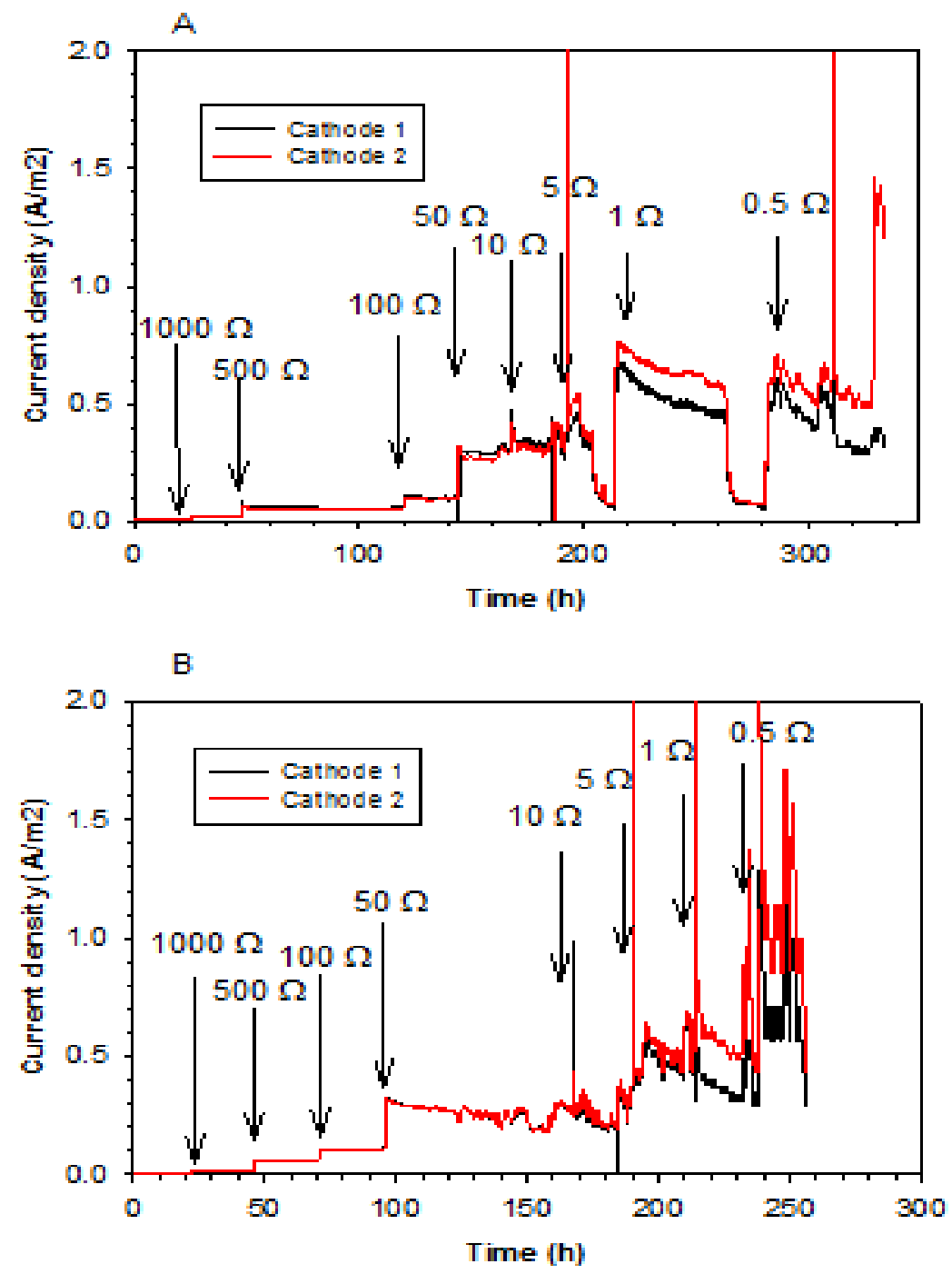

Figure 5.3 A and 5.3 B Evolution of current density of duplicate experiments in time at different external resistances for cathode 1 (black) and cathode 2 (red) at a copper concentration of $1 \mathrm{~g} / \mathrm{L}$.

magnitude lower than the current densities obtained for a lab cell by Rodenas et al. $(2015)^{37,69}$.

From the data obtained in Figure 5.3 power curves were constructed (Figure 5.4A and 5.4B) From the power curves, the maximum power density can be extracted. For the first experiment Figure 5.4A shows that maximum power production of the first experiment was $62 \mathrm{~mW} / \mathrm{m}^{2}$ and $53 \mathrm{~mW} / \mathrm{m}^{2}$ for cathodes $\mathrm{A} 1$ and $\mathrm{A} 2$ respectively while in the second experiment (Figure 5.4B) the maximum power production was $48 \mathrm{~mW} / \mathrm{m}^{2}$ for both cathodes. 

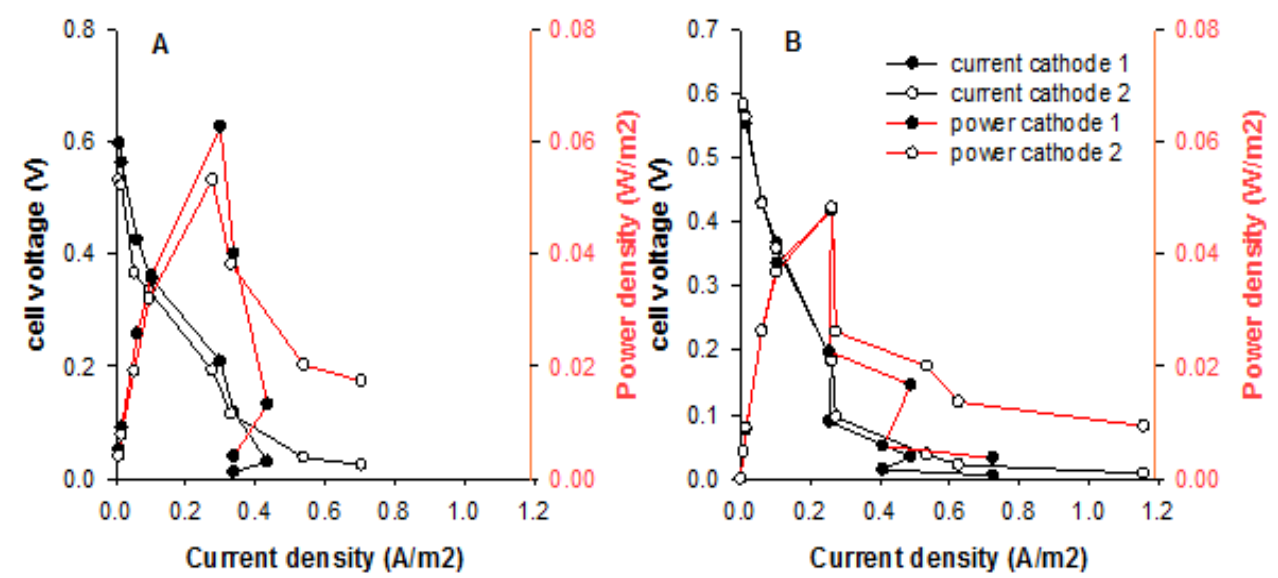

Figure 5.4 A and 5.4 B. Polarization (black) and power (red) curves of the two different sides of the biocassette known as cathode 1 (black dot) and cathode 2 (white dot) at an initial copper concentration of $1 \mathrm{~g} / \mathrm{L}$

\section{Performance indicators of the prototype}

Several performance indicators of the BES were evaluated in the previous section and summarized here in table 5.1. The performance indicators of maximum current density $\left(\mathrm{J}_{\text {peak }}\right)$, maximum power density $\left(\mathrm{P}_{\max }\right)$ and open circuit voltage $\left(\mathrm{V}_{\mathrm{OC}}\right)$ were extracted from the polarization plots depicted in figures $5.4 \mathrm{~A}$ and $5.4 \mathrm{~B}$ for the experiments at $1 \mathrm{~g} / \mathrm{L}$, and from the results of the experiments at $0.5 \mathrm{~g} / \mathrm{L}$ and $0.1 \mathrm{~g} / \mathrm{L}$. The open circuit voltage is the maximum voltage that can be extracted from the cell, when no current is flowing. When the circuit is closed and current start flowing, the chemical potential energy is transformed into electrical energy and power can be extracted from the cell. Because of the internal resistance of the system, part of the energy is dissipated and therefore the voltage in a closed circuit is lower. Both experiments at $1 \mathrm{~g} / \mathrm{L}$ have similar open circuit voltages, however, in the first experiment, higher power density was found than in the second experiment. Also, $\mathrm{V}_{\mathrm{OC}}$ dropped slightly when cathode copper concentration decreased.

The anode Coulombic efficiency depicted in table 5.1 was lower than $12 \%$ in all experiments. This is probably due to competing microbial processes for the available acetate like sulfate reduction and methanogenesis. Acetate was fed in excess to allow for sufficient electron donor for current generation. At the same time an excess of acetate leads to methane formation ${ }^{109,110}$. Impact of methanogens can be minimized by limiting the dosing of influent and decrease the substrate loading to the system. Furthermore, part of the acetate may have been used for sulfate reduction that is being transferred through the membrane from the cathode compartment. 


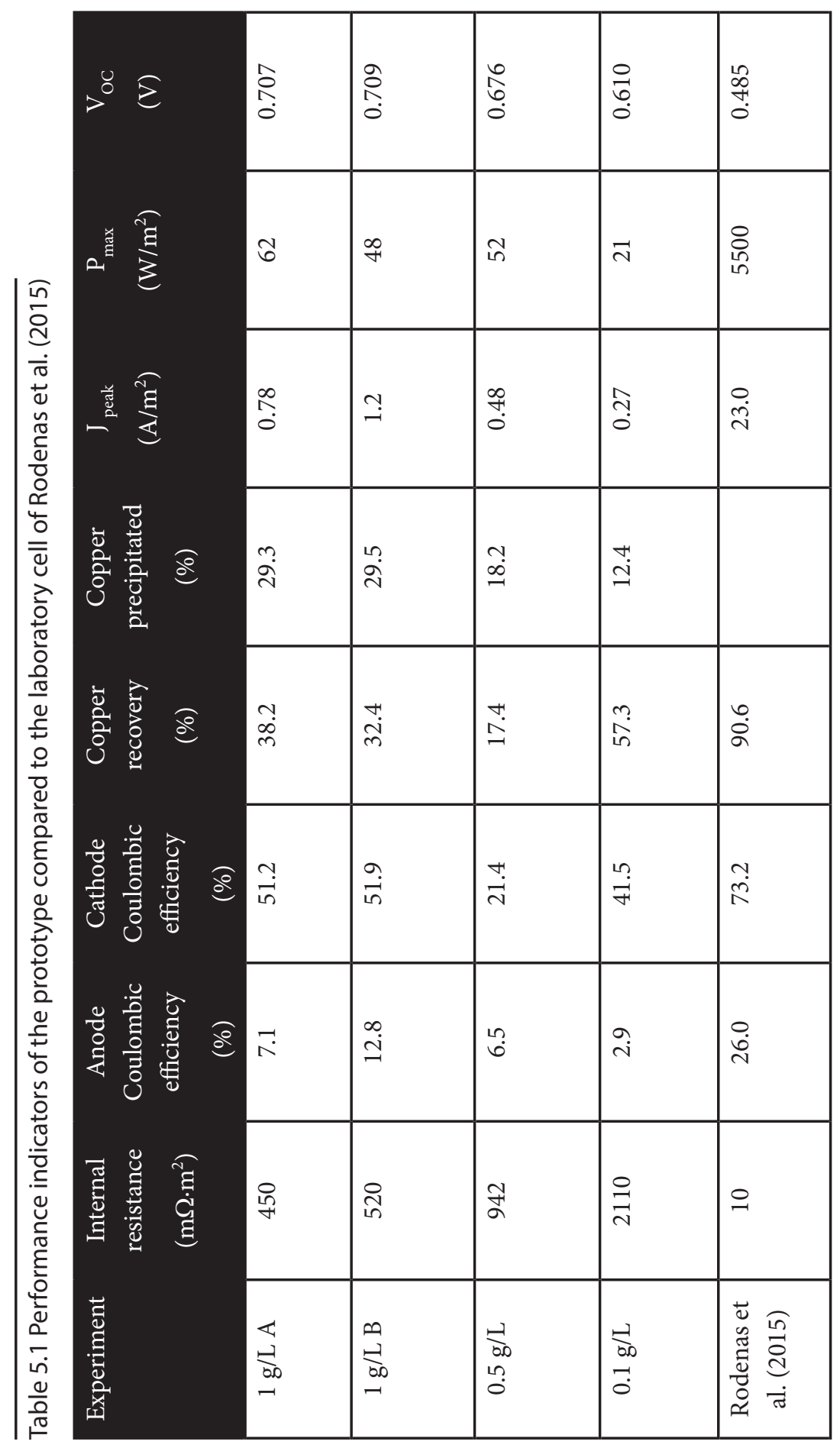


In the first experiment at $1 \mathrm{~g} / \mathrm{L}$, a cathodic Coulombic efficiency of $51.2 \%$ was achieved with a copper recovery of the $38.2 \%$ and a fraction of $29.3 \%$ of copper precipitated in the bottom of the reactor. The maximum cathode Coulombic efficiency achieved for this prototype during the second experiment at $1 \mathrm{~g} / \mathrm{L}$ was $51.9 \%$ with a copper recovery of a $32.4 \%$, and $29.5 \%$ of the copper precipitated remaining as a non-soluble residuum at the bottom of the reactor. The cathode Coulombic efficiency decreased for the experiment at $0.5 \mathrm{~g} / \mathrm{L}$ to $21.4 \%$ and a copper recovery of only $17.4 \%$ was obtained as expected due to the poor Coulombic efficiency. By contrast, the Coulombic efficiency of cathode increased again at $0.1 \mathrm{~g} / \mathrm{L}$ to $41.5 \%$ with a copper recovery of 57.3\%. The cathodic Coulombic efficiency in Rodenas et al. (2015) was a $22 \%$ higher than the achieved in this study, while the copper recovery was $90.6 \%$. To find the reason for this difference in behaviour between the experiments at different copper concentrations we studied the internal resistance distribution calculated from the voltage losses measured for each component of the electrochemical cell.

\section{Internal resistance distribution of the prototype}

Current and power densities of the prototype were considerably lower than those achieved in previous work. One of the reasons is in the new cell design used here, which allowed the anode module and the cathodes to be removed separately at any moment, without disassembling the complete system. This design aims for future application of this BES for copper recovery from the cathode. However, this resulted in a much higher internal resistance than observed in previous work.

The internal resistance of the cell depicted in table 1 is a measurement of the voltage losses of the cell when a current flows through. Table 1 shows that the internal resistance increases at lower concentrations of copper, going from $450 \mathrm{~m} \Omega \cdot \mathrm{m}^{2}$ at $1 \mathrm{~g} / \mathrm{L}$ to $2100 \mathrm{~m} \Omega . \mathrm{m}^{2}$ at $0.1 \mathrm{~g} / \mathrm{L}$. These resistances are one to two orders of magnitude higher than the internal resistance achieved in Rodenas et al. (2015). When the internal resistance for each side of the prototype was calculated from the point at maximum current density, we found that for the first experiment the average internal resistance for cathode 1 cell was $1473 \mathrm{~m} \Omega . \mathrm{m}^{2}$ while the average internal resistance for cathode 2 cell was $890 \mathrm{~m} \Omega . \mathrm{m}^{2}$. Because they are in parallel, the resistance of the total prototype was $550 \mathrm{~m} \Omega \cdot \mathrm{m}^{2}$. For the second experiment at $1 \mathrm{~g} / \mathrm{L}$ the numbers are similar, cell with cathode 1 had an internal resistance of $931 \mathrm{~m} \Omega \cdot \mathrm{m}^{2}$, while cell with cathode 2 was $678 \mathrm{~m} \Omega . \mathrm{m}^{2}$. The total internal resistance of the prototype in experiment 2 was $400 \mathrm{~m} \Omega \mathrm{m}^{2}$.

To have a more detailed analysis of the performance of the system, the contribution of each part of the system to the internal resistance was calculated by equations 4 and 5 . The partial internal resistances were calculated from the overpotentials in the electrodes, and the voltage losses on membrane and electrolytes at every external resistance ${ }^{109}$. Figure 5 shows the distribution of the internal resistance at different external resistances for both cathode 
compartments in the experiment $\mathrm{A}$ at $1 \mathrm{~g} / \mathrm{L}$. This figure shows that the anode had the main contribution to total internal resistance, between $45 \%$ to $55 \%\left(734 \mathrm{~m} \Omega \cdot \mathrm{m}^{2}\right.$ to $\left.850 \mathrm{~m} \Omega \cdot \mathrm{m}^{2}\right)$. It is followed by the cathode losses between $20 \%$ to $35 \%\left(209 \mathrm{~m} \Omega \cdot \mathrm{m}^{2}\right.$ to $\left.420 \mathrm{~m} \Omega \cdot \mathrm{m}^{2}\right)$. Both the ionic and membrane contribution to the total internal resistance was small. However, the membrane resistance increased at higher current densities because at these higher current densities, more ions need to be transported. It reached a value of $185 \mathrm{~m} \Omega \cdot \mathrm{m}^{2}$ for the side of cathode $1220 \mathrm{~m} \Omega \cdot \mathrm{m}^{2}$ for membrane on cathode 2 side.

In addition, we analyzed voltage losses of the anode for each experiment. Experiment $\mathrm{A}$ at $1 \mathrm{~g} / \mathrm{L}$ showed an anode voltage loss of $319 \mathrm{mV}$, while the other experiments showed values of $376 \mathrm{mV}, 421 \mathrm{mV}$ and $280 \mathrm{mV}$ for the experiments $1 \mathrm{~g} / \mathrm{L} \mathrm{B}, 0.5 \mathrm{~g} / \mathrm{L}$ and $0.1 \mathrm{~g} / \mathrm{L}$ respectively. These voltage losses correspond to the internal resistance and indicate that the bioanode has lower energy losses at lower copper concentrations .During this experiments; sulfate was the counter ion of copper. Sulfate is transport through the AEM to compensate charge. It has been demonstrated previously in Rodenas et al. (2015) the influence of sulfate as electron donor scavenger in the anolyte to produce sulfide, consequently decreasing the coulombic efficiency on the anode..

At low current densities cathodes 1 and 2 showed negative contribution at high external resistance due to presence of dissolved oxygen. Membrane also showed similar tendency due to diffusion of ions. Consequently, negative values for both cathodes and membrane are shown in figure 5.5.The bioanode shows a behaviour above $100 \%$ because the total internal resistance was smaller than anode resistance.

Table 5.2 shows the difference between the pilot prototype and the previous lab cell design described in Rodenas et al. (2015). A priori, no major differences are depicted between the materials, membranes, recirculation speed, HRT or volumes are shown. However, the prototype was designed with four felt layers on each side of the current collector and holes forcing the flow going from the side of cathode 2 to the side of cathode 1 at a recirculation flow of $500 \mathrm{ml} / \mathrm{min}$. By contrast, the cell in Rodenas et al. (2015) was designed with only one felt layer, and also a flow pattern through the anode with a recirculation flow of $200 \mathrm{~mL} / \mathrm{min}$. Another difference is the distance between electrodes. Rodenas et al. (2015) cell had a distance between electrodes that was seven times smaller compared to the prototype that had $3.5 \mathrm{~cm}$ between cathode and anode. This difference in electrode separation affects directly to the current density distribution and to the internal resistance contribution of the electrodes ${ }^{111}$.

As mentioned previously, the bioanode was the main contributor to internal resistance and the possible explanations are: insufficient mixing and limited mass transfer and poor current collection. These two challenges can be further improved in new designs by increasing the recirculation and the current collector distribution. 
Another difference is the electrode choice; Rodenas et al. (2015) showed a negative effect of using copper electrodes at low concentrations. For this reason, we made use of Stainless Steel to avoid copper dissolving from the cathode at low current densities due to the acidic conditions and the presence of oxygen.
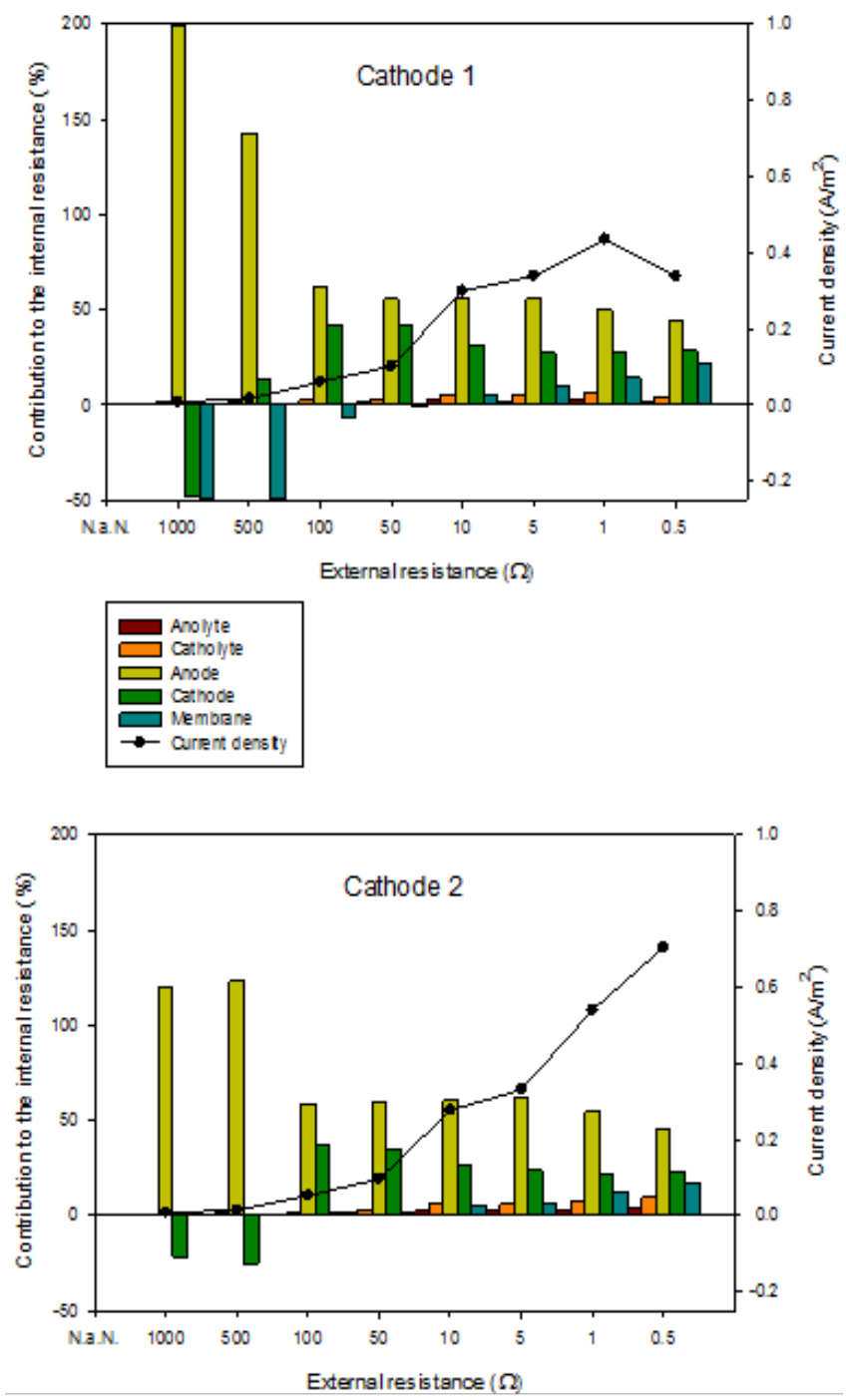

Figure 5.5. Anode internal resistance contribution (light green bar), Cathode internal resistance contribution (dark green bar), Membrane internal resistance contribution (blue bar), catholyte internal resistance contribution (orange bar) and anoloyte internal resistance contribution (red bar) at different external resistances and versus current density. 
Table 5.2 Summary of design parameters of prototype compared to Rodenas et al. (2015)

\begin{tabular}{|c|c|c|}
\hline Design parameters & Prototype & Rodenas et al. (2015) \\
\hline Cathode material & Stainless Steel & Copper \\
\hline Anode material & $\begin{array}{l}\text { Graphite felt/ Titanium } \\
\text { electrode with platinum } \\
\text { coated mesh }\end{array}$ & $\begin{array}{l}\text { Graphite felt/Titanium } \\
\text { current collector }\end{array}$ \\
\hline Distance between electrodes & $3.5 \mathrm{~cm}$ & $5 \mathrm{~mm}$ \\
\hline Membrane & AEM & AEM \\
\hline Surface anode & $835 \mathrm{~cm}^{2}$ & $100 \mathrm{~cm}^{2}$ \\
\hline Surface cathode & $700 \mathrm{~cm}^{2}$ & $100 \mathrm{~cm}^{2}$ \\
\hline Volume anolyte & $1 \mathrm{~L}$ & $500 \mathrm{ml}$ \\
\hline Volume catholyte & $32.2 \mathrm{~L}$ & $10 \mathrm{~L}$ \\
\hline Anolyte recirculation flow & $500 \mathrm{~mL} / \mathrm{min}$ & $200 \mathrm{ml} / \mathrm{min}$ \\
\hline Catholyte recirculation flow & & $200 \mathrm{ml} / \mathrm{min}$ \\
\hline Anolyte HRT & $325 \mathrm{~min}$ & $200 \mathrm{~min}$ \\
\hline Catholyte HRT & Infinite (batch reactor) & Infinite (batch reactor) \\
\hline Mixing mode anolyte & Recirculation by pumping & Gas sparging and stirring \\
\hline Mixing mode catholyte & Stirring & None \\
\hline Volume of inoculum & $200 \mathrm{ml}$ & $200 \mathrm{ml}$ \\
\hline
\end{tabular}




\subsection{Discussion}

We successfully demonstrated the design and operation of a prototype BESs for the recovery of copper suitable for upscaling. The design of this prototype was based on the electroplating baths found in electrowinning industry and allowed for flexible replacement of both the anode and the cathode electrodes and be good BES at the same time. This prototype system produced current densities of $1.2 \mathrm{~A} / \mathrm{m}^{2}$. The analysis of the internal resistance distribution revealed that the main contribution to the internal resistance of the prototype was in the bioanode. Copper was successfully plated in the cathode and recovered. In contrast, the bioanode did not work according to expectations of the high current densities achieved for previous BES cell designs. The internal resistance and low coulombic efficiency may be related to insufficientmass transfer, competing reactions such as methanogenesis, sulfate reduction, or acidification of the biofilm by the formed protons.

Further research on up-scaled prototypes must know the difficulties found in this study to overcome them and seek solutions for future up-scaled BES. 


\subsection{Supplementary information}

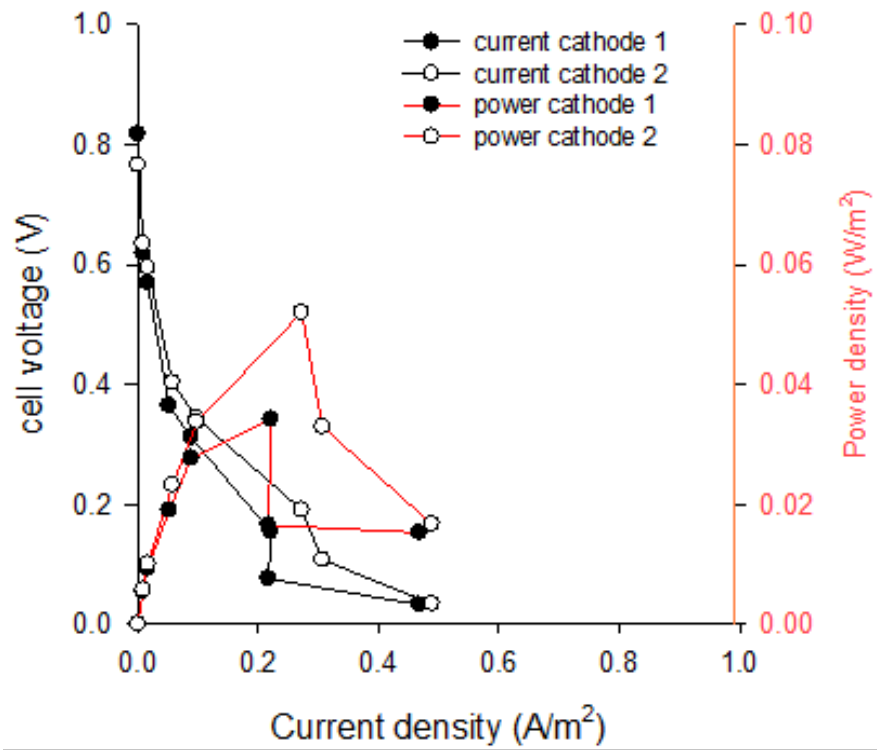

Figure 5.1S. Polarization (black) and power (red) curves of the two different sides of the biocassette known as cathode 1 (black dot) and cathode 2 (white dot) at an initial copper concentration of 0.5 $g / L$

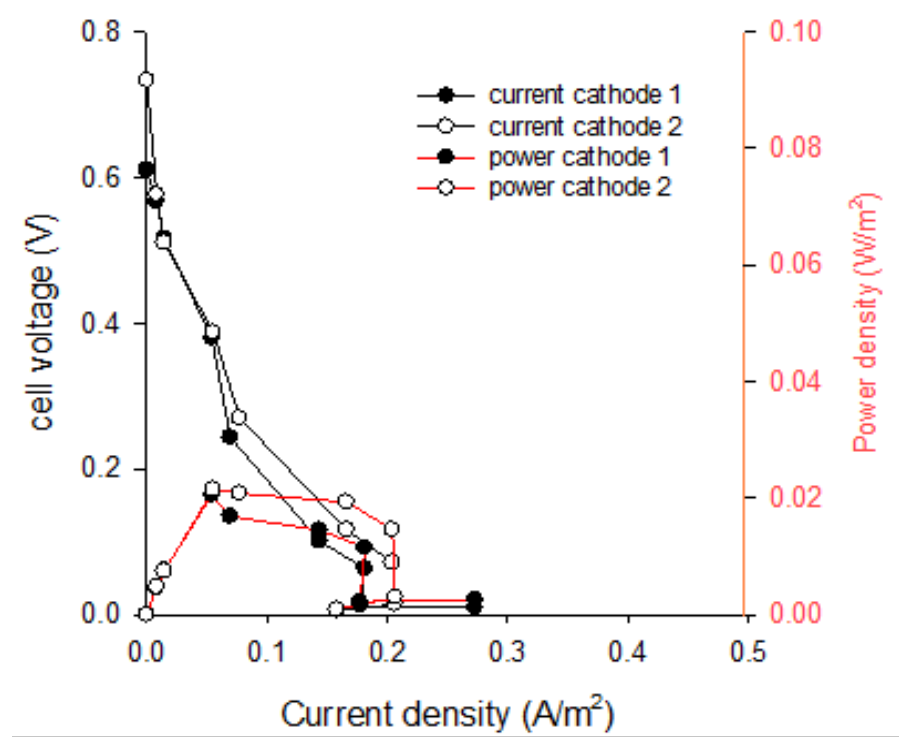

Figure 5.2S. Polarization (black) and power (red) curves of the two different sides of the biocassette known as cathode 1 (black dot) and cathode 2 (white dot) at an initial copper concentration of 0.1 $g / L$ 
Chapter 6. Discussion 
In the previous chapters, the improvements made to BESs for metal recovery have been presented. In these chapters, several components of the BESs and their effects on performance of the overall system have been described. The proof of principle of metal recovery using BESs by ter Heijne et al. $(2010)^{27}$ was used as the reference study. The main parameter to describe BESs performance from an engineering point of view is the internal resistance, followed by the current and power densities and the Coulombic efficiencies.

In chapter 2 we presented improvements to the cell design which led to a low internal resistance of $0.01 \Omega . \mathrm{m}^{2}$ and consequent higher current densities. In this study, we used a flow-through anode with graphite felt, instead of a flat electrode used in the reference study. This electrode offers a higher specific surface area for bacteria to grow, and, at the same time, mass transfer limitations may be decreased due to better mixing at the anolyte-electrode interface. Furthermore, an anion exchange membrane (AEM) was used instead of the bipolar membrane (BPM) used by ter Heijne et al. $(2010)^{27}$. This AEM has a lower internal resistance for ion transport compared to the $\mathrm{BPM}^{112,113}$. Finally, the distance between the electrodes was reduced, decreasing the internal resistance through a reduction of the ionic resistance of the electrolyte. These changes resulted in a maximum current density of $25 \mathrm{~A} / \mathrm{m}^{2}$ and a power density production of $5.5 \mathrm{~W} / \mathrm{m}^{2}$.

In addition to improvements in reactor design, hydrogen as an alternative electron donor has been investigated. In chapter 3 the use of hydrogen as electron donor was explored to make this technology suitable for locations where the organic waste material is not available as an electron donor but hydrogen is. Use of hydrogen gas for copper recovery produces a theoretical energy of $0.54 \mathrm{kWh} / \mathrm{kg}$ of $\mathrm{Cu}$, however, in practice, we reached $0.11 \mathrm{kWh} / \mathrm{kg}$ of $\mathrm{Cu}$. We showed that the current density was limited by mass transfer of hydrogen towards the biofilm. In Chapter 4, therefore, a gas diffusion electrode was used to reduce this mass transfer limitation. This resulted in an increase in current density from $1.8 \mathrm{~A} / \mathrm{m}^{2}$ to $17 \mathrm{~A} / \mathrm{m}^{2}$. In these experiments, where also bicarbonate was present, acetate was detected, and the role of this in situ formed acetate in the overall process was discussed.

In chapter 5, the reactor that coupled acetate oxidation to copper reduction was tested at two stages of scale up with a design to harvest the copper from the cathode. An analysis of the internal resistance over the different cell components was depicted. The performance on current density, coulombic efficiencies and power production of these designs were shown, and solutions for future application were suggested.

Finally, in this chapter, the results obtained in this thesis are put into perspective with existing technologies and suggestions are made for future improvements to make this technology more attractive for industrial applications. 


\subsection{Where do we need to go for industrial application}

In this thesis, the model component for metal recovery was copper, because of its large industrial use, its economic value, and its presence as a pollutant in mining and industrial wastes. As discussed in the introduction, copper usage has increased worldwide from 18000 metric tons in 2010 to 22000 metric tons in 2016 and has kept increasing further over recent years. From this used copper, only $30 \%$ is recycled ${ }^{114}$. Several technologies are already available for the recovery and recycling of copper from industrial waste streams.

\section{Qualitative evaluation of current technologies and BESs for metal recovery}

As described in the introduction, BESs should be put into perspective with state of the art copper recovery technologies to assess their advantages and disadvantages. Tablel gives an overview of the different aspects a to compare BES with Solvent Extraction/Electro-Winning (SX/EW), flocculation, chemical precipitation and filtration. First, we compare the specific energy consumption of these five different technologies to recover copper from the waste stream. The specific energy consumption in $\mathrm{kWh} / \mathrm{Kg}$ of copper is important because it enables to calculate the cost regarding energy use. Second, in many technologies additional chemical substances like solvents, precipitation agents, flocculants, salts or buffering agents are required. This chemical consumption will influence the operational costs of the technology. Third, the concentration range of metals in the waste stream will determine the range of application of the technology. For example, if the technology is most suitable to work at low concentrations, it can be used for remediation and removal of toxic wastes $(\mathrm{mg} / \mathrm{L})$, while if it only works at high levels, the technology requires preconcentration steps like solvent extraction or water evaporation $(\mathrm{g} / \mathrm{L})$. Fourth, we took into consideration the environmental impact regarding waste production or disposal since, the metal product itself might not be harmful, the precipitated salts or the concentrates can be toxic. Furthermore, acidic conditions release the metals, redisolving them, causing lixiviation of the ionic species into water bodies. Fifth, the footprint the technology requires is important to assess the investment costs, and most of the technologies require a large space due to the large volume of water to work with. For example, an installation for SX/EW requires plating baths, precipitation reactors, press filters or preconcentration reactors. Sixth, The product quality evaluates the state of the end product, which determines if the product should be processed further. Finally, the removal efficiency is important as it shows which part of the copper is recovered in the final product, and wich part is not possible to recover. It therefore also indicates how much of the copper could potentially end up in the wastewaters. The threshold in Europe for water of industrial use is $50 \mathrm{Kg} \mathrm{Cu} /$ year with a maximum concentration allowed of $0.5 \mathrm{mg} / \mathrm{L}^{115}$. However, European legislation 
is moving towards zero waste of heavy metals in water bodies; this fact will force industries to improve their water treatment facilities by incorporating one of the technologies discussed above. For example, the actual legislation requires for streams of $1 \mathrm{~g} / \mathrm{L}$ copper a removal of the $99.95 \%$. Today these requirements are only achieved by combination of technologies such as chemical precipitation followed by flocculation and filtration making the water treatment more expensive at lower concentration of copper in water.

Table 6.1: Qualitative comparison between state of the art technologies and BESs for metal recovery from wastewaters. This comparison takes into account the specific energy consumption, chemical consumption, the suitable concentration range of application, the environmental impact of the end product, the space required, the end product and the recovery efficiency ${ }^{6,116,117}$.

\begin{tabular}{|c|c|c|c|c|c|}
\hline Technique & BES & SX-EW & Flocculation & $\begin{array}{l}\text { Chemical } \\
\text { precipitation }\end{array}$ & Filtration \\
\hline $\begin{array}{c}\text { Energy } \\
\text { consumption }\end{array}$ & $\begin{array}{c}\text { Production } \\
0.11 \mathrm{kWh} / \mathrm{kg} \\
\text { of } \mathrm{Cu}\end{array}$ & $\begin{array}{c}\text { High } \\
2.70 \mathrm{kWh} / \mathrm{kg} \\
\text { of } \mathrm{Cu}\end{array}$ & None & None & Low $^{6}$ \\
\hline $\begin{array}{l}\text { Chemicals } \\
\text { consumption }\end{array}$ & $\begin{array}{c}\text { Low } \\
\text { Acetate }\end{array}$ & $\begin{array}{l}\text { Moderate } \\
\text { Solvents }\end{array}$ & $\begin{array}{l}\text { High } \\
\text { Floculants }\end{array}$ & $\begin{array}{l}\text { High } \\
\text { H2S }\end{array}$ & $\begin{array}{c}\text { Low } \\
\text { Floculants }\end{array}$ \\
\hline $\begin{array}{c}\text { Concentration } \\
\text { range }\end{array}$ & $\mathrm{g} / \mathrm{L}-\mathrm{mg} / \mathrm{L}$ & $\mathrm{g} / \mathrm{L}$ & $g / L-m g / L$ & $\mathrm{~g} / \mathrm{L}-\mathrm{mg} / \mathrm{L}$ & $\mathrm{g} / \mathrm{L}$ \\
\hline $\begin{array}{c}\text { Env. Impact of } \\
\text { end product }\end{array}$ & Low & Low & Moderate & High & Low \\
\hline Footprint & $\begin{array}{c}\text { Low } \\
<100 \mathrm{~m}^{2} \\
\end{array}$ & $\begin{array}{c}\text { Low } \\
<100 \mathrm{~m}^{2} \\
\end{array}$ & $\begin{array}{c}\text { High } \\
>100 \mathrm{~m}^{2} \\
\end{array}$ & $\begin{array}{c}\text { High } \\
>100 \mathrm{~m}^{2} \\
\end{array}$ & $\begin{array}{c}\text { Low } \\
<100 \mathrm{~m}^{2} \\
\end{array}$ \\
\hline End product & Metal & Metal & $\begin{array}{c}\text { Salt/ } \\
\text { Concentrated }\end{array}$ & Salt & Concentrated \\
\hline $\begin{array}{c}\text { Removal } \\
\text { efficiency (\%) }\end{array}$ & 99.8 & 99.0 & 81.1 & 99.9 & 99.5 \\
\hline
\end{tabular}

When comparing all these criteria, BESs have several advantages compared to the other state of the art technologies. Considering energy input, SX/EW requires a high energy demand to run the process. Considering chemical consumption, chemical precipitation, which uses sulfide as most common precipitating agent in the mining industry, produces a highly pure salt that again should be treated as a mining ore. Both chemical precipitation and SX/EW should be combined to produce metal plates for industrial purposes. Furthermore, 
flocculation is mainly used for industrial wastewater treatment plants like ceramic or glass industry to removed the heavy metals from the waste stream in a separate fraction, and similar to chemical precipitation; it also requires a high amount of chemicals and does not produce a valuable product, however, it does produce a harmful precipitate. Considering the footprint, flocculation and chemical precipitation require big reactor volume to manage the sludge generated. However the bigger the reactor does not directly translate in more expensive design. By contrast BES, SX/EW and filtration require bigger investment on materials and reactor design than flocculation or chemical precipitation ${ }^{6}$. The balance between the different factors compared in Table 6.1 is essential to decide which technique or which set of them is adapted to the needs of a given industry.

\subsection{Economic evaluation of BESs for metal recovery}

In addition to the performance indicators used in table 1, the economic feasibility of copper recovery in BESs needs to be considered. For BESs to become applicable in industry for the recovery of metals, an evaluation between capital expenditure and cost is required ${ }^{118-120}$. In general, the main disadvantage of BESs compared to other technologies is the high investment for the materials. Especially, the electrodes, current collectors, and membranes have a big impact on this investment. Therefore, to be competitive with the processes mentioned above, the BES needs to work at a high current density to reduce its footprint and therefore its specific investment costs. As described in the first paragraph of this chapter the internal resistance is the dominant factor in determining the current produced by the system. Therefore, several business cases were calculated for the economic feasibility of copper recovery using BESs as a function of internal resistance. The business cases includes three scenarios where different electron donors are considered: (i) the electron donor is available onsite (wastewater), (ii) ethanol as electron donor, and (iii) hydrogen is produced on-site through steam reforming. Furthermore, these three businesses cases were calculated for two different systems; copper recovery with (i) an MFC at a constant voltage output of $0.5 \mathrm{~V}$, (ii) an MEC at an applied voltage of $0.5 \mathrm{~V}$.

Table 2 shows an overview of the parameters used for the calculations and their values. For ethanol we use a price $0.76 € / \mathrm{Kg}^{121}$ and a copper stock market price of $4.4 € / \mathrm{Kg}^{122}$ are used. In this model we use a price of $2.7 € / \mathrm{Kg}$ of Hydrogen produced via steam reforming in industrial locations ${ }^{123}$. However, the cost of producing hydrogen by electrolysis is $2.82 € / \mathrm{Kg}^{124}$, it is cleaner but much more expensive due to the investment in electrodes. In several industrial locations, hydrogen is not recycled but produced by other processes and can be considered as a waste product. The hydrogen prize could decrease when using on-site hydrogen from a smelter or 
an electrolysis company the price of hydrogen could be even lower prices. Furthermore, the electricity cost is assumed to be $0.06 € / \mathrm{kWh}^{125}$.

In case an MFC is used for copper recovery, electrical power is produced and discharged to the electrical grid (revenue). In case an MEC is used to recover copper electrical power has to be supplied from the grid (costs). To model both BES cases MFC and MEC an open circuit potential equal to the theoretical cell potential was used for a cell operated on $10 \mathrm{mM}$ acetate and $1 \mathrm{~g} / \mathrm{L}$ copper $(0.65 \mathrm{~V})$. The internal resistance in combination with voltage output will define the current density, and this, in turn, determines the amount of required electron donor and recovered copper. Furthermore, a Coulombic efficiencies of $84 \%$ for the cathode and $95 \%$ for the anode which are conservative numbers obtained from Ter Heijne et al. (2010) ${ }^{27}$. The investment cost of a BES is $13.6 € / \mathrm{m}^{2}$ per year ${ }^{25}$. From all the state of the art technologies, SX/ EW is the technology that has as final product metallic copper, and it is an electrochemical technique. We use it as a reference of industrial application. For the comparison with SX/EW, we took the production cost of $2.29 € / \mathrm{Kg} \mathrm{Cu}$ described by Readette and Marwood (2014) ${ }^{126}$

Table 6.2: List of parameters used for calculations of the economic model of BES for metal recovery

\begin{tabular}{|c|c|c|}
\hline Parameter & Price & Source \\
\hline Ethanol & $0.76 € / \mathrm{Kg}$ & Alibaba $^{121}$ \\
\hline Copper & $4.4 € / \mathrm{Kg}$ & Alibaba $^{122}$ \\
\hline Hydrogen gas & $2.7 € / \mathrm{Kg}$ & Mueller et al. (2007) ${ }^{123}$ \\
\hline Electricity & $0.06 € / \mathrm{kWh}$ & $\begin{array}{l}\text { Centraal Bureau voor de } \\
\text { Statiestiek }^{125}\end{array}$ \\
\hline BES investment cost & $13.6 € / \mathrm{m} 2$ per year & Sleutels et al. $(2012)^{25}$ \\
\hline SX/EW & $2.29 € / \mathrm{Kg} \mathrm{Cu}$ & $\begin{array}{l}\text { Readette and Marwood } \\
(2014)^{126}\end{array}$ \\
\hline
\end{tabular}

Figure 6.1 shows the results for the four different business cases in an MFC in comparison to SX/EW. In this figure, we assume a constant cell voltage of $0.5 \mathrm{~V}$ which gives a current density as a function of the internal resistance. From the current density, the amount of electron donor and the amount of plated copper can be calculated using the stoichiometric relation for the specific reaction. This figure shows that for all electron donors the profit for recovered copper decreases at increasing internal resistance because the produced current density decreases. For the same reason, the expenses decrease at higher internal resistance. At higher current density more copper is recovered, and at the same time, higher amounts of chemicals are required.

For all electron donors, there is a minimum operational cost of $13.6 € / \mathrm{m}^{2}$ per year related to the operational costs. This operational cost decreases with decreasing internal resistance 
for an MFC (Figure 6.1) because the energy produced can be discharged to the grid. The profit from copper decreases with increasing internal resistance, because lower amounts of copper are recovered at higher internal resistance.

Figure 6.1 shows that for all electron donors, the revenues become higher than the cost when the internal resistance decreases below $400 \mathrm{~m} \Omega . \mathrm{m}^{2}$. The most profitable business case is when wastewater is used as the electron donor since this electron donor does not require any additional costs. Hydrogen and ethanol have similar revenues, both curves in Figure 6.1 are one next to the other.

Figure 6.1 also shows the comparison with SX/EW as a competing technology. For SX/ EW a constant price per $\mathrm{Kg}$ of copper was assumed, resulting in a constant negative slope in relation to the increasing internal resistance. The MFC for copper removal becomes attractive as an alternative for SX/EW for an internal resistance lower than $150 \mathrm{~m} \Omega . \mathrm{m}^{2}$ when either wastewater or hydrogen are used as an electron donor. Figure 6.2 shows the results when copper is being recovered in an MEC for the four different business cases in comparison to $\mathrm{SX} / \mathrm{EW}$. In the calculations, a constant applied cell voltage of $0.5 \mathrm{~V}$ was assumed to calculate the current density as a function of the internal resistance. Similar to the calculations with the MFC, a number of electron donors and the amount of plated copper can be calculated from the current density using the stoichiometric relation for the specific reaction.

This figure shows that for all electron donors the profit for recovered copper decreases at increasing internal resistance because the produced current density decreases. For the same reason, the expenses decrease at higher internal resistance. At higher current density more copper is recovered, and at the same time, higher amounts of electron donor are required. In all scenarios evaluated, there is a minimum operational cost included of $13.6 € / \mathrm{m}^{2}$ per year. Using an MEC implies that power from the grid has to be invested. In Figure 6.2 the operational cost for an MEC, therefore, increase when the internal resistance is reduced and the current density increases. However, it can generally be considered that by applying external power also higher current densities can be achieved ${ }^{25}$.

In this figure, we observe that for all electron donors, the revenues are higher than the cost for an internal resistance below $2500 \mathrm{~m} \Omega . \mathrm{m}^{2}$

Again, here the comparison with SX/EW as a competing technology is included in the figure. For SX/EW we assume a constant price per $\mathrm{Kg}$ of Copper, resulting in a constant negative slope in relation to the increasing internal resistance. The use of wastewaters, hydrogen and ethanol supplied are more beneficial than SX/EW at internal resistances below $1500 \mathrm{~m} \Omega \mathrm{m}^{2}$. The MEC for copper removal becomes attractive as an alternative for SX/EW for an internal resistance lower than $1500 \mathrm{~m} \Omega . \mathrm{m}^{2}$ when either wastewater, hydrogen or ethanol are used as an electron donor.

Figure 6.1 show the internal resistance achieved in this thesis (Chapter 2) $10 \mathrm{~m} \Omega \cdot \mathrm{m}^{2}$ is 
Rodenas et al. (2015)

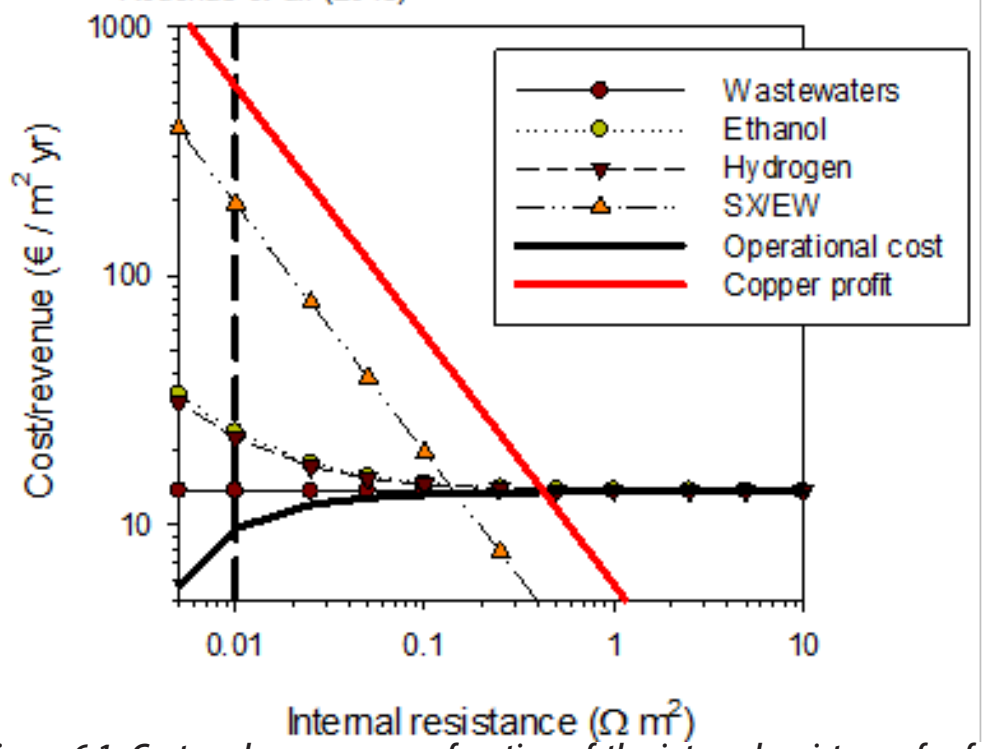

Figure 6.1. Cost and revenue as a function of the internal resistance for four different electron donors for an MFC with an output voltage of $0.5 \mathrm{~V}$. As a reference technology the costs for SX/EW are included. Also, the results achieved in this thesis (Chapter 2) are shown.

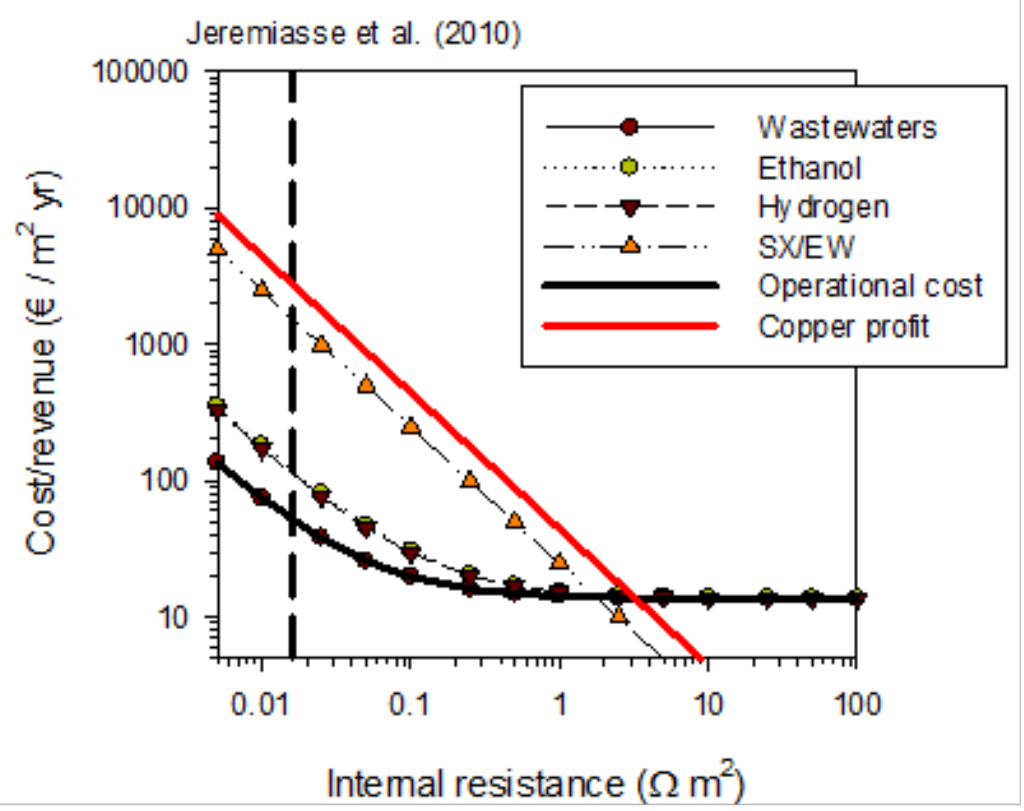

Figure6.2. Cost and revenue as a function of internal resistance for different electron donors for an MEC with an applied voltage of $0.5 \mathrm{~V}$. As a reference technology, the costs for SX/EW are included. Dashed line indicates the internal resistance value achieved by Jeremiasse et al. (2010) 
one order of magnitude lower than the minimum internal resistance to have benefits from copper $400 \mathrm{~m} \Omega \cdot \mathrm{m}^{2}$, and also one order of magnitude lower than the resistance of $150 \mathrm{~m} \Omega \cdot \mathrm{m}^{2}$ required to be competitive with SX/EW. Of course, the internal resistance in chapter two was only demonstrated at lab scale. The challenge will be to show the same performance at an industrial scale which will be discussed later in this chapter. Figure 6.2 show the internal resistance of $16 \mathrm{~m} \Omega \mathrm{m}^{2}$ achieved also in laboratory by Jeremiasse et al. (2010) for hydrogen production instead of copper recovery. However, this MEC demonstrates that the resistances achieved are also two orders of magnitude lower than the $1500 \mathrm{~m} \Omega . \mathrm{m}^{2}$ required to compete with SX/EW.

\subsection{This thesis in perspective with state of literature}

The economic analysis in the previous paragraph revealed that there is a maximum allowable internal resistance for BESs to recover copper. Figure 6.1 and 6.2 show that a maximum internal resistance of $400 \mathrm{~m} \Omega \cdot \mathrm{m}^{2}$ is allowed which is higher than the internal resistance achieved in this thesis (Chapter 2). Here we want to extend this comparison to other reports of performance and internal resistance in the literature of BESs for copper recovery.

As mention in the introduction chapter, to assess the performance of the BES the polarization curve must be recorded. Therefore, in all experimental chapters (2 to 5$)$ in this thesis, polarization curves were depicted which show the optimal voltage and current for maximum power production. From the data of the polarization curve and the cell design used, the following key parameters are extracted: internal resistance $\left(\mathrm{R}_{\text {int }}\right)$, maximum current density $\left(\mathrm{J}_{\max }\right)$, the maximum power $\left(\mathrm{P}_{\max }\right)$, open cell voltage $\left(\mathrm{V}_{\mathrm{oc}}\right)$, specific surface area $(\mathrm{A})$ and the removal efficiency. The specific surface is the relation between the surface of the anode and volume of the reactor. It is a measure of the amount of surface that is available for the biofilm to attach and produce current. This parameter, to a large extend, is a measure for the footprint of the reactor and the material use required for its design. The open circuit voltage is the maximum potential energy that the cell can deliver. When the Voc is close to the theoretical (thermodynamical) maximum determined by the reactions at anode and cathode, it is an indication of the efficiency of the system. The copper removal efficiency is the efficiency at which copper is removed from the catholyte. Table 6.3 gives an overview of these important parameters for MFCs studies for copper recovery from 2010 when the first copper recovery study was publish to 2016 .

In 2010 ter Heijne et al. (2010) published the first paper on copper recovery using a BES ${ }^{27}$ They achieved a maximum current density of $6 \mathrm{~A} / \mathrm{m}^{2}$ and a power production of $0.8 \mathrm{~W} /$ $\mathrm{m}^{2}$. In this first study an internal resistance of $21 \mathrm{~m} \Omega \cdot \mathrm{m}^{2}$ was achieved by using two parallel 
graphite plates separated electrolyte compartments of $1.5 \mathrm{~cm}$ with a BPM in between. Cheng et al. (2013) came to a closer internal resistance of $56 \mathrm{~m} \Omega \cdot \mathrm{m}^{2}$ by using carbon fiber brushes and AEM. In chapter 2 of this thesis study, the current density achieved was one order of magnitude higher than previous studies, and the internal resistance was only $10 \mathrm{~m} \Omega . \mathrm{m}^{2}$. Up to the date, the highest current obtained for copper recovery by a BES was published by Rodenas et al. (2015) (Chapter 2) with a value of $25 \mathrm{~A} / \mathrm{m}^{2}$ due to the low internal resistance.

Considering the power density, Table 6.3 shows that only two studies reached more than $1 \mathrm{~W} / \mathrm{m}^{2}$ produced. These two cases are Cheng et al. (2013) with a power production of $1.7 \mathrm{~W} /$ $\mathrm{m}^{2}$ and Rodenas et al. (2015) with a power production of $5.5 \mathrm{~W} / \mathrm{m}^{2}$. To do so, Cheng et al. (2013) used carbon brushes, successfully aiming to increase the specific surface area of the bioanode. Furthermore, they also used an AEM to reduce the contribution of the membrane to the total internal resistance. Instead of the carbon brush, Rodenas et al. (2015) used a carbon felt as the anode material which also has a high specific surface area. However, due to its flat structure on average it is, closer to the membrane than carbon brushes reducing the overall distance between the electrodes.

These results show that the specific surface area is an important parameter for the design of the BES This specific surface area highly depends on the materials choice. Rodenas et al (2015), Fedje et al (2015) used graphite felts with a specific surface areas of 100 and $106 \mathrm{~m}^{2} /$ $\mathrm{m}^{3}$ while Cheng et al. (2013) used carbon brushes with specific surfaces of $157 \mathrm{~m}^{2} / \mathrm{m}^{3}$.

The $\mathrm{V}_{\mathrm{OC}}$ is related to the maximum energy that the cell can deliver since it is related to the energy levels that the biofilm can deliver electrons to the anode and the copper in solution to take them in the cathode. The higher the $\mathrm{V}_{\mathrm{OC}}$ it is, the closer is the cell potential to the equilibrium potential, and theoretically the better the catalysis of the reactions is, because the overpotential is lower. The equilibrium potential of a cell working with $10 \mathrm{mM}$ acetate as electron donor and $1 \mathrm{~g} / \mathrm{L}$ of copper is poised at $0.65 \mathrm{~V}$. This number varies depending of the species involved in the redox processes. Shen et al (2015) and Wu et al. (2015) showed $\mathrm{V}_{\mathrm{OC}}$ of $0.68 \mathrm{~V}$ and $0.64 \mathrm{~V}$ respectively and close to the thermodynamic equilibrium potential. By contrast, ter Heijne (2010) and Rodenas et al. (2015) showed a $\mathrm{V}_{\mathrm{OC}}$ of $0.61 \mathrm{~V}$ and $0.48 \mathrm{~V}$ respectively, showing higher power and current densities and lower internal resistances.

The comparison between removal efficiencies shows that there are three cases reaching removal efficiencies higher than $99 \%$. This removal efficiency strongly depends on the current achieved and the duration of the experiment. For example, Ter Heijne et al. (2010) achieved a $99.88 \%$ removal with a current density of $6.2 \mathrm{~A} / \mathrm{m}^{2}$ in an experiment of 10 days with a starting concentration of $1 \mathrm{~g} / \mathrm{L}$ while Wang et al. (2010) achieved $99.97 \%$ removal efficiency in 11 hours for a starting concentration of $50 \mathrm{mg} / \mathrm{L}$. This two different results show that as mentioned in Table 6.1, this technology can remove at high efficiencies for high and low concentrations of copper in water. 
Table 6.3: Copper removal by different BESs reported from 2010 to 2016

\begin{tabular}{|c|c|c|c|c|c|c|}
\hline $\begin{array}{c}\text { Internal } \\
\text { resistance } \\
\left(\Omega \mathrm{m}^{2}\right)\end{array}$ & $\begin{array}{c}J_{\text {peak }} \\
\left(\mathrm{A} / \mathrm{m}^{2}\right)\end{array}$ & $\begin{array}{c}\mathrm{P}_{\max } \\
\left(\mathrm{W} / \mathrm{m}^{2}\right)\end{array}$ & $\begin{array}{c}\text { Specific } \\
\text { surface } \\
\left(\mathrm{m}^{2} / \mathrm{m}^{3}\right)\end{array}$ & $\mathrm{V}_{\mathrm{oc}}(\mathrm{V})$ & $\begin{array}{c}\text { Removal } \\
(\%)\end{array}$ & Authors \\
\hline $9 \times 10-3\left(\Omega \mathrm{m}^{3}\right)$ & $\begin{array}{c}26.9 \\
\left(\mathrm{~A} / \mathrm{m}^{3}\right)\end{array}$ & $\begin{array}{c}6.5 \\
\left(\mathrm{~W} / \mathrm{m}^{3}\right)\end{array}$ & 40 & 0.42 & 99.7 & $\begin{array}{l}\text { Wu D et al. } \\
(2016)^{127}\end{array}$ \\
\hline 1.39 & 0.57 & 0.45 & 50 & - & 63.7 & $\begin{array}{c}\text { Yang } \\
\text { J et al. } \\
(2016)^{128}\end{array}$ \\
\hline 0.579 & 0.47 & 0.128 & 40 & & & $\begin{array}{c}\text { Wang } \\
\text { Q. et al. } \\
(2016)^{129}\end{array}$ \\
\hline $\begin{array}{l}3 \times 10-3 \\
\left(\Omega \mathrm{m}^{3}\right)\end{array}$ & $\begin{array}{c}38 \\
\left(\mathrm{~A} / \mathrm{m}^{3}\right)\end{array}$ & $\begin{array}{c}4.8(\mathrm{~W} / \\
\left.\mathrm{m}^{3}\right)\end{array}$ & 22 & 0.68 & 51 & $\begin{array}{l}\text { Shen } \\
\text { J., et al. } \\
(2015)^{130}\end{array}$ \\
\hline $\begin{array}{l}9 \times 10-3 \\
\left(\Omega \mathrm{m}^{3}\right)\end{array}$ & $\begin{array}{c}141.3 \\
\left(\mathrm{~A} / \mathrm{m}^{3}\right)\end{array}$ & $\begin{array}{c}18.8(\mathrm{~W} / \\
\left.\mathrm{m}^{3}\right)\end{array}$ & 106 & - & 79 & $\begin{array}{c}\text { Fedje } \\
\text { K.K., et al. } \\
(2015)^{131}\end{array}$ \\
\hline 0.86 & 0.09 & 0.007 & 188 & 0.32 & & $\begin{array}{c}\text { Huang } \\
\text { Let al. } \\
(2015)^{132}\end{array}$ \\
\hline $\begin{array}{l}2 \times 10-3 \\
\left(\Omega \mathrm{m}^{3}\right)\end{array}$ & $\begin{array}{c}45 \\
\left(\mathrm{~A} / \mathrm{m}^{3}\right)\end{array}$ & $\begin{array}{c}4.62(\mathrm{~W} / \\
\left.\mathrm{m}^{3}\right)\end{array}$ & 60 & 0.64 & 28 & $\begin{array}{c}\text { Wu D. } \\
\text { et al. } \\
(2015)^{133}\end{array}$ \\
\hline 0.010 & 23 & 5.5 & 100 & 0.485 & & $\begin{array}{c}\text { Rodenas } \\
\text { et al. } \\
(2015)^{134}\end{array}$ \\
\hline
\end{tabular}




\begin{tabular}{|c|c|c|c|c|c|c|}
\hline $\begin{array}{c}\text { Internal } \\
\text { resistance } \\
\left(\Omega \mathrm{m}^{2}\right)\end{array}$ & $\begin{array}{c}\mathrm{J}_{\text {peak }} \\
\left(\mathrm{A} / \mathrm{m}^{2}\right)\end{array}$ & $\begin{array}{c}\mathrm{P}_{\max } \\
\left(\mathrm{W} / \mathrm{m}^{2}\right)\end{array}$ & $\begin{array}{c}\text { Specific } \\
\text { surface } \\
\left(\mathrm{m}^{2} / \mathrm{m}^{3}\right)\end{array}$ & $\mathrm{V}_{\mathrm{oc}}(\mathrm{V})$ & $\begin{array}{c}\text { Removal } \\
(\%)\end{array}$ & Authors \\
\hline 0.056 & 5.5 & 1.7 & 157 & 0.45 & 87 & $\begin{array}{c}\text { Cheng } \\
\text { S.-A. et al. } \\
(2013)^{59}\end{array}$ \\
\hline * & 0.34 & * & 33 & 0.4 & 84.3 & $\begin{array}{l}\text { Modin } \\
\text { O et al. } \\
(2012)^{28}\end{array}$ \\
\hline 0.222 & 0.95 & 0.2 & 20 & 0.58 & 96 & $\begin{array}{c}\text { Zhang } \\
\text { L. et al.. } \\
(2102)^{135}\end{array}$ \\
\hline 0.782 & 0.143 & 0.016 & 12.1 & 0.48 & 96 & $\begin{array}{l}\text { Tao H.-C } \\
\text { et al. } \\
(2011)^{39}\end{array}$ \\
\hline 1.09 & 0.142 & 0.022 & 140 & - & 70 & $\begin{array}{c}\text { Tao H.- } \\
\text { C., et al. } \\
(2011)\end{array}$ \\
\hline 0.221 & 1.2 & 0.319 & 35.6 & 0.595 & 99.97 & $\begin{array}{l}\text { Wang Z et } \\
\text { al. }(2010)^{37}\end{array}$ \\
\hline 0.021 & 6.2 & 0.8 & 66 & 0.61 & 99.88 & $\begin{array}{c}\text { Heijne } \\
\text { A.T. et al.. } \\
(2010)^{27}\end{array}$ \\
\hline
\end{tabular}

* If in the table there is no value (Modin et al. 2012) means that the cell works in short circuit and no power is extracted

\subsection{Possible improvements}

As shown in the previous paragraphs, based on both economics and performance, BESs are a technology that could potentially compete with the state of the art metallurgical wastewater treatment techniques. The aim of this thesis was to overcome the limitations in BES for copper recovery. We showed improvements in cell design, current density, and internal resistance, and studied the effects of scaling-up in a new design. At the same time, there are still other 
limitations that need to be overcome, such as methanogenesis or interference of sulfate reducers that decrease the Coulombic efficiency of the anode. In the next paragraph, some future directions will be discussed that may help BESs to become applicable in practice. The directions include alternative electron donors and niche applications.

\section{New electron donors}

In Chapters 3 and 4, hydrogen has been used as an alternative electron donor to acetate, because it is produced as a waste product in the electrowinning industry. The use of alternative indigenous electron donors opens new niche applications and extends the implementation of the technology to places where no organic resources are available. In the mining industry, wastewaters contain a broad range of pollutants that could serve as an electron donor. In the past years, in addition to hydrogen, other electron donors for metal recovery have been studied. From the environmental point of view, most attractive ones are sulfur compounds sometimes present in tailing ponds from mining industry such as thiosulfates and tetrathionate ${ }^{97}$. These compounds are pollutants that should be oxidized or be removed from the wastewaters. One example is by Sulonen et al. (2016) ${ }^{136}$ who demonstrated the long-term electricity production by bacteria able to oxidize tetrathionate $\left(\mathrm{S}_{4} \mathrm{O}_{6}{ }^{2-}\right)$ in acidic conditions, according to:

$$
\mathrm{S}_{4} \mathrm{O}_{6}{ }^{2-}+10 \mathrm{H}_{2} \mathrm{O} \leftrightarrow 4 \mathrm{SO}_{4}{ }^{2-}+14 \mathrm{e}-+20 \mathrm{H}^{+}
$$

They coupled the oxidation of tetrathionate to the reduction of $\mathrm{Cu}^{2+}$ and $\mathrm{Fe}^{3+}$ and showed a current density of $0.43 \mathrm{~A} / \mathrm{m}^{2}$ and a power generation of $17.6 \mathrm{~mW} / \mathrm{m}^{2}$.

Furthermore, Ni et al. (2016) characterized the microbial species capable of oxidizing sulfur compounds like thiosulphates $\left(\mathrm{S}_{2} \mathrm{O}_{3}{ }^{2-}\right)$.

$$
\mathrm{S}_{2} \mathrm{O}_{3}^{2-}+5 \mathrm{H}_{2} \mathrm{O} \leftrightarrow 2 \mathrm{SO}_{4}^{2-}+8 \mathrm{e}-+10 \mathrm{H}^{+}
$$

In this work, the oxidation of thiosulphates was coupled to the reduction of $\mathrm{Fe}^{3+}$, and being used in bioremediation while producing cell voltage of $105 \mathrm{mV}$.

These studies show that there may be niche applications for BES for metal reduction, in which the oxidation of sulfur compounds in the mining wastewaters can be coupled to the reduction of metals.

Other electron donors can be found in printed circuitry industry and electronic wastes. The residues produced by this industry contain electron donors and electron acceptors in the same solution. The electron acceptors are metals like silver, gold or copper while the electron donors are the leaching and solvent agents used to recover those metals. These leaching agents are used to extract the metal dissolved from the solid residues. One example is the use of oxalic acid as a leaching agent. It can be produced by fungi in aerobic conditions and used to leach the metals as a chelating agent, and can finally be oxidized at a bioanode to produce power ${ }^{137,138}$. 
Another electron donor for electricity production is ethanol. Bioethanol is accessible world wide for electricity production. In mining locations at remote areas, ethanol oxidation combined with copper recovery could be a good opportunity to produce electricity and copper at the same time replacing diesel for power generation in mines.

\section{New electron acceptors:}

As mentioned in the previous section, there are waste streams containing all kind of heavy metals (cobalt, lead, zinc, etc...), precious metals (gold, silver, palladium, platinum) or rare earth metals (niobium, or gadolinium) They are used for many technological applications due to their optical, electronic and magnetic properties, in LEDs devices and electronic devices, or contrast agents for medical purposes. Annex I shows that BESs have also been used to recover these metals, and summarize their performance. These metals can change the revenues, allowing higher internal resistances, and may lead to new niche applications for the technology.

\section{Future perspectives in cell configuration and up-scaling.}

In chapter 2, a high-rate MFC for copper reduction was described, that was able to produce current densities of $20 \mathrm{~A} / \mathrm{m}^{2}$. This high current was the result of improvements made to the cell: a flow-through anode, short distance between the electrodes, and the use of an Anion exchange Membrane (AEM), leading to an internal resistance of $10 \mathrm{~m} \Omega \cdot \mathrm{m}^{2}$. In chapter 5 , a prototype MFC was designed and tested. This prototype had a new configuration in order to allow the anodes and cathodes to be easily removed from the cell. The drawback of this prototype is that the total internal resistance increased considerably compared to the system described in chapter 2. Analysis of the voltage losses over the different compartments of the cells revealed that the anode had a major contribution to the voltage losses. This prototype thus needs further improvements to make the system economic: lower internal resistance is required as described by Detzel et al. (2009) and Ibrahim et al. (2013) $)^{139,140}$. Janicek et al. (2014) also summarized the parameters to take into consideration for future scaling-up of Microbial Fuel Cells: short distance between electrodes, high surface/volume ratio ${ }^{108}$.

In this thesis we identified the following limitations that led to high internal resistance:

- Insufficient electrolyte mixing

- Low available surface area

- Non-optimal current collection

- Too high distance between electrodes

- Type of electron donor

Possible directions for future MFC design need to take into account these limitations. 
For example, tubular cells have been designed with a patterned interior can enhance mass transport by using the Coriolis effect. ${ }^{138}$ These tubular cells employ scaffolds or patterned interior to maximize mixing and minimizing the mass transfer limitations.

Another potential direction is the use of capacitive fluidized electrodes with activated carbon particles, as studied by Deeke et al. $(2015)^{141}$. This reactor design allows a high electrode surface area available for the biofilm to be in contact with the electrolyte. Also, mass transfer limitations may be reduced in this system as particles are freely moving through the solution. Electrode surface area is crucial as the biofilm density determines the current. Possible ways to provide a high specific surface area, beside activated carbon granules, is, for example, the use of brushed anodes like anodes used by Logan et al. (2007) ${ }^{142}$ or anode materials that get close to membrane or cathode, like graphite felts described by Sleutels (2009) ${ }^{54}$.

\subsection{Concluding remarks}

Last but not least, once the business model is set, and scaling-up is feasible, the technology is ready to move to real application. Heavy metals pose a severe environmental problem and are considered by some authors as a toxic time bomb now laying in anaerobic sediments ${ }^{124}$. The source of these toxic metals can be mining industry, smelters or simply the disposal of electronic products that we use daily. The metals can be oxidized and lixiviate, be trapped in soils, and be mobilized by acidification, thereby slowly leaching into the environment. This acidification is the result of microbial activity related to organic matter or sulfur compounds, exposing heavy metals trapped in clays and chemically bound to water. Metal removal, in combination with recovery and reuse, is, therefore, essential to preventing the explosion of this toxic time bomb. We can reduce the environmental impact of mining (deforestation, aquifer contamination, soil acidification and many other problems) by recovering and reusing the heavy metals in a sustainable way, and thereby decrease our environmental footprint as a society. 


\section{English summary}

Heavy metals are essential for living beings and society. They are the basis for many industries, for example, they are used as catalyst, pesticides, fertilizers, but also form key components for electronic industry and construction materials. These metals need to be extracted from mineral ores, after which they can be transformed into a product that has the required characteristics or recycled to have a new use. Metal production processes require energy and cause negative environmental impacts, depending on which extraction and production technology is used. Current technologies for the production of metals are based on a series of processes: first of all the mineral is mined, then this mineral is processed to concentrate the metal, followed by a melting and extraction process, to finally end up in a refining process by smelting or electroplating ${ }^{1}$. This thesis is a study of Bioelectrochemical Systems (BES) as an alternative technology to the state of the art technologies for its use on metal recovery, removal and production.

Chapter 1 is an introduction to the bioelectrochemical recovery of heavy metals explaining the basic concepts required to understand the following chapters. In this chapter the state of the art technologies for metal recovery are explained. Bioelectrochemical systems are described to have an overview of its possibilities for its use on metal recovery.

Chapter 2 explains the improvements made on cell design to achieve current densities of $25 \mathrm{~A} / \mathrm{m}^{2}$ and power densities of $5.5 \mathrm{~W} / \mathrm{m}^{2}$ with acetate as electron donor and copper as electron acceptor. An study of the internal resistance distribution of the cell is shown to explain the energy losses over the different compartments of the cell.

Chapter 3 studies the use of hydrogen gas as electron donor for its use on copper recovery. These chapter is proof of principle of the capabilities of the biofilm t oxidize hydrogen gas to produce electricity and recover copper simultaneously.

Chapter 4 brings further the research on chapter 3 by improving the use of hydrogen gas as electron donor. The use of a gas diffusion electrode to grow a biofilm combine with the study of multiple parameter brings the cell to a current production of $1 \mathrm{~A} / \mathrm{m}^{2}$. The current density achieved is comparable to the current densities achieved on chapter 2 .

Chapter 5 shows an upscale prototype to incorporate BES technology into electroplating industry by replacing the traditional anodes for a bioanode module design. In this chapter advantages and disadvantages are studied through the analysis of the internal resistance distribution along the compartments of the cell.

Finally, in chapter 6 the BES technology is put in perspective compared to other state of the art technologies. An economic analysis of the cost and revenues is depicted together with 
a comparison with Solvent Extraction/Electro-Wining. At the end of this chapter a list of possible improvements and nice applications are discussed.

Overall, this thesis shows that metal recovery is possible by using BES. Its use as a future technology strongly depends on find the proper niche for its application. This thesis focus on copper recovery as model heavy metal present in industrial and mining wastewaters. However, other metals had been recovered or remove by this technology (ANNEX I) showing the versatility of this technology. Further research in the use of newer electron donors or electron acceptors will broader the field and its impact in society. 


\section{References}

(1) Barakat, M. a. New trends in removing heavy metals from industrial wastewater. Arab. J. Chem. 2011, 4 (4), 361-377.

(2) Henckens, M. L. C. M.; Driessen, P. P. J.; Worrell, E. Metal scarcity and sustainability, analyzing the necessity to reduce the extraction of scarce metals. Resour. Conserv. Recycl. 2014, 93, 1-8.

(3) Drielsma, J. A.; Russell-Vaccari, A. J.; Drnek, T.; Brady, T.; Weihed, P.; Mistry, M.; Simbor, L. P. Mineral resources in life cycle impact assessment-defining the path forward. Int. J. Life Cycle Assess. 2015, 21 (1), 85-105.

(4) Johnson, K.M.; Hammarstrom, J.M.; Zientek, M.L.; and Dicken, C. L. USGS Fact Sheet 2014-3004: Estimate of Undiscovered Copper Resources of the World, $2013 \mathrm{http} / / /$ pubs.usgs.gov/fs/2014/3004/ (accessed Mar 16, 2016).

(5) Harmsen, J. H. M.; Roes, A. L.; Patel, M. K. The impact of copper scarcity on the efficiency of 2050 global renewable energy scenarios. Energy 2013, 50, 62-73.

(6) Fu, F.; Wang, Q. Removal of heavy metal ions from wastewaters: A review. J. Environ. Manage. 2011, 92 (3), 407-418.

(7) Mahmoud, A.; Hoadley, A. F. A. An evaluation of a hybrid ion exchange electrodialysis process in the recovery of heavy metals from simulated dilute industrial wastewater. Water Res. 2012, 46 (10), 3364-3376.

(8) Coman, V.; Robotin, B.; Ilea, P. Nickel recovery/removal from industrial wastes: A review. Resour. Conserv. Recycl. 2013, 73, 229-238.

(9) Wan Ngah, W. S.; Teong, L. C.; Hanafiah, M. A. K. M. Adsorption of dyes and heavy metal ions by chitosan composites: A review. Carbohydr. Polym. 2011, 83 (4), 1446-1456.

(10) Zhong, L.; Peng, X.; Yang, D.; Sun, R. Adsorption of Heavy Metals by a Porous Bioadsorbent from Lignocellulosic Biomass Reconstructed in an Ionic Liquid. J. Agric. Food Chem. 2012, 60 (22), 5621-5628.

(11) Moldoveanu, G. a.; Papangelakis, V. G. Recovery of rare earth elements adsorbed on clay minerals: I. Desorption mechanism. Hydrometallurgy 2012, 117-118, 71-78.

(12) Audinos, R. Improvement of metal recovery by electrodialysis. J. Memb. Sci. 1986, 27 (2), 143-154.

(13) Iizuka, A.; Yamashita, Y.; Nagasawa, H.; Yamasaki, A.; Yanagisawa, Y. Separation 
of lithium and cobalt from waste lithium-ion batteries via bipolar membrane electrodialysis coupled with chelation. Sep. Purif. Technol. 2013, 113, 33-41.

(14) Buzzi, D. C.; Viegas, L. S.; Rodrigues, M. A. S.; Bernardes, A. M.; Tenório, J. A. S. Water recovery from acid mine drainage by electrodialysis. Miner. Eng. 2013, 40, 82-89.

(15) Sadyrbaeva, T. Z. Electrodialytic separation of cobalt(II) and nickel(II) using liquid membranes based on tri-n-octylamine and trialkylbenzylammonium chloride. Russ. J. Appl. Chem. 2013, 86 (2), 186-191.

(16) Dermont, G.; Bergeron, M.; Richer-Laflèche, M.; Mercier, G. Remediation of metalcontaminated urban soil using flotation technique. Science of the Total Environment . 2010, pp 1199-1211.

(17) Khosa, M. K.; Jamal, M. A.; Hussain, A.; Muneer, M.; Zia, K. M.; Hafeez, S. Efficiency of Aluminum and Iron Electrodes for the Removal of Heavy Metals [(Ni (II), Pb (II), Cd (II)] by Electrocoagulation Method. J. Korean Chem. Soc. 2013, 57 (3), 316-321.

(18) Guzmán, A.; Nava, J. L.; Coreño, O.; Rodríguez, I.; Gutiérrez, S. Arsenic and fluoride removal from groundwater by electrocoagulation using a continuous filter-press reactor. Chemosphere 2016, 144, 2113-2120.

(19) Assadi, A.; Fazli, M. M.; Emamjomeh, M. M.; Ghasemi, M. Optimization of lead removal by electrocoagulation from aqueous solution using response surface methodology. Desalin. Water Treat. 2015, 57 (20), 9375-9382.

(20) Chehade, Y.; Siddique, A.; Alayan, H.; Sadasivam, N.; Nusri, S.; Ibrahim, T. Recovery of Gold, Silver, Palladium , and Copper from Waste Printed Circuit Boards. 2012.

(21) Potter, M. C. Electrical Effects Accompanying the Decomposition of Organic Compounds Published by: The Royal Society Electrical Effects accompanying the Decormposition of Organic. Proc. R. Soc. London. Ser. B 1911, 84 (571), 260-276.

(22) Bennetto, H Peter and Stirling, John L and Tanaka, Kazuko and Vega, C. A. Anodic reactions in microbial fuel cells. Biotechnol. Bioeng. 1983, 25 (2), 559--568.

(23) Kim, B. H.; Ikeda, T.; Park, H. S.; Kim, H. J.; Hyun, M. S.; Kano, K.; Takagi, K.; Tatsumi, H. Electrochemical activity of an Fe(III)-reducing bacterium, Shewanella putrefaciens IR-1, in the presence of alternative electron acceptors. Biotechnol. Tech. 1999, 13 (7), 475-478.

(24) Pant, D.; Van Bogaert, G.; Diels, L.; Vanbroekhoven, K. A review of the substrates used in microbial fuel cells (MFCs) for sustainable energy production. Bioresour. Technol. 2010, 101 (6), 1533-1543.

(25) Sleutels, T. H. J. a; Ter Heijne, A.; Buisman, C. J. N.; Hamelers, H. V. M. Bioelectrochemical systems: an outlook for practical applications. ChemSusChem 2012, 5 (6), 1012-1019. 
(26) Lu, M.; Li, S. F. Y. Cathode Reactions and Applications in Microbial Fuel Cells: A Review. Crit. Rev. Environ. Sci. Technol. 2012, 42 (23), 2504-2525.

(27) Heijne, A. Ter; Liu, F.; Weijden, R. van der; Weijma, J.; Buisman, C. J. N.; Hamelers, H. V. M.; van der Weijden, R.; Ter Heijne, A. Copper recovery combined with electricity production in a microbial fuel cell. Environ. Sci. Technol. 2010, 44 (11), 4376-4381.

(28) Modin, O.; Wang, X.; Wu, X.; Rauch, S.; Fedje, K. K. Bioelectrochemical recovery of $\mathrm{Cu}, \mathrm{Pb}, \mathrm{Cd}$, and Zn from dilute solutions. J. Hazard. Mater. 2012, 235-236, 291-297.

(29) Wang, G.; Huang, L.; Zhang, Y. Cathodic reduction of hexavalent chromium [Cr(VI)] coupled with electricity generation in microbial fuel cells. Biotechnol. Lett. 2008, 30 (11), 1959-1966.

(30) Wang, Z.; Lim, B.; Choi, C. Removal of $\mathrm{Hg} 2+$ as an electron acceptor coupled with power generation using a microbial fuel cell. Bioresour. Technol. 2011, 102 (10), 6304-6307.

(31) Zhang, L. J.; Tao, H. C.; Wei, X. Y.; Lei, T.; Li, J. B.; Wang, A. J.; Wu, W. M. Bioelectrochemical recovery of ammonia-copper(II) complexes from wastewater using a dual chamber microbial fuel cell. Chemosphere 2012, 89 (10), 1177-1182.

(32) Wang, Y.-H. H.; Wang, B.-S. S.; Pan, B.; Chen, Q.-Y. Y.; Yan, W. Electricity production from a bio-electrochemical cell for silver recovery in alkaline media. Appl. Energy 2013, 112, 1337-1341.

(33) Du, Z.; Li, H.; Gu, T. A state of the art review on microbial fuel cells: A promising technology for wastewater treatment and bioenergy. Biotechnol. Adv. 2007, 25 (5), 464-482.

(34) Tao, H. C.; Gao, Z. Y.; Ding, H.; Xu, N.; Wu, W. M. Recovery of silver from silver(I)containing solutions in bioelectrochemical reactors. Bioresour. Technol. 2012, 111, 92-97.

(35) Kalathil, S.; Lee, J.; Cho, M. H. Gold nanoparticles produced in situ mediate bioelectricity and hydrogen production in a microbial fuel cell by quantized capacitance charging. ChemSusChem 2013, 6 (2), 246-250.

(36) Zhang, B.; Feng, C.; Ni, J.; Zhang, J.; Huang, W. Simultaneous reduction of vanadium (V) and chromium (VI) with enhanced energy recovery based on microbial fuel cell technology. J. Power Sources 2012, 204, 34-39.

(37) Wang, Z.; Lim, B.; Lu, H.; Fan, J.; Choi, C. Cathodic reduction of Cu 2+ and electric power generation using a microbial fuel cell. Bull. Korean Chem. Soc. 2010, 31 (7), 20252030.

(38) Wang, Y. H.; Wang, B. S.; Pan, B.; Chen, Q. Y.; Yan, W. Electricity production from a bio-electrochemical cell for silver recovery in alkaline media. Appl. Energy 2013.

(39) Tao, H. C.; Liang, M.; Li, W.; Zhang, L. J.; Ni, J. R.; Wu, W. M. Removal of copper 
from aqueous solution by electrodeposition in cathode chamber of microbial fuel cell. J. Hazard. Mater. 2011, 189 (1-2), 186-192.

(40) Huang, L.; Guo, R.; Jiang, L.; Quan, X.; Sun, Y.; Chen, G. Cobalt leaching from lithium cobalt oxide in microbial electrolysis cells. Chem. Eng. J. 2013, 220, 72-80.

(41) Qin, B.; Luo, H.; Liu, G.; Zhang, R.; Chen, S.; Hou, Y.; Luo, Y. Nickel ion removal from wastewater using the microbial electrolysis cell. Bioresour. Technol. 2012, 121, 458-461.

(42) Huang, L.; Li, T.; Liu, C.; Quan, X.; Chen, L.; Wang, A.; Chen, G. Synergetic interactions improve cobalt leaching from lithium cobalt oxide in microbial fuel cells. Bioresour. Technol. 2013, 128, 539-546.

(43) Sleutels, T. H. J. A.; Hamelers, H. V. M.; Rozendal, R. A. .; Buisman, C. J. N. Ion transport resistance in Microbial Electrolysis Cells with anion and cation exchange membranes. Int. J. Hydrogen Energy 2009, 34 (9), 3612-3620.

(44) Bassignana, I. C.; Reiss, H. Ion transport and water dissociation in bipolar ion exchange membranes. J. Memb. Sci. 1983, 15 (1), 27-41.

(45) Norgate, T. E.; Rankin, W. J. The Role of Metals in Sustainable Development. In; 2002; pp 49-55.

(46) Mcaleer, M. Pricing of Non-ferrous Metals Futures on the London Metal Exchange Pricing of Non-ferrous Metals Futures on the London Metal Exchange. 2006, No. March.

(47) Geman, H.; Smith, W. O. Theory of storage, inventory and volatility in the LME base metals. Resour. Policy 2013, 38 (1), 18-28.

(48) Vegliò, F.; Quaresima, R.; Fornari, P.; Ubaldini, S. Recovery of valuable metals from electronic and galvanic industrial wastes by leaching and electrowinning. Waste Manag. 2003, 23 (3), 245-252.

(49) Logan, B. E.; Elimelech, M. Membrane-based processes for sustainable power generation using water. Nature 2012, 488 (7411), 313-319.

(50) Zhang, L. J.; Tao, H. C.; Wei, X. Y.; Lei, T.; Li, J. B.; Wang, A. J.; Wu, W. M. Bioelectrochemical recovery of ammonia-copper(II) complexes from wastewater using a dual chamber microbial fuel cell. Chemosphere 2012, 89 (10), 1177-1182.

(51) Foley, J. M.; Rozendal, R. A.; Hertle, C. K.; Lant, P. A.; Rabaey, K. Life Cycle Assessment of High-Rate Anaerobic Treatment, Microbial Fuel Cells, and Microbial Electrolysis Cells. 2010.

(52) Pant, D.; Singh, A.; Van Bogaert, G.; Gallego, Y. A.; Diels, L.; Vanbroekhoven, K. An introduction to the life cycle assessment (LCA) of bioelectrochemical systems (BES) for sustainable energy and product generation: Relevance and key aspects. Renew. Sustain. 
Energy Rev. 2011, 15 (2), 1305-1313.

(53) Rozendal, R. A.; Hamelers, H. V. M.; Molenkamp, R. J.; Buisman, C. J. N. Performance of single chamber biocatalyzed electrolysis with different types of ion exchange membranes. Water Res. 2007, 41 (9), 1984-1994.

(54) Sleutels, T. H. J. a.; Lodder, R.; Hamelers, H. V. M.; Buisman, C. J. N. Improved performance of porous bio-anodes in microbial electrolysis cells by enhancing mass and charge transport. Int. J. Hydrogen Energy 2009, 34 (24), 9655-9661.

(55) Sleutels, T. H. J. A.; Hamelers, H. V. M.; Buisman, C. J. N. Effect of mass and charge transport speed and direction in porous anodes on microbial electrolysis cell performance. Bioresour. Technol. 2011, 102 (1), 399-403.

(56) Kuntke, P.; Sleutels, T.; Saakes, M.; Buisman, C. J. N. Hydrogen production and ammonium recovery from urine by a Microbial Electrolysis Cell. Int. J. Hydrogen Energy 2014, 39 (10), 4771-4778.

(57) ter Heijne, A.; Hamelers, H. V. M.; Saakes, M.; Buisman, C. J. N. Performance of nonporous graphite and titanium-based anodes in microbial fuel cells. Electrochim. Acta 2008, 53 (18), 5697-5703.

(58) Hamilton, W. A. Sulphate-reducing bacteria and anaerobic corrosion. Annu. Rev. Microbiol. 1985, 39, 195-217.

(59) Cheng, S.-A.; Wang, B.-S.; Wang, Y.-H. Increasing efficiencies of microbial fuel cells for collaborative treatment of copper and organic wastewater by designing reactor and selecting operating parameters. Bioresour. Technol. 2013, 147, 332-337.

(60) Alvarado, S. Long term energy-related environmental issues of copper production. Energy 2002, 27 (2), 183-196.

(61) Babich, H.; Stotzky, G. Heavy metal toxicity to microbe-mediated ecologic processes: A review and potential application to regulatory policies. Environ. Res. 1985, 36 (1), 111-137.

(62) Islam, E. U.; Yang, X.; He, Z.; Mahmood, Q. Assessing potential dietary toxicity of heavy metals in selected vegetables and food crops. J. Zhejiang Univ. Sci. B 2007, 8 (1), 1-13.

(63) Norgate, T. E.; Jahanshahi, S.; Rankin, W. J. Assessing the environmental impact of metal production processes. J. Clean. Prod. 2007, 15 (8-9), 838-848.

(64) Rabaey, K.; Angenent, L.; Schröder, U.; Keller, J. Bioelectrochemical systems : from extracellular electron transfer to biotechnological application; 2010.

(65) Lim, B. S.; Lu, H.; Choi, C.; Liu, Z. X. Recovery of silver metal and electric power generation using a microbial fuel cell. Desalin. Water Treat. 2014, 54 (13), 3675-3681.

(66) Choi, C.; Cui, Y. Recovery of silver from wastewater coupled with power generation 
using a microbial fuel cell. Bioresour. Technol. 2012, 107, 522-525.

(67) Lefebvre, O.; Neculita, C. M.; Yue, X.; Ng, H. Y. Bioelectrochemical treatment of acid mine drainage dominated with iron. J. Hazard. Mater. 2012, 241-242, 411-417.

(68) Ter Heijne, A.; Hamelers, H. V. M.; Buisman, C. J. N. Microbial fuel cell operation with continuous biological ferrous iron oxidation of the catholyte. Environ. Sci. Technol. 2007, 41 (11), 4130-4134.

(69) Rodenas Motos, P.; ter Heijne, A.; van der Weijden, R.; Saakes, M.; Buisman, C. J. N.; Sleutels, T. H. J. A. High Rate Copper and energy recovery in Microbial Fuel Cells. Front. Microbiol. 2015, 6 (MAY), 527.

(70) Lovley, D. R. Bug juice: harvesting electricity with microorganisms. Nat. Rev. Microbiol. 2006, 4 (7), 497-508.

(71) Hamelers, H. V. M.; Ter Heijne, A.; Sleutels, T. H. J. A.; Jeremiasse, A. W.; Strik, D. P. B. T. B.; Buisman, C. J. N. New applications and performance of bioelectrochemical systems. Applied Microbiology and Biotechnology. 2010, pp 1673-1685.

(72) Cobley, A. J.; Saez, V. The use of ultrasound to enable low temperature electroless plating. Circuit World. 2012, pp 12-15.

(73) Speck, J. A. Mechanical fastening, joining, and assembly; CRC Press, 1997; Vol. 109.

(74) Cox, R. Waste/By-Product Hydrogen. Fuel Cell Hydrog. Energy Assoc. 2011.

(75) Bouwer, H.; Chaney, R. L. Land treatment of wastewater. Adv. Agron 1974, 26, $133-$ 176.

(76) Treharne, R.; Wright, D. Acid mine water treatment process. Google Patents 1974.

(77) Debe, M. K. Electrocatalyst approaches and challenges for automotive fuel cells. Nature 2012, 486 (7401), 43-51.

(78) MINH, N. Solid oxide fuel cell technology?features and applications. Solid State Ionics 2004, 174 (1-4), 271-277.

(79) Freguia, S.; Rabaey, K.; Yuan, Z.; Keller, J. Syntrophic processes drive the conversion of glucose in microbial fuel cell anodes. Environ. Sci. Technol. 2008, 42 (21), 7937-7943.

(80) Lee, H. S.; Torres, C. I.; Parameswaran, P.; Rittmann, B. E. Fate of H2 in an upflow single-chamber microbial electrolysis cell using a metal-catalyst-free cathode. Environ. Sci. Technol. 2009, 43 (20), 7971-7976.

(81) Lee, H. S.; Rittmann, B. E. Significance of biological hydrogen oxidation in a continuous single-chamber microbial electrolysis cell. Environ. Sci. Technol. 2010, 44 (3), 948-954. 
(82) Rozendal, R. A.; Jeremiasse, A. W.; Hamelers, H. V. M.; Buisman, C. J. N. Hydrogen production with a microbial biocathode. Environ. Sci. Technol. 2008, 42 (2), 629-634.

(83) Wang, Z.; Gao, M.; Zhang, Y.; She, Z.; Ren, Y.; Wang, Z.; Zhao, C. Perchlorate reduction by hydrogen autotrophic bacteria in a bioelectrochemical reactor. J. Environ. Manage. 2014, 142, 10-16.

(84) Zehnder, A. J. B.; Huser, B. A.; Brock, T. D.; Wuhrmann, K. Characterization of an acetate-decarboxylating, non-hydrogen-oxidizing methane bacterium. Arch. Microbiol. 1980, $124(1), 1-11$.

(85) Heijne, A. T.; Liu, F.; Weijden, R. V. D.; Weijma, J.; Buisman, C. J. N.; Hamelers, H. V. M.; Ter Heijne, A. Copper recovery combined with electricity production in a microbial fuel cell. Environ. Sci. Technol. 2010, 44 (11), 4376-4381.

(86) Jeremiasse, A. W.; Hamelers, H. V; Croese, E.; Buisman, C. J. Acetate enhances startup of a H 2-producing microbial biocathode. Biotechnol. Bioeng. 2012, 109 (3), 657-664.

(87) Dubin, V. M.; Jentz, D. W.; Collazo-Davila, C. Method of copper electroplating. US 6432821 B1, 2002.

(88) Ntagia, E.; Rodenas, P.; Ter Heijne, A.; Buisman, C. J. N.; Sleutels, T. H. J. A. Hydrogen as electron donor for copper removal in bioelectrochemical systems. Int. J. Hydrogen Energy 2016, 41 (13).

(89) Horst, A. E. W.; Mangold, K.-M.; Holtmann, D. Application of gas diffusion electrodes in bioelectrochemical syntheses and energy conversion. Biotechnol. Bioeng. 2015.

(90) Yoho, R. A.; Popat, S. C.; Fabregat-Santiago, F.; Giménez, S.; Heijne, A. ter; Torres, C. I.; Beyenal, H.; Babauta, J. Electrochemical Impedance Spectroscopy as a Powerful Analytical Tool for the Study of Microbial Electrochemical Cells. In Biofilms in Bioelectrochemical Systems; John Wiley \& Sons, Inc: Hoboken, NJ, USA, 2015; pp 249-280.

(91) Patil, S. A.; Arends, J. B. A.; Vanwonterghem, I.; Meerbergen, J. van; Guo, K.; Tyson, G. W.; Rabaey, K. Selective Enrichment Establishes a Stable Performing Community for Microbial Electrosynthesis of Acetate from CO2. 2015.

(92) van Houten, R. T.; Yun, S. Y.; Lettinga, G. Thermophilic sulphate and sulphite reduction in lab-scale gas-lift reactors using $\mathrm{H} 2$ and $\mathrm{CO} 2$ as energy and carbon source. Biotechnol. Bioeng. 1997, 55 (5), 807-814.

(93) van Houten, B. H. G. W.; Roest, K.; Tzeneva, V. A.; Dijkman, H.; Smidt, H.; Stams, A. J. M. Occurrence of methanogenesis during start-up of a full-scale synthesis gas-fed reactor treating sulfate and metal-rich wastewater. Water Res. 2006, 40 (3), 553-560.

(94) Visser, A. The anaerobic treatmento of sulfate containing wastewater, Wageningen University, 1995. 
(95) Cord-Ruwisch, R.; Seitz, H.-J.; Conrad, R. The capacity of hydrogentrophic anaerobic bacteria to compete for traces of hydrogen depends on the redox potential of the electron acceptor. Arch Microbiol 1988, 149, 350-357.

(96) Lever, M. A. Acetogenesis in the energy-starved deep biosphere-a paradox? Front. Microbiol. 2012, 2 (JAN), 1-18.

(97) Caccavo, F. J.; Lonergan, D. J.; Lovley, D. R.; Davis, M.; Stolz, J. F.; McInerney, M. J. Geobacter sulfurreducens sp. nov., a hydrogen- and acetate-oxidizing dissimilatory metalreducing microorganism. Appl. Envir. Microbiol. 1994, 60 (10), 3752-3759.

(98) Torres, C. I.; Marcus, A. K.; Rittmann, B. E. Kinetics of consumption of fermentation products by anode-respiring bacteria. Appl. Microbiol. Biotechnol. 2007, 77 (3), 689-697.

(99) Striegl, R. G.; Michmerhuizen, C. M. Hydrologic influence on methane and carbon dioxide dynamics at two north-central Minnesota lakes.

(100) Ezekwe, I. C.; Ezekwe, A. S.; Chima, G. N. Metal Loadings and Alkaline Mine Drainage from Active and Abandoned Mines in the Ivo River Basin Area of Southeastern Nigeria. Mine Water Environ. 2013, 32 (2), 97-107.

(101) EPA. Quality Criteria for Water, 1986. NEPIS 1986, p 450.

(102) WHO. Hardness in Drinking-water; 1996; Vol. 2.

(103) Kuntke, P.; Śmiech, K. M.; Bruning, H.; Zeeman, G.; Saakes, M.; Sleutels, T.; Hamelers, H. V. M.; Buisman, C. J. N. Ammonium recovery and energy production from urine by a microbial fuel cell. water Res. 2012, 46 (8), 2627-2636.

(104) Logan, B. E. Scaling up microbial fuel cells and other bioelectrochemical systems. Appl. Microbiol. Biotechnol. 2010, 85 (6), 1665-1671.

(105) Brown, R. K.; Harnisch, F.; Wirth, S.; Wahlandt, H.; Dockhorn, T.; Dichtl, N.; Schröder, U. Evaluating the effects of scaling up on the performance of bioelectrochemical systems using a technical scale microbial electrolysis cell. Bioresour. Technol. 2014, 163, $206-$ 213.

(106) Premier, G. C.; Kim, J. R.; Michie, I.; Popov, A.; Boghani, H.; Fradler, K.; Dinsdale, R. M.; Guwy, A. J. Issues of scale in microbial fuel cells and bioelectrochemical systems. In World Renewable Energy Forum, WREF 2012, Including World Renewable Energy Congress XII and Colorado Renewable Energy Society (CRES) Annual Conferen; 2012; Vol. 6, pp 49184925.

(107) Sleutels, T. H. J. a.; Heijne, A. Ter; Buisman, C. J. N. N.; Hamelers, H. V. M. M. Steadystate performance and chemical efficiency of Microbial Electrolysis Cells. Int. J. Hydrogen Energy 2013, 38 (18), 7201-7208. 
(108) Janicek, A.; Fan, Y.; Liu, H. Design of microbial fuel cells for practical application: a review and analysis of scale-up studies. Biofuels 2014, 5 (1), 79-92.

(109) Sleutels, T. H. J. A.; Darus, L.; Hamelers, H. V. M.; Buisman, C. J. N. Effect of operational parameters on Coulombic efficiency in bioelectrochemical systems. Bioresour. Technol. 2011, 102 (24), 11172-11176.

(110) Sleutels, T.; Molenaar, S.; Heijne, A.; Buisman, C. Low Substrate Loading Limits Methanogenesis and Leads to High Coulombic Efficiency in Bioelectrochemical Systems. Microorganisms. Multidisciplinary Digital Publishing Institute January 2016, p 7.

(111) Tobias, C. W.; Wijsman, R. Theory of the Effect of Electrode Resistance on Current Density Distribution in Electrolytic Cells. J. Electrochem. Soc. 1953, 100 (10), 459.

(112) Dhar, B. R.; Lee, H.-S. Membranes for bioelectrochemical systems: challenges and research advances. Environ. Technol. 2013, 34 (13-14), 1751-1764.

(113) Krol, J. J.; Jansink, M.; Wessling, M.; Strathmann, H. Behaviour of bipolar membranes at high current density Water diffusion limitation. 1998, 14, 41-52.

(114) International Copper Study Group. The World Copper Factbook 2016; 2016.

(115) 2 nd European meeting of the International Society for Microbial Electrochemistry and Technology. 2014, No. September, 3-5.

(116) Wang, H.; Ren, Z. J. Bioelectrochemical metal recovery from wastewater: a review. Water Res. 2014, 66, 219-232.

(117) Cui, J.; Zhang, L. Metallurgical recovery of metals from electronic waste: a review. J. Hazard. Mater. 2008, 158 (2-3), 228-256.

(118) Chris A. Fleming. PLATSOL PROCESS provides a viable alternative to smelting. SGS mineral Services 2002.

(119) James, P. I.; Baker, M. Profitable copper production from low-grade waste ores. 2015.

(120) Scott, K.; Yu, E. H. Microbial electrochemical and fuel cells : fundamentals and application.

(121) Dalian BaoDalian Baotai Chemical Co., Ltd.tai Chemical Co., L. Ethanol(Ethyl Alcohol) CAS No.: 64-17-5 https://www.alibaba.com/product-detail/Ethanol-EthylAlcohol-_60402128125.html (accessed Dec 16, 2016).

(122) London Stock Market. Copper price http://www.lme.com/metals/non-ferrous/ copper/.

(123) Mueller-Langer, F.; Tzimas, E.; Kaltschmitt, M.; Peteves, S. Techno-economic assessment of hydrogen production processes for the hydrogen economy for the short and 
medium term. Int. J. Hydrogen Energy 2007, 32 (16), 3797-3810.

(124) Ayres, R. U.; Ayres, L. W.; Råde, I.; Rade, I. The Life Cycle of Copper, its Co-Products and By-Products. J. Ind. Ecol. 2002, No. 24.

(125) CBS StatLine - Aardgas en elektriciteit, gemiddelde prijzen van eindverbruikers http://statline.cbs.nl/StatWeb/publication/?VW $=$ T\&DM=SLNL\&PA=81309NED\&D1= $1,3,5,8,11,15 \& \mathrm{D} 2=0 \& \mathrm{D} 3=1 \& \mathrm{D} 4=0-3,5-8,10-13,15-18,20-23,1 \& \mathrm{H} \mathrm{D}=$ 120813-1059\&HDR $=$ T\&STB=G2,G1,G3.

(126) Readette, David (Mworx Pty Ltd, Australia); Marwood, Brad (Tiger Resources Ltd, A. 4th Annual Nickel-Cobalt-Copper Event ALTA 2013. In TIGER RESOURCES' KIPOI COPPER PROJECT STAGE II - PHASED DEVELOPMENT OF A 50,000TPA INTEGRATED AGITATED LEACH, HEAP LEACH, SX-EW; Perth, Australia, 2014; p 51.

(127) Wu, D.; Huang, L.; Quan, X.; Li Puma, G. Electricity generation and bivalent copper reduction as a function of operation time and cathode electrode material in microbial fuel cells. J. Power Sources 2016, 307, 705-714.

(128) Yang, J.; Zhou, M.; Hu, Y.; Yang, W. Cost-effective copper removal by electrosorption powered by microbial fuel cells. Bioprocess Biosyst. Eng. 2016, 39 (3), 511-519.

(129) Wang, Q.; Huang, L.; Pan, Y.; Zhou, P.; Quan, X.; Logan, B. E.; Chen, H. Cooperative cathode electrode and in situ deposited copper for subsequent enhanced Cd(II) removal and hydrogen evolution in bioelectrochemical systems. Bioresour. Technol. 2016, 200, 565-571.

(130) Shen, J.; Sun, Y.; Huang, L.; Yang, J. Microbial electrolysis cells with biocathodes and driven by microbial fuel cells for simultaneous enhanced $\mathrm{Co}(\mathrm{II})$ and $\mathrm{Cu}(\mathrm{II})$ removal. Front. Environ. Sci. Eng. 2015, 9 (6), 1084-1095.

(131) Fedje, K.; Modin, O.; Strömvall, A.-M. Copper Recovery from Polluted Soils Using Acidic Washing and Bioelectrochemical Systems. Metals (Basel). 2015, 5 (3), 1328-1348.

(132) Huang, L.; Wang, Q.; Jiang, L.; Zhou, P.; Quan, X.; Logan, B. E. Adaptively Evolving Bacterial Communities for Complete and Selective Reduction of $\mathrm{Cr}(\mathrm{VI}), \mathrm{Cu}(\mathrm{II})$, and $\mathrm{Cd}(\mathrm{II})$ in Biocathode Bioelectrochemical Systems. Environ. Sci. Technol. 2015, 49 (16), 9914-9924.

(133) Wu, D.; Pan, Y.; Huang, L.; Quan, X.; Yang, J. Comparison of Co(II) reduction on three different cathodes of microbial electrolysis cells driven by $\mathrm{Cu}(\mathrm{II})$-reduced microbial fuel cells under various cathode volume conditions. Chem. Eng. J. 2015, 266, 121-132.

(134) Motos, P. R.; Rodenas, P.; Weijden, R. D. Van Der; Buisman, C. J. N.; Heijne, A. Copper recovery in Microbial Fuel Cells at High Current and Power densities. 2014, No. January, 1-9.

(135) Zhang, L.-J.; Tao, H.-C.; Wei, X.-Y.; Lei, T.; Li, J.-B.; Wang, A.-J; Wu, W.-M. Bioelectrochemical recovery of ammonia-copper(II) complexes from wastewater using a dual 
chamber microbial fuel cell. Chemosphere 2012, 89 (10), 1177-1182.

(136) Sulonen, M. L. K., Kokko, M. E., Lakaniemi, A.-M., \& Puhakka, J. A. (2015). Electricity generation from tetrathionate in microbial fuel cells by acidophiles. Journal of Hazardous Materials, 284, 182-9.

(137) Philipp P. Bosshard; Reinhard Bachofen, and; Brandl ${ }^{*}$, H. Metal Leaching of Fly Ash from Municipal Waste Incineration by Aspergillus niger. 1996.

(138) Ferreira, M.; Pinto, M. F.; Soares, O. S. G. P.; Pereira, M. F. R.; Órfão, J. J. M.; Figueiredo, J. L.; Neves, I. C.; Fonseca, a M.; Parpot, P. Electrochimica Acta Electrocatalytic oxidation of oxalic and oxamic acids in aqueous media at carbon nanotube modified electrodes. Electrochim. Acta 2012, 60, 278-286.

(139) Detzel, C. J.; Thorson, M. R.; Van Wie, B. J.; Ivory, C. F. A study of the Coriolis effect on the fluid flow profile in a centrifugal bioreactor. Biotechnol. Prog. 2009, 25 (4), 1025-1034.

(140) Ibrahim, D. S., Veerabahu, C., Palani, R., Devi, S., \& Balasubramanian, N. (2013). Flow dynamics and mass transfer studies in a tubular electrochemical reactor with a mesh electrode. Computers \& Fluids, 73, 97-103.

(141) Deeke, A.; Sleutels, T. H. J. A.; Donkers, T. F. W.; Hamelers, H. V. M.; Buisman, C. J. N.; Ter Heijne, A. Fluidized Capacitive Bioanode As a Novel Reactor Concept for the Microbial Fuel Cell. Environ. Sci. Technol. 2015, 49 (3), 1929-1935.

(142) Logan, B.; Cheng, S.; Watson, V.; Estadt, G. Graphite fiber brush anodes for increased power production in air-cathode microbial fuel cells. Environ. Sci. Technol. 2007, 41 (9), $3341-3346$. 


\section{ANNEX I}

Tables of performance of the different heavy metals removed from waste waters Table A 1: Silver removal by Microbial Fuel cells

\begin{tabular}{|c|c|c|c|c|c|}
\hline Voc & $\mathrm{J}_{\max }\left(\mathrm{A} / \mathrm{m}^{2}\right)$ & $\mathrm{P}_{\max }\left(\mathrm{W} / \mathrm{m}^{2}\right)$ & $\begin{array}{c}\text { Specific } \\
\text { Surface } \\
\left(\mathrm{m}^{2} / \mathrm{m}^{3}\right)\end{array}$ & removal (\%) & Authors \\
\hline 0.749 & 5.67 & 4.25 & 1.16 & 98.3 & $\begin{array}{c}\text { Lim et al } \\
(2015)\end{array}$ \\
\hline 0.95 & 4.25 & 1.93 & 13.6 & 98.2 & $\begin{array}{c}\text { Lim et al. } \\
(2014)\end{array}$ \\
\hline 0.6 & & 0.317 & 33.2 & 99.9 & $\begin{array}{c}\text { Yun-Hai et. } \\
\text { Al. (2013) }\end{array}$ \\
\hline 0.89 & 0.3 & 0.11 & 45 & 75 & $\begin{array}{c}\text { Tao et al. } \\
(2012)\end{array}$ \\
\hline
\end{tabular}

Table A 2: Gold removal by Microbial Fuel cells

\begin{tabular}{|c|c|c|c|c|c|} 
Voc & $\mathrm{J}_{\max }\left(\mathrm{A} / \mathrm{m}^{2}\right)$ & $\mathrm{P}_{\max }\left(\mathrm{W} / \mathrm{m}^{2}\right)$ & $\begin{array}{c}\text { Specific } \\
\text { Surface } \\
\left(\mathrm{m}^{2} / \mathrm{m}^{3}\right)\end{array}$ \\
\hline 1.4 & 0.198 & 0.042 & 1.16 & 4 & $\begin{array}{c}\text { Kalathil et al. } \\
(2013)\end{array}$ \\
\hline
\end{tabular}

Table A3: Cadmium removal by Microbial Electrolysis cells

\begin{tabular}{|c|c|c|c|c|c|} 
Voc & $\mathrm{J}_{\max }\left(\mathrm{A} / \mathrm{m}^{2}\right)$ & $\mathrm{P}_{\max }\left(\mathrm{W} / \mathrm{m}^{2}\right)$ & $\begin{array}{c}\text { Specific } \\
\text { Surface } \\
\left(\mathrm{m}^{2} / \mathrm{m}^{3}\right)\end{array}$ & $\begin{array}{c}\text { removal } \\
(\%)\end{array}$ & Authors \\
\hline 0.5 & 2.5 & 1.25 & 40 & 46.6 & $\begin{array}{c}\text { Wang et al. } \\
(2016)\end{array}$ \\
\hline 1.173 & 13.05 & 10.22 & 1.28 & 95 & Choi et al. (2014) \\
\hline 0.316 & 11.7 & 3.7 & 15 & 90 & $\begin{array}{c}\text { Abourached et al } \\
(2014) .\end{array}$ \\
\hline
\end{tabular}




\begin{tabular}{|c|c|c|c|c|c|}
\hline Voc & $\mathrm{J}_{\max }\left(\mathrm{A} / \mathrm{m}^{2}\right)$ & $\mathrm{P}_{\max }\left(\mathrm{W} / \mathrm{m}^{2}\right)$ & $\begin{array}{c}\text { Specific } \\
\text { Surface }\end{array}$ & $\begin{array}{c}\text { removal } \\
(\%)\end{array}$ & Authors \\
$\left(\mathrm{m}^{2} / \mathrm{m}^{3}\right)$ & & $\begin{array}{c}\text { Modin et al } \\
.(2012)\end{array}$ \\
\hline 0.6 & 1.689 & 1.01 & 33 & 62 &
\end{tabular}

Table A4: Cobalt removal by Microbial Electrolysis cells

\begin{tabular}{|c|c|c|c|c|c|}
\hline Vin & $\mathrm{J}_{\max }\left(\mathrm{A} / \mathrm{m}^{2}\right)$ & $\mathrm{P}_{\max }\left(\mathrm{W} / \mathrm{m}^{2}\right)$ & \multicolumn{2}{c|}{$\begin{array}{c}\text { Specific } \\
\text { Surface } \\
\left(\mathrm{m}^{2} / \mathrm{m}^{3}\right)\end{array}$} \\
\hline 68 & $38\left(\mathrm{~A} / \mathrm{m}^{3}\right)$ & $4.8\left(\mathrm{~W} / \mathrm{m}^{3}\right)$ & 22 & 51 & $\begin{array}{c}\text { Shem et al. } \\
(2015) .\end{array}$ \\
\hline 0.64 & 0.7 & 0.102 & 92.3 & 28 & $\begin{array}{c}\text { Wu et al. } \\
(2015) .\end{array}$ \\
\hline 0.36 & $26\left(\mathrm{~A} / \mathrm{m}^{3}\right)$ & $1.5\left(\mathrm{~W} / \mathrm{m}^{3}\right)$ & & & $\begin{array}{c}\text { Huang et al } \\
(2015)\end{array}$ \\
\hline 0.24 & $21\left(\mathrm{~A} / \mathrm{m}^{3}\right)$ & $3.7\left(\mathrm{~W} / \mathrm{m}^{3}\right)$ & 28.3 & & $\begin{array}{c}\text { Huang et al. } \\
(2014)\end{array}$ \\
\hline 0.25 & 0.2 & 0.05 & 6 & 92.7 & $\begin{array}{c}\text { Huang et al. } \\
(2013)\end{array}$ \\
\hline
\end{tabular}

Table A5: Chromium removal by Microbial Fuel Cells

\begin{tabular}{|c|c|c|c|c|c|}
\hline Voc & $\mathrm{J}_{\max }\left(\mathrm{A} / \mathrm{m}^{2}\right)$ & $\mathrm{P}_{\max }\left(\mathrm{W} / \mathrm{m}^{2}\right)$ & $\begin{array}{l}\text { Specific } \\
\text { Surface } \\
\left(\mathrm{m}^{2} / \mathrm{m}^{3}\right)\end{array}$ & $\begin{array}{c}\text { removal } \\
(\%)\end{array}$ & Authors \\
\hline & 2.5 & 0.53 & 28.1 & 97 & $\begin{array}{c}\text { Chen Cet al. } \\
(2016)\end{array}$ \\
\hline & 0.3 & & & & $\begin{array}{c}\text { Wang et al. } \\
\text { (2016) }\end{array}$ \\
\hline 0.79 & 0.02 & 0.0017 & 10 & 73 & $\begin{array}{c}\text { Xafenias et al } \\
(2015)\end{array}$ \\
\hline & & & & & $\begin{array}{c}\text { Nancharaiah et } \\
\text { al. (2015) }\end{array}$ \\
\hline
\end{tabular}




\begin{tabular}{|c|c|c|c|c|c|}
\hline Voc & $\mathrm{J}_{\max }\left(\mathrm{A} / \mathrm{m}^{2}\right)$ & $\mathrm{P}_{\max }\left(\mathrm{W} / \mathrm{m}^{2}\right)$ & $\begin{array}{l}\text { Specific } \\
\text { Surface } \\
\left(\mathrm{m}^{2} / \mathrm{m}^{3}\right)\end{array}$ & $\begin{array}{c}\text { removal } \\
(\%)\end{array}$ & Authors \\
\hline 0.35 & 0.125 & 0.008 & 188 & & $\begin{array}{l}\text { Huang et al. } \\
\quad(2015)\end{array}$ \\
\hline 0.3 & 0.14 & 0.009 & 55 & 79.3 & $\begin{array}{c}\text { Wu et } \\
\mathrm{al}(2015)\end{array}$ \\
\hline 0.55 & 3.4 & 0.776 & 20 & 98 & $\begin{array}{c}\text { Gangadharan } \\
\text { et al. (2015) }\end{array}$ \\
\hline 0.088 & & 0.027 & 40.4 & 86.7 & $\begin{array}{l}\text { Revelo et al } \\
\quad(2015)\end{array}$ \\
\hline \multirow[t]{8}{*}{0.23} & 0.39 & 0.018 & 1.6 & & $\begin{array}{c}\text { Xafenias et al } \\
\text { (2013) }\end{array}$ \\
\hline & 0.1 & 0.026 & & & Liu et al (2012) \\
\hline & 1.1 & 0.45 & & & $\begin{array}{c}\text { Zhang et al. } \\
\text { (2012) }\end{array}$ \\
\hline & 0.0339 & 0.011 & & & $\begin{array}{l}\text { Huang et al } \\
\text { (2011) }\end{array}$ \\
\hline & 0.0095 & 0.0025 & & & $\begin{array}{l}\text { Huang et al. } \\
\text { (2011) }\end{array}$ \\
\hline & 0.011 & 0.0039 & & & $\begin{array}{l}\text { Huang et al. } \\
\text { (2011) }\end{array}$ \\
\hline & 0.123 & 0.056 & & & $\begin{array}{c}\text { Tandukar et } \\
\text { al. (2009) }\end{array}$ \\
\hline & 2 & 1.6 & & & Li et al. (2008) \\
\hline 1.09 & 1.5 & 0.453 & 4.5 & 99 & $\begin{array}{c}\text { Wang et al. } \\
(2008)\end{array}$ \\
\hline
\end{tabular}


Table A6: Copper removal by Microbial Fuel Cells

\begin{tabular}{|c|c|c|c|c|c|}
\hline Voc & $\mathrm{J}_{\max }\left(\mathrm{A} / \mathrm{m}^{2}\right)$ & $\mathrm{P}_{\max }\left(\mathrm{W} / \mathrm{m}^{2}\right)$ & $\begin{array}{l}\text { Specific } \\
\text { Surface } \\
\left(\mathrm{m}^{2} / \mathrm{m}^{3}\right)\end{array}$ & $\begin{array}{c}\text { removal } \\
(\%)\end{array}$ & Authors \\
\hline 0.42 & $\begin{array}{c}26.9 \\
\left(\mathrm{~A} / \mathrm{m}^{3}\right)\end{array}$ & $\begin{array}{c}6.5 \\
\left(\mathrm{~W} / \mathrm{m}^{3}\right)\end{array}$ & 40 & 99.7 & Wu et al. (2016) \\
\hline- & 0.57 & 0.45 & 50 & 63.7 & $\begin{array}{c}\text { Yang J et al. } \\
(2016)\end{array}$ \\
\hline & 0.47 & 0.128 & 40 & & $\begin{array}{c}\text { Wang et al. } \\
(2016)\end{array}$ \\
\hline 0.68 & $\begin{array}{c}38 \\
(\mathrm{~A} / \mathrm{m} 3)\end{array}$ & $\begin{array}{c}4.8 \\
(\mathrm{~W} / \mathrm{m} 3)\end{array}$ & 22 & 51 & $\begin{array}{c}\text { Shen et al. } \\
(2015)\end{array}$ \\
\hline- & $141.3\left(\mathrm{~A} / \mathrm{m}^{3}\right)$ & $18.8\left(\mathrm{~W} / \mathrm{m}^{3}\right)$ & 106 & 79 & $\begin{array}{c}\text { Fedje et al. } \\
(2015)\end{array}$ \\
\hline 0.32 & 0.09 & 0.007 & 188 & & $\begin{array}{l}\text { Huang et al. } \\
\text { (2015) }\end{array}$ \\
\hline 0.55 & 3.4 & 0.776 & 20 & 98 & $\begin{array}{c}\text { Gangadharan et } \\
\text { al. (2015) }\end{array}$ \\
\hline 0.64 & $45\left(\mathrm{~A} / \mathrm{m}^{3}\right)$ & $4.62\left(\mathrm{~W} / \mathrm{m}^{3}\right)$ & 60 & 28 & $\begin{array}{c}\text { Wu D., et al } \\
(2015)\end{array}$ \\
\hline 0.485 & 23 & 5.5 & 100 & & $\begin{array}{l}\text { Motos P.R. et al. } \\
\qquad(2015)\end{array}$ \\
\hline 0.45 & 5.5 & 1.7 & 16.7 & 87 & $\begin{array}{c}\text { Cheng et al. } \\
\text { (2013) }\end{array}$ \\
\hline 0.4 & 0.34 & & 33 & 84.3 & $\begin{array}{c}\text { Modin et al. } \\
(2012)\end{array}$ \\
\hline 0.58 & 0.95 & 0.2 & 20 & 96 & $\begin{array}{c}\text { Zhang et al. } \\
\text { (2012) }\end{array}$ \\
\hline 0.48 & 0.143 & 0.016 & 12.1 & 96 & Tao et al. (2011) \\
\hline- & 0.142 & 0.022 & 140 & 70 & Tao et al. (2011) \\
\hline
\end{tabular}




\begin{tabular}{|c|c|c|c|c|c|}
\hline Voc & $\mathrm{J}_{\max }\left(\mathrm{A} / \mathrm{m}^{2}\right)$ & $\mathrm{P}_{\max }\left(\mathrm{W} / \mathrm{m}^{2}\right)$ & $\begin{array}{c}\text { Specific } \\
\text { Surface } \\
\left(\mathrm{m}^{2} / \mathrm{m}^{3}\right)\end{array}$ & $\begin{array}{c}\text { removal } \\
(\%)\end{array}$ \\
\hline 0.595 & 1.2 & 0.319 & 35.6 & 99.97 & $\begin{array}{c}\text { Wang et al. } \\
(2011)\end{array}$ \\
\hline 0.61 & 6.2 & 0.8 & 66 & 99.88 & $\begin{array}{c}\text { Heijne et al. } \\
(2010)\end{array}$ \\
\hline
\end{tabular}

Table A7: Nickel removal by Microbial Electrolysis Cells

\begin{tabular}{|c|c|c|c|c|c|}
\hline Vin & $\mathrm{J}_{\max }\left(\mathrm{A} / \mathrm{m}^{2}\right)$ & $\mathrm{P}_{\max }\left(\mathrm{W} / \mathrm{m}^{2}\right)$ & $\begin{array}{l}\text { Specific } \\
\text { Surface } \\
\left(\mathrm{m}^{2} / \mathrm{m}^{3}\right)\end{array}$ & $\begin{array}{c}\text { removal } \\
(\%)\end{array}$ & Authors \\
\hline 1.2 & 0.598 & 0.184 & 11.4 & 94.8 & $\begin{array}{ccc}\text { Li } & \text { Yet } & \text { al. } \\
(2015) & & \end{array}$ \\
\hline 1.1 & $\underset{\mathrm{m} 3)^{304}(\mathrm{~A} /}{ }$ & $\begin{array}{l}334 \quad(\mathrm{~W} / \\
\mathrm{m} 3)^{-}\end{array}$ & 46.7 & 67 & $\begin{array}{l}\text { Qin B et al. } \\
\text { (2012) }\end{array}$ \\
\hline
\end{tabular}

Table A8: Lead removal by Microbial Electrolysis Cells

\begin{tabular}{|c|c|c|c|c|c|}
\hline Vin & $\mathrm{J}_{\max }\left(\mathrm{A} / \mathrm{m}^{2}\right)$ & $\mathrm{P}_{\max }\left(\mathrm{W} / \mathrm{m}^{2}\right)$ & $\begin{array}{l}\text { Specific } \\
\text { Surface } \\
\left(\mathrm{m}^{2} / \mathrm{m}^{3}\right)\end{array}$ & $\begin{array}{c}\text { removal } \\
(\%)\end{array}$ & Authors \\
\hline 0.5 & 0.6 & 0.19 & 11.42 & & $\begin{array}{ccc}\begin{array}{c}\text { Li } \\
(2015)\end{array} & \text { Yet } & \text { al. }\end{array}$ \\
\hline 0.6 & 1.689 & 1.01 & 33 & 47.5 & $\begin{array}{l}\text { Modin et al. } \\
(2012)\end{array}$ \\
\hline
\end{tabular}

Table A9: Vanadium removal by Microbial Electrolysis Cells

\begin{tabular}{|c|c|c|c|c|c|} 
Voc & $\mathrm{J}_{\max }\left(\mathrm{A} / \mathrm{m}^{2}\right)$ & $\mathrm{P}_{\max }\left(\mathrm{W} / \mathrm{m}^{2}\right)$ & $\begin{array}{c}\text { Specific } \\
\text { Surface }\end{array}$ & $\begin{array}{c}\text { removal } \\
(\%)\end{array}$ & Authors \\
$\left(\mathrm{m}^{2} / \mathrm{m}^{3}\right)$ & $\begin{array}{c}\text { Zhang et al. } \\
(2012)\end{array}$ \\
\hline 0.997 & 5.5 & 0.97 & & 15 & \\
\hline
\end{tabular}


Table A10: Zinc removal by Microbial Electrolysis Cells

\begin{tabular}{|c|c|c|c|c|c|}
\hline Vin & $\mathrm{J}_{\max }\left(\mathrm{A} / \mathrm{m}^{2}\right)$ & $\mathrm{P}_{\max }\left(\mathrm{W} / \mathrm{m}^{2}\right)$ & $\begin{array}{c}\text { Specific } \\
\text { Surface } \\
\left(\mathrm{m}^{2} / \mathrm{m}^{3}\right)\end{array}$ & $\begin{array}{c}\text { removal } \\
(\%)\end{array}$ \\
\hline 0.7 & 50 & 35 & 17.7 & 99 & $\begin{array}{c}\text { Teng et al. } \\
(2016)\end{array}$ \\
\hline 0.472 & 0.786 & 0.372 & 12 & 56 & $\begin{array}{c}\text { Fradler et al. } \\
(2014)\end{array}$ \\
\hline 0.316 & 11.7 & 3.7 & 15 & 97 & $\begin{array}{c}\text { Abourached } \\
\text { et al. (2014) }\end{array}$ \\
\hline 0.8 & 1.689 & 1.35 & 33 & 44.2 & $\begin{array}{c}\text { Modin et al. } \\
(2012)\end{array}$ \\
\hline
\end{tabular}




\section{ANNEX II}

\section{Model business case scenario for evaluation of different electron donors on copper recovery:}

We evaluated the MFC Technology for copper recovery, by comparing to an State of the art Technology Solvent Extraction/Electrowinning (SX/EW). This model used the following assumptions:

- Cathodic coulombic efficiency $\left(\eta_{\text {cathode }}\right)$ of $95 \%$

- Anodic coulombic efficiency $\left(\eta_{\alpha v o \delta \varepsilon}\right)$ of $84 \%$

- We assume an investment (Inv) cost of $13.6 € / \mathrm{m} 2$ per year

This model used the paràmetres described in table 6.2 to calculate the price $(\mathrm{Pr}, € / \mathrm{Kg}))$.

Calculation of the current density:

To calculate the current density, we assume an equivalent circuit of a voltage source with an internal resistance in series.

$$
J\left(A / m^{2}\right)=-\frac{V_{\text {cell }}(V)-V_{O C}(V)}{R_{\text {int }}\left(\Omega \cdot m^{2}\right)}
$$

Where $\mathrm{J}$ is the current density measured in $\mathrm{A} / \mathrm{m}^{2}, \mathrm{~V}_{\mathrm{OC}}$ is the voltage at open circuit of the cell measured in volts $(\mathrm{V})$, Vcell is the voltage output or voltage applied to the cell measured in volts $(\mathrm{V})$ and $\mathrm{R}_{\mathrm{int}}$ is the internal resistance measured in $\Omega . \mathrm{m} 2$.

Calculation of the amount of amount of electrons per year:

$$
\mathrm{X}(\text { mole }- \text { year })=\frac{J\left(A / m^{2}\right) \cdot t(s / \text { year })}{F(C / m o l)}
$$

Where $\mathrm{X}$ is the number of electrons moved through the equivalent circuit in a year. $\mathrm{t}$ is the number of seconds in a year, and $\mathrm{F}$ is the Faraday constant $(96485 \mathrm{C} / \mathrm{mol})$.

Calulation of the electricity cost/revenue (Ele) depending if the system works as an MFC or MEC:

$$
\text { Ele }=\frac{\mathrm{X}\left(\text { mole }^{-} / \text {year }\right) \cdot\left(-V_{\text {cell }}(\mathrm{V})\right) \cdot F(\mathrm{C} / \mathrm{mol}) \cdot 0.06(€ / \mathrm{kWh})}{3600(\mathrm{~s} / \mathrm{hour}) \cdot 1000(\mathrm{~W} / \mathrm{kW})}
$$


The electricity cost can be either negative or positive depending if the voltage cell is positive (power output) the electricity will represent a revenue and if the the cell voltage is negative (power input) the electricity will be taken from the network.

Calculation of the cost of an electron donor:

$$
\operatorname{Cost}_{\text {edonor }}\left(€ / \text { year } \cdot \mathrm{m}^{2}\right)=\frac{\mathrm{X}\left(\mathrm{mole}^{-} / \text {year }\right) \cdot v \cdot \operatorname{Pr}(€ / \mathrm{Kg})}{\mathrm{Mm}(\mathrm{mol} / \mathrm{Kg}) \cdot \eta_{\text {anode }}}+\mathrm{Inv}+\text { Ele }
$$

where Costedonor is the cost of the electron donor in a year per $\mathrm{m}^{2}$ of elèctrode area, $v$ is the stoichiometry coefficient for the oxidation reaction related to the number of electron mols per mol of electron donor, $\mathrm{Pr}$ is the price of the electron donor defined in Table 6.2, Inv is the investment required for the maintenance of the BES reactor, Mn is the molar mass of the electron donor molecule and $\eta_{\text {anode }}$ is the coulombic efficiency of the electron donor oxidation.

Calculation of the copper profit:

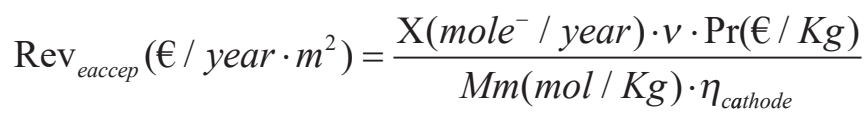

where $\operatorname{Rev}_{\text {eaccep }}$ is the revenue of the electron acceptor in a year per $\mathrm{m}^{2}$ of elèctrode area, vis the stoichiometry coefficient for the oxidation reaction related to the number of electron mols per mol of electron donor, $\mathrm{Pr}$ is the price of the electron acceptor (copper) defined in Table $6.2, \mathrm{Mn}$ is the molar mass of the electron acceptor and $\eta_{\text {cathode }}$ is the coulombic efficiency of the electron donor oxidation.

Calculation of the amount of $\mathrm{Kg}$ of copper per year:

The mass of metal deposited in a year of electroplating can be calculated using equation A.6

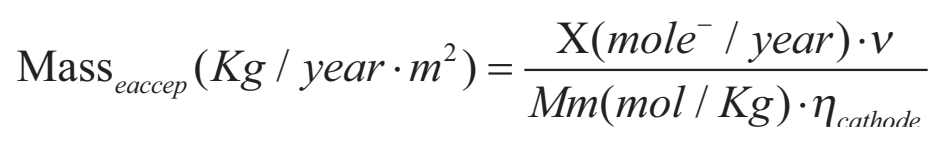

where Mass $_{\text {eaccep }}$ is the amount of metal deposited over the a square meter elèctrode in a year $\left(\mathrm{kg} /\right.$ year $\left.\cdot \mathrm{m}^{2}\right)$.

To compare with the state of the art technology SX/EW we calculate the cost of the copper using this technology by equation A.7. 
$S X / \mathrm{EW}_{\text {cost }}=\operatorname{Mass}_{\text {eaccep }}\left(\mathrm{kg} /\right.$ year $\left.\cdot \mathrm{m}^{2}\right) \cdot \operatorname{Production} \operatorname{cost}(€ / \mathrm{kg})$

where the SX/EWcost is the cost of SX/EW technology is calculated from the production cost and the mass of metal produced in a year per area of electrode. 


\section{About the author:}

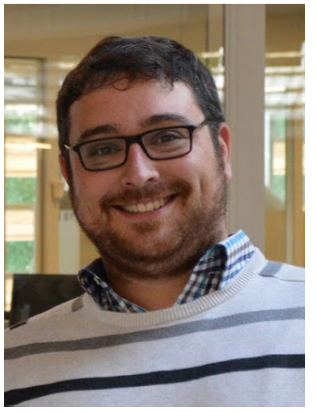

Pau Rodenas Motos was born in Castellón de la plana (Spain) the 1st of April of 1984. In 2002 he finished pre-universitary education in Institut Ribalta. In 2007 he graduated as Licenciado en Quimica (Chemistry B.Sc.) in Universitat Jaume I (Spain).

Between 2010 and 2012 he studied the Master in Molecular Nanoscience and Nanotechnology in Universitat Jaume I with a Master Thesis in water splitting using photoactive semiconductors.

In 2012 he started as Ph.D. candidate and researcher at WETSUS to participate in the European project from the 7th Framework program BIOELECTROMET.

Between 1993 and 2007 he did musical studies as Contrabass player in Conservatori MestreTarrega in Castellón de la plana (Spain). 
AEM

BES

BPM

CEM

EC

EW

GDE

HRT

ICP/OES

LED

MEC

MFC

NHE

PTFE

PMMA

SX/EW

TOC

XRD

Anion exchange membrane

Abreviation list

Bio-electrochemical system

Bipolar membrane

Cation exchange membrane

Electrocoagulation

Electrowinning

Gas diffusion electrode

Hydraulic retention time

Induced coupled plasma/Optical emission spectroscopy

Light emmiting diode

Microbial electrolysis cell

Microbial fuel cell

Normalized hydrogen electrode

Polytethafluoroethylene

Polymethylmetacrylate

Solvent Extraction/Electrowinning

Total organic carbon

$\mathrm{X}$-ray difraction

$\mathrm{J}_{\text {peak }} \quad$ Peak current $\left(\mathrm{A} / \mathrm{m}^{2}\right)$

$\mathrm{J}_{\max } \quad$ Current density at maximum power point $\left(\mathrm{A} / \mathrm{m}^{2}\right)$

$\mathrm{P}_{\max } \quad$ Maximum power $\left(\mathrm{W} / \mathrm{m}^{2}\right)$

$\mathrm{V}_{\max } \quad$ Voltage at maximum power point (V)

$\mathrm{V}_{\mathrm{oc}} \quad$ Voltage at open circuit $(\mathrm{V})$

E Potential (V)

$\Delta \mathrm{G}_{\mathrm{r}} \quad$ Gibbs free energy $\left.(\mathrm{J} / \mathrm{mol})\right)$

$\mathrm{R} \quad$ Gas constant $(8.31 \mathrm{~J} / \mathrm{K} . \mathrm{mol})$

$\mathrm{T} \quad$ Temperature $(\mathrm{K})$

F Faraday constant $(96485 \mathrm{~mol} / \mathrm{C})$

$\eta_{\text {anode }}$ Coulombic efficiency of the anode

$\eta_{\text {cathode }}$ Coulombic efficiency of the cathode

$\varphi_{\text {Cath }} \quad$ Measured cathode overpotential (theoretical cathode potential-measured cathode potential) $(\mathrm{V})$ 
$\varphi_{\text {Anod }}$ Measured anode overpotential (theoretical anode potential-measured anode potential) (V)

$\varphi_{\text {mem }} \quad$ Volltage lost across the membrane (cathode ref potential-anode ref potential) $(\mathrm{V})$.

$\Phi \quad$ Voltage loss in each cell compartment (V)

$\mathrm{R}_{\text {int }} \quad$ Internal resistance $\left(\Omega \cdot \mathrm{m}^{2}\right)$ 


\section{Glossary}

Acceptor: Molecule, element or compound that accepts electrons during an electrochemical reaction. See also Oxidant.

Adsorption: the process by which a gas or liquid accumulates and chemical binds to the surface of a solid. This is how metal hydrides store hydrogen.

Anion: A negatively charged ion due to having more electrons than protons.

Anion Exchange Membrane (AEM): Membrane with positively charged groups that allows negative ions going through.

Anode: One of two electrodes in a battery or fuel cell. It is where oxidation occurs in a fuel cell, leading to electron release. When fuel cells are generating electricity, the anode is positively charged.

Bio-electrochemical System (BES): Device that drives an electrochemical process by the use of a biological catalyst.

Catalyst: Any substance that increases the rate of a chemical reaction.

Cathode: One of two electrodes in a battery or fuel cell. It is where reduction occurs, meaning electrons are captured rather than released. In fuel cells that are producing electricity the cathode is negatively charged.

Cation: A positive ion. The proton liberated from hydrogen is a cation.

Cation Exchange Membrane (CEM): Membrane with negatively charged groups that allows positive ions going through.

Coulomb: The standard international unit of electric charge. Abbreviated as $\mathrm{C}$, it is equal to one ampere of electricity in one second $(\mathrm{A} / \mathrm{sec})$.

Coulombic efficiency $(\eta)$ : Relation between the amount of charges use for a redox reaction and the charges transferred from cathode to anode.

Current density (J): Flux of electrons through a Surface measured as the number of charges that crosses a Surface per unit of time. This magnitude is expressed in $\left(\mathrm{A} / \mathrm{m}^{2}\right)$

Donor: Molecule, element or compound that donates electrons during an electrochemical reaction.

Electrical Conductivity: A measure of how well a material can conduct an electric current. In other words, a measure of the resistance to the flow of electrically charged particles.

Electricity: A general term that encompasses the flow of charged particles.

Electrochemical cell: A device that produces electricity through a chemical reaction.

Electrode: A terminal that carries an electric current. 
Electrolysis: The breakdown of a chemical through the application of an electric charge to it. This process is commonly used to break water into hydrogen and oxygen.

Electrolyte: A compound that can conduct electricity or charged particles. In a fuel cell, the electrolyte allows ions to move from one electrode to the other, but is impermeable to electrons.

Electron: A sub-atomic particle that is negatively charge and circles the nucleus.

Fouling: The accumulation of unwanted material on a solid surface. This commonly occurs in internal combustion engines were carbon is deposited on services such a spark plugs and cylinder heads.

Hydrocarbon: An organic compound that consists only of hydrogen and carbon atoms.

Hydrogen: The smallest of all elements, consisting of a single proton and a single electron. Hydrogen is the fuel for most fuel cells and the most abundant element in the universe.

Internal Resistance $\left(\mathbf{R}_{\mathrm{int}}\right)$ : The internal resistance is a magnitude to express the energy losses of an electrochemical systems. This magnitude is expressed in $\Omega \mathrm{m}^{2}$.

Microbial electrolysis cell (MEC): A electrolysis cell that uses biological processes to power none-spontaneous reactions powered by an external power source that supplies electrical current. Generally bacteria are used.

Microbial fuel cell (MFC): A fuel cell that uses biological processes to generate electrical current. Generally bacteria are used.

Open Cicuit Voltage (OCV, Voc): Voltage measured between anode and cathode when no current flows between them. This magnitude is measured in volts $(\mathrm{V})$

Oxidant: An oxidizing agent. In a chemical reaction, this component gains electrons.

Oxidation: The loss of electrons by an element or compound.

Power (P): the rate at which the work is performed for energy is transmitted.

Potential (E): Energy level of the chemical species involved in a electrochemical process. This magnitude is measured in volts $(\mathrm{V})$.

Redox: Short for reduction-oxidation reaction. This is a chemical reaction in which atoms undergo a change in the oxidation number, usually gaining or losing electrons.

Reduction: Gain of electrons by an element or compound.

Renewable energy: Any energy produced from a natural resource, which does not have an immediate, finite limit. This includes such things as sun, wind, water, and geothermal heat.

Steam reforming: A process of producing hydrogen from hydrocarbons in the presence of a metal-based catalyst such as nickel at high temperatures $\left(700-1100^{\circ} \mathrm{C}\right)$.

Voltage: the difference in electrical potential between two points. This magnitude is measured in volts $(\mathrm{V})$ 


\section{To my father Lose Kodenas Fuster my first teacher and the first person to inspire me to study water treatment plants and chemistry}

The research described in this thesis was performed in the cooperation framework of Wetsus, european centre of excellence for sustainable water technology (www.wetsus.nl). Wetsus is co-funded by the Dutch Ministry of Economic Affairs and Ministry of Infrastructure and Environment, the European Union Regional Development Fund, the Province of Fryslân, and the Northern Netherlands Provinces.

The author would like to thank the participants of the research theme "Resource Recovery" for the fruitful discussions and their financial support.

This work is also part of BioelectoMET project. Title: Bioelectrochemical systems for metal recovery. Funded under the Seventh Framework Programme (FP7) Research area: ENV.2011.3.1.9-1 (Eco-innovation).

The research was also possible thanks to the participation of Annemerel Mol, Olivia Berzal de Frutos, Jasper van Puffelen, Gonzalo Molina, Eleftheria Ntagia, Fanghi Zhu and the technical and laboratory teams working at WETSUS . 


\section{SENSE}

Netherlands Research School for the

Socio-Economic and Natural Sciences of the Environment

\section{I P L O M A}

For specialised PhD training

The Netherlands Research School for the

Socio-Economic and Natural Sciences of the Environment

(SENSE) declares that

\section{Pau Rodenas Motos}

born on 1 April 1984 in Castellón de la plana, Spain

has successfully fulfilled all requirements of the Educational Programme of SENSE.

Leeuwarden, 21 April 2017

the Chairman of the SENSE board

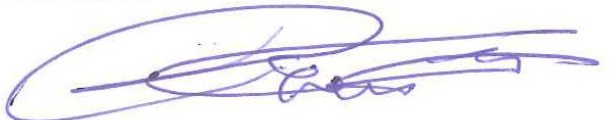

Prof. dr. Huub Rijnaarts the SENSE Director of Education

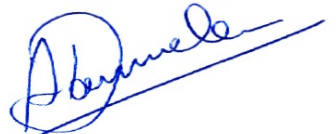

Dr. Ad van Dommelen

The SENSE Research School has been accredited by the Royal Netherlands Academy of Arts and Sciences (KNAW)

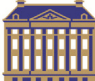

$\begin{array}{llllllllllllllllllllll}K & O & N & I & N & K & L & I & J & K & E & N & E & D & E & R & L & A & N & D & S & E\end{array}$

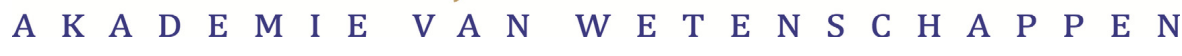




\section{SENSE}

The SENSE Research School declares that Mr Pau Rodenas Motos has successfully fulfilled all requirements of the Educational PhD Programme of SENSE with a work load of $41.5 \mathrm{EC}$, including the following activities:

\section{SENSE PhD Courses}

- Environmental research in context (2013)

- SENSE writing week (2013)

- Research in context activity: 'Co-organising 7th European summer school on electrochemical engineering' (2015)

\section{Other PhD and Advanced MSc Courses}

- Masterclass biobased innovation, Wageningen University (2013)

- OLI stream analyser course, Wageningen University (2013)

o Electrochemistry Summer School, University of Southhampton (2013)

- Training presenting, WETSUS (2014)

- European summer school on electrochemical engineering, European Federation of Chemical Engineers (2015)

- Reinvent yourself: unleash your creativity, edX online course University of Texas (2015)

- Optical Materials and Devices, edX online course Massachusetts Institute of Technology (2016)

\section{Management and Didactic Skills Training}

- Organising Wetsus patent course (2015)

- Organising BioelectroMET Value from Urine workshop 'Up-scaling of bioelectrochemical systems towards application' (2016)

- Supervising three MSc students with thesis entitled 'Selective recovery of copper, lead, cadmium and zinc with an acetate microbial electrolysis cell by controlling cathode potential', 'Bioelectrochemical recovery of metals using hydrogen as electron donor' and 'Improvement of Hydrogen Substrate Bioelectrochemical System for Metal Recovery by Increasing Mass Transfer Rate'(2014-2016)

\section{Oral Presentations}

- High rate copper recovery with MFC. European International Society for Microbial Electrochemistry and Technology meeting, 3-5 September 2014, Alcalá de Henares, Spain

- Hydrogen as an electron donor for copper removal in bioelectrochemical systems, International Society for Microbial Electrochemistry and Technology, 1-4 October 2015, Tempe, Arizona, United States of America

SENSE Coordinator PhD Education 